\title{
Hybrid hierarchical heterostructures of nanoceramic phosphors as imaging agents for multiplexing and living cancer cells translocation
}

David G. Calatayud*, Teresa Jardiel*, Mara S. Bernardo, Vincenzo Mirabello, Haobo Ge, Rory L. Arrowsmith, Fernando Cortezon-Tamarit, Lorena Alcaraz, Josefa Isasi, Pablo Arévalo, Amador C. Caballero, Sofia I. Pascu* and Marco Peiteado*

\section{Corresponding Authors}

* David G. Calatayud - Instituto de Cerámica y Vidrio, Keslen 5, Campus de Cantoblanco, 28049, Madrid, Spain.

orcid.org/0000-0003-2633-2989

E-mail: dgcalatayud@icv.csic.es

* Teresa Jardiel - Instituto de Cerámica y Vidrio, Keslen 5, Campus de Cantoblanco, 28049, Madrid, Spain. orcid.org/0000-0002-0163-7324

E-mail: jardiel@icv.csic.es

* Sofia I. Pascu - Department of Chemistry, University of Bath, Claverton Down, BA2 7AY, Bath, UK. orcid.org/0000-0001-6385-4650

E-mail: s.pascu@bath.ac.uk

* Marco Peiteado - Instituto de Cerámica y Vidrio, Keslen 5, Campus de Cantoblanco, 28049, Madrid, Spain. orcid.org/0000-0003-3510-6676

E-mail: mpeiteado@icv.csic.es

\section{Table of Contents}

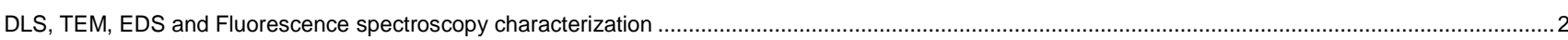

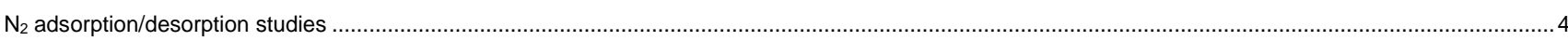

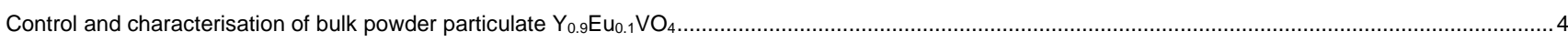

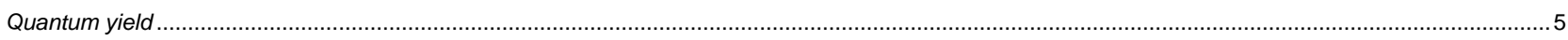

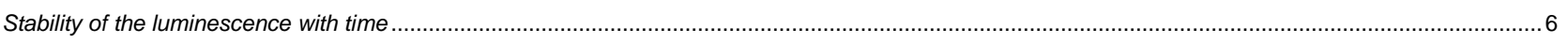

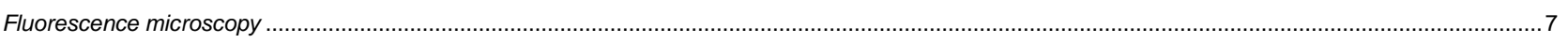

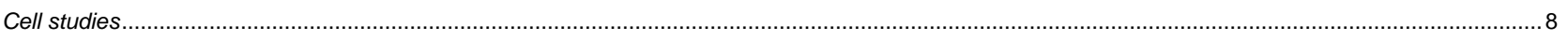

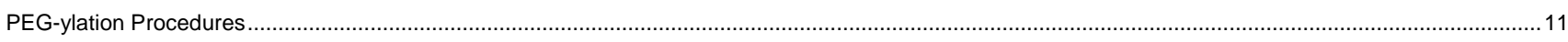

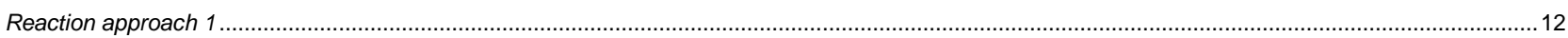

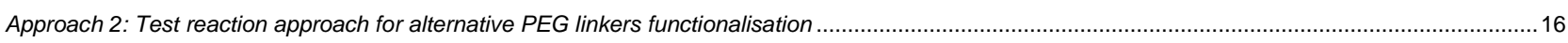

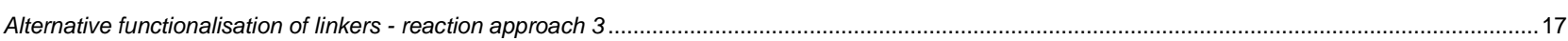

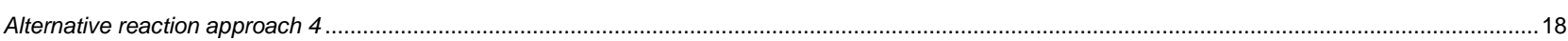

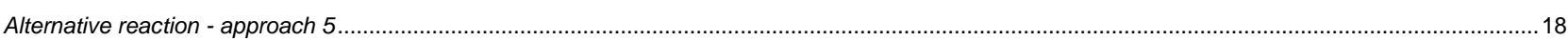

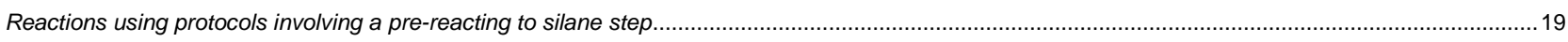

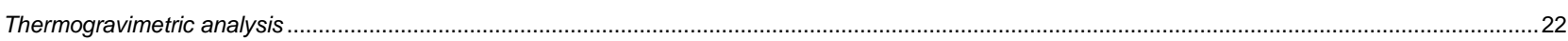

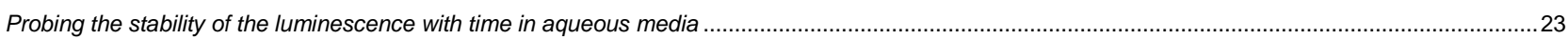

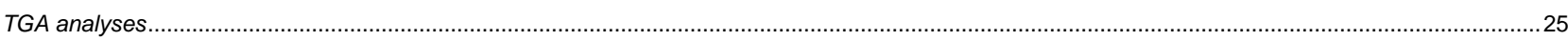

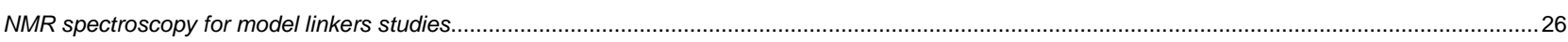

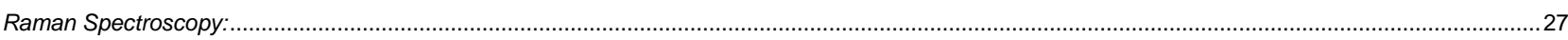

GPC

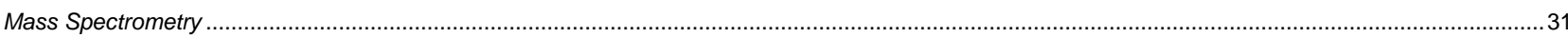

Confocal fluorescence imaging microscopy of $\mathrm{Y}_{0.9} \mathrm{Er}_{0.1} \mathrm{VO}_{4}$ and corresponding functional composites ...................................................................... 42

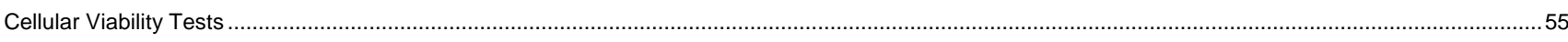

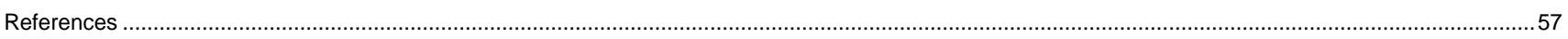




\section{DLS, TEM, EDS and Fluorescence spectroscopy characterization}

The degree of agglomeration of the nanoparticles in solution was followed by dynamic light scattering (DLS) measurements working with aqueous suspensions of $1 \mathrm{mg} / \mathrm{ml}$ in concentration. The results reveal the formation of agglomerates of around $1 \mu \mathrm{m}$ in size (Figure S1), which would point to a strong trend of the synthesized nanos towards agglomeration; as explained in the text, this preliminary parameter will not be a major impediment to the subsequent production of composites with a suitable degree with which to achieve an unprecedented incorporation of the manufactured nanoparticles into the cells.

а)

Size Distribution by Number

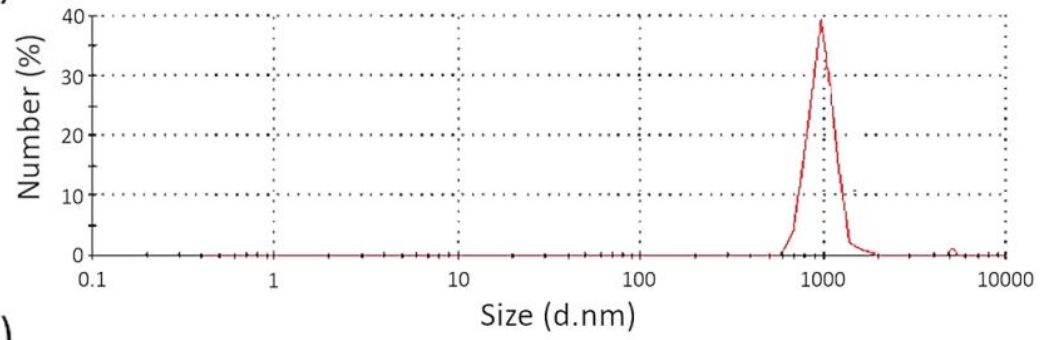

b)

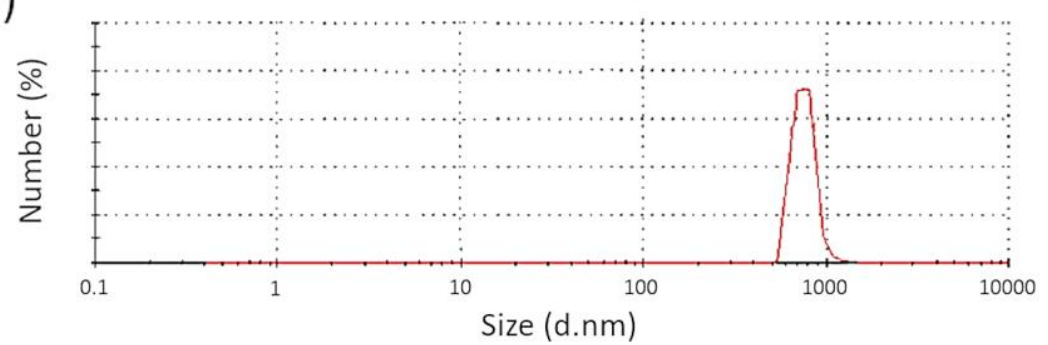

Figure S1. Dynamic light scattering spectra in water of a) $\mathrm{Y}_{0.9} \mathrm{Er}_{0.1} \mathrm{VO}_{4}$ (concentration $=1 \mathrm{mg} / \mathrm{ml}$ in water) and b) $\mathrm{Y}_{0.9} \mathrm{Eu}_{0.1} \mathrm{VO}_{4}$ (concentration $=1 \mathrm{mg} / \mathrm{ml}$ in water).

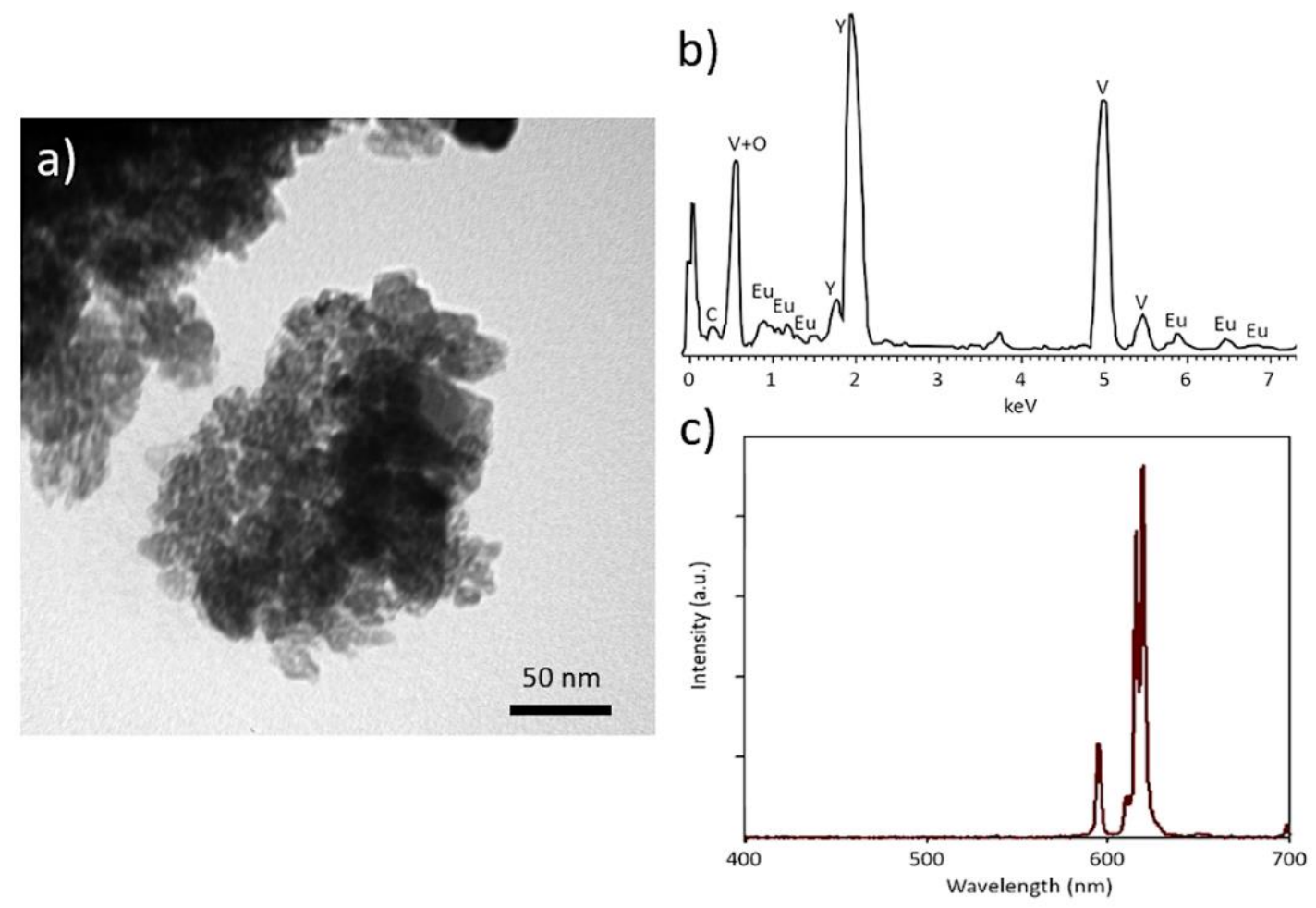

Figure S2. a) TEM micrographs, b) EDS analyses and c) solid state fluorescence emission spectra of bulk powder particulate $\mathrm{Y}_{0.9} \mathrm{Eu}_{0.1} \mathrm{VO}_{4}\left(\lambda_{\text {exc }}=350 \mathrm{~nm}\right)$. 
Figure $\mathrm{S} 3$ show the EDS of @SiO 2 composites (those for Chitosan are alike, barely showing an increased intensity in the $\mathrm{C}$ and $\mathrm{O}$ signals). The EDX analyses in both samples indicate a homogeneous composition in agreement with the nominal $\mathrm{Y}_{0.9} \mathrm{Eu}_{0.1} \mathrm{VO}_{4}$ and $\mathrm{Y}_{0.9} \mathrm{Er}_{0.1} \mathrm{VO}_{4}$ formulas and the published data on commercial powder Eu: $\mathrm{YVO}_{4}$ samples. The results indicate that the lanthanide dopants, either $\mathrm{Er}$ or $\mathrm{Eu}$, are effectively incorporated into the vanadate matrix by this novel hydrothermal method and are maintained after the processes of obtaining the coreshell composites.
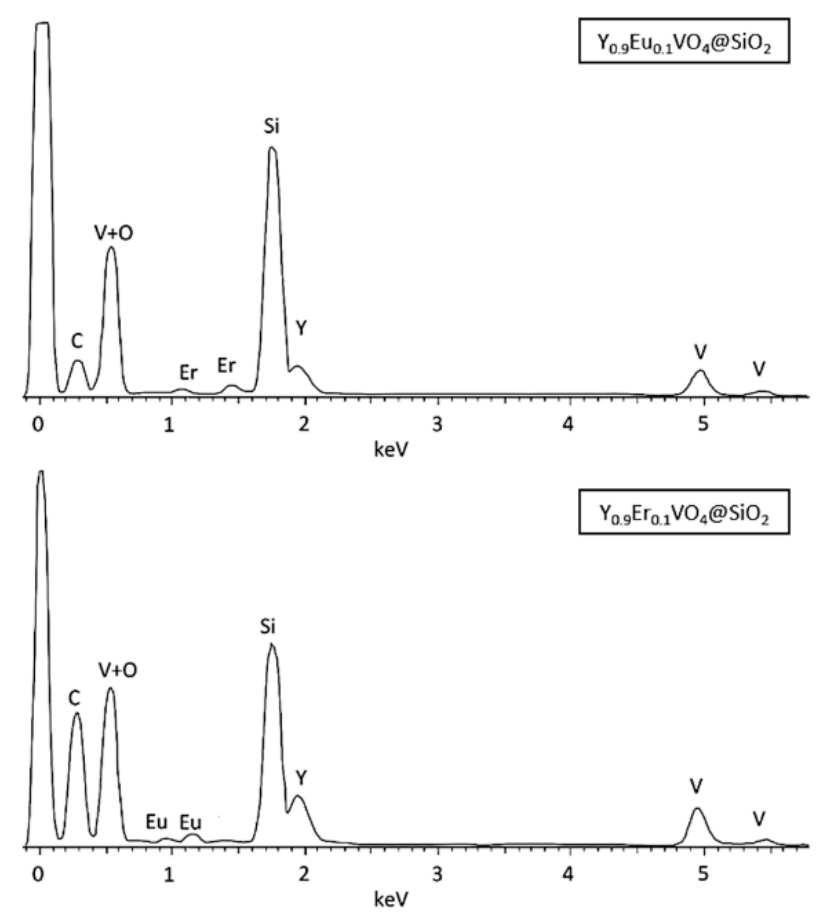

Figure S3. EDS analyses of $\mathrm{Y}_{0.9} \mathrm{Eu}_{0.1} \mathrm{VO}_{4} @ \mathrm{SiO}_{2}$ and $\mathrm{Y}_{0.9} \mathrm{Er}_{0.1} \mathrm{VO}_{4} @ \mathrm{SiO}_{2}$ composites.

a)

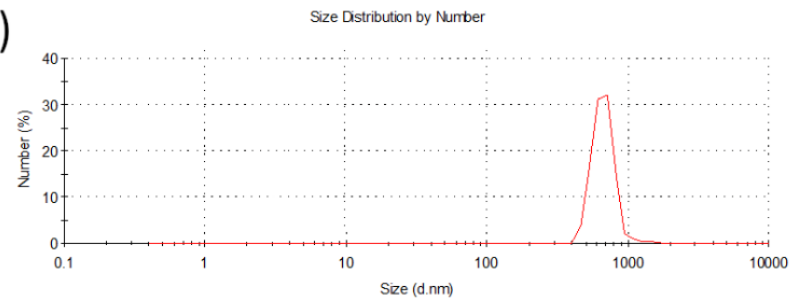

b)

Size Distribution by Number

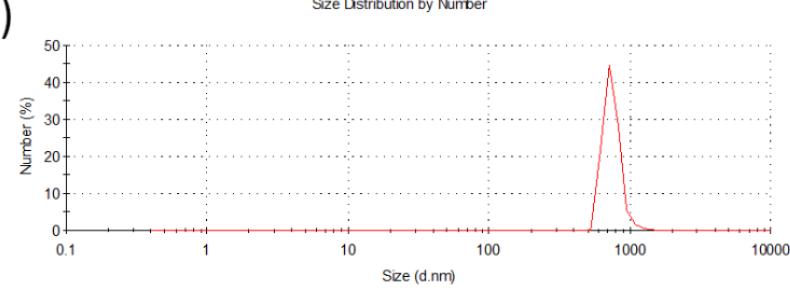

c)

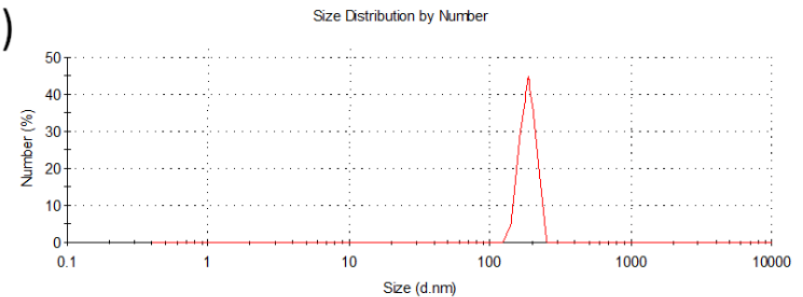

Figure S4. Dynamic light scattering spectra of a) $1 \mathrm{mg} / \mathrm{ml}$ of $\mathrm{Y}_{0.9} \mathrm{Er}_{0.1} \mathrm{VO}_{4} @ \mathrm{SiO}_{2}$ composite in water, b) $1 \mathrm{mg} / \mathrm{ml}$ of $\mathrm{Y}_{0.9} \mathrm{Eu}_{0.1} \mathrm{VO}_{4} @ \mathrm{SiO}_{2}$ composite in water and c) $0.1 \mathrm{mg} / \mathrm{ml} \mathrm{Y}_{0.9} \mathrm{Eu}_{0.1} \mathrm{VO}_{4} @ \mathrm{SiO}_{2}$ composite in water. 


\section{$\mathbf{N}_{2}$ adsorption/desorption studies}
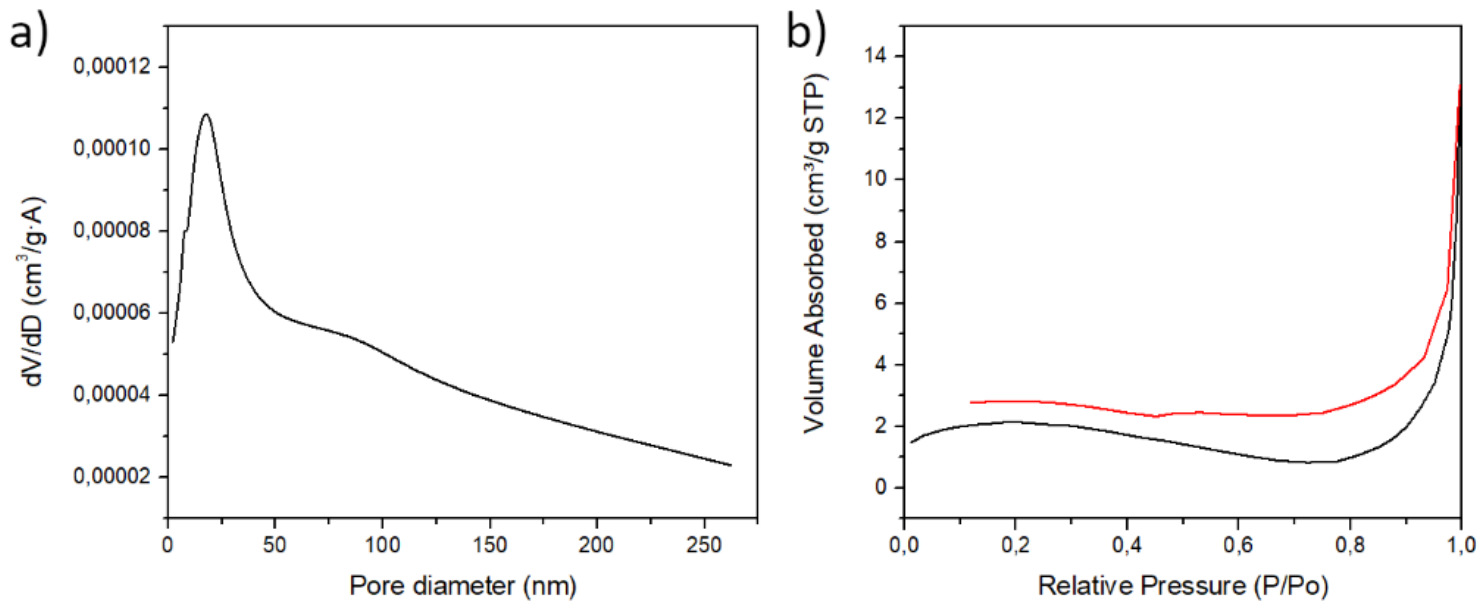

Figure S5. a) Pore size distribution curves and b) nitrogen adsorption-desorption BET isotherms of $\mathrm{Y}_{0.9} \mathrm{Er}_{0.1} \mathrm{VO}_{4}$.

\section{Control and characterisation of bulk powder particulate $\mathrm{Y}_{0.9} \mathrm{Eu}_{0.1} \mathrm{VO}_{4}$}

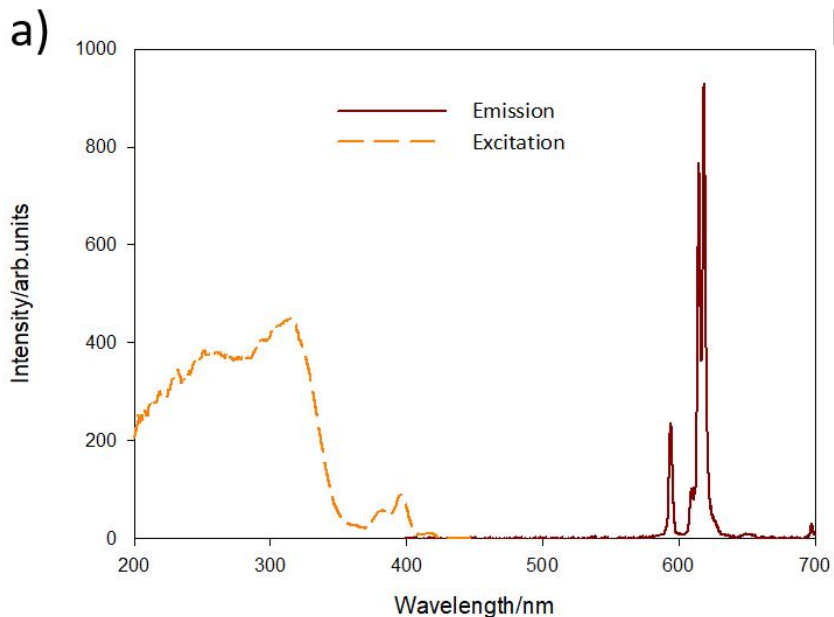

b)

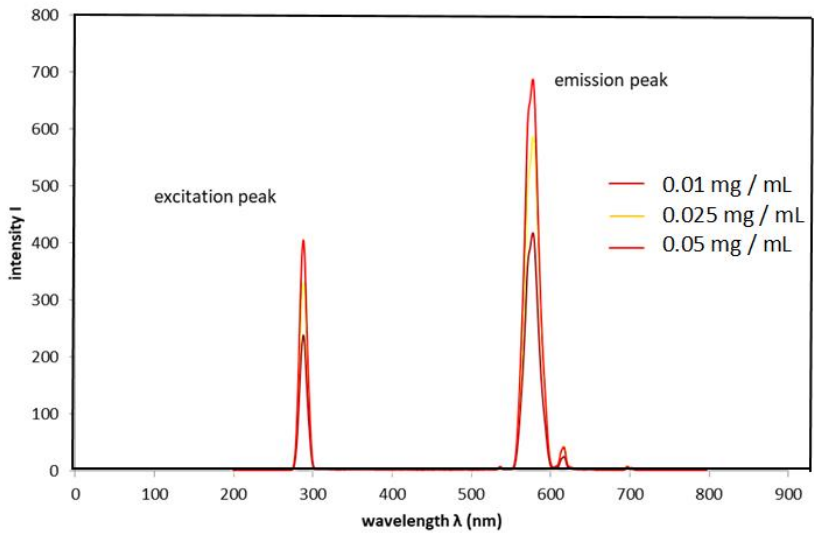

Figure S6. a) Solid state fluorescence excitation and emission spectra of bulk powder particulate $\mathrm{Y}_{0.9} \mathrm{Eu}_{0.1} \mathrm{VO}_{4}\left(\lambda_{\mathrm{exc}}=350 \mathrm{~nm}\right)$ and b) fluorescence excitation and emission spectra bulk powder particulate $\mathrm{Y}_{0.9} \mathrm{Eu}_{0.1} \mathrm{VO}_{4}$ in water at different concentrations $\left(\lambda_{\text {exc }}=280 \mathrm{~nm}\right)$.

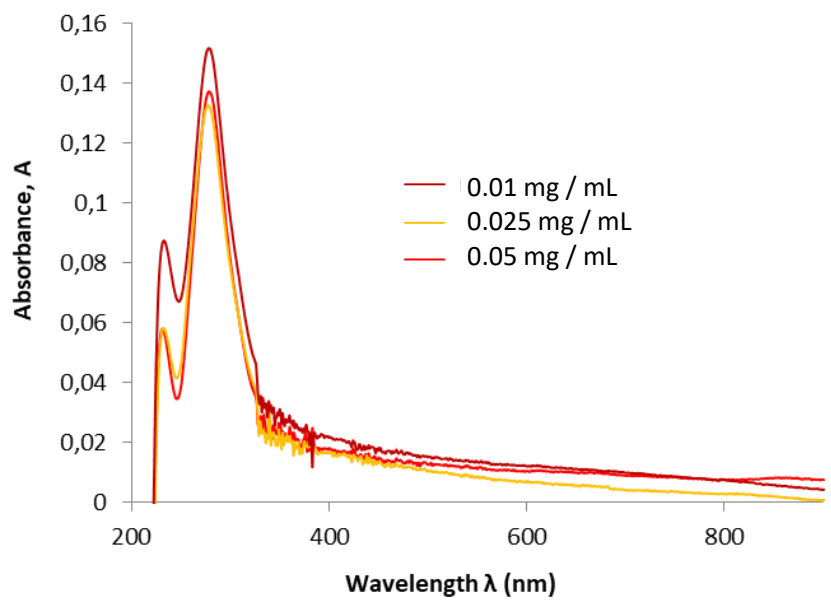

Figure S7. UV-vis spectra of bulk powder particulate $\mathrm{Y}_{0.9} \mathrm{Eu}_{0.1} \mathrm{VO}_{4}$ in water at different concentrations. 


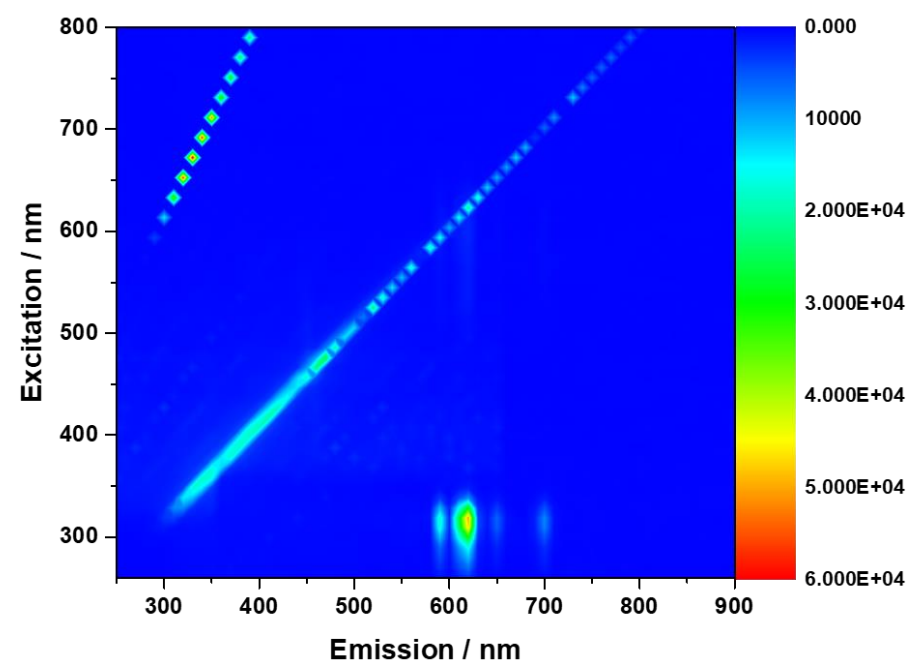

Figure S8. Normalized 2D fluorescence contour plots recorded for dispersions in water $(0.05 \mathrm{mg} / \mathrm{mL})$ of bulk powder particulate $\mathrm{Y}_{0.9} \mathrm{Eu}_{0.1} \mathrm{VO}_{4}$.

\section{Quantum yield}

Figure S6 shows the excitation / emission spectra of bulk powder particulate $\mathrm{Y}_{0.9} \mathrm{Eu}_{0.1} \mathrm{VO}_{4}$ with different concentrations in water. As it can be seen on the spectra samples absorbed at $280 \mathrm{~nm}$. So, the calculated quantum yields were obtained at $280 \mathrm{~nm}$ using tryptophan which absorbs at 280 and $290 \mathrm{~nm}$ as reference. Figure S9 shows the fluorescence emission spectra of tryptophan and fluorescein.

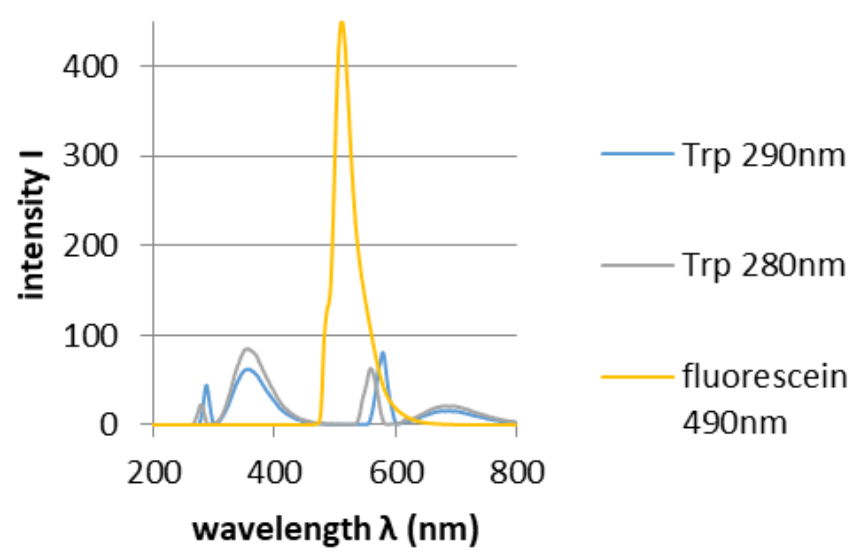

Figure S9. Fluorescence excitation and emission spectra of tryptophan and fluorescein in water.

The table S1 shows the quantum yield of fluorescein and tryptophan and the refractive index of both compounds.

$$
Q s=\mathrm{Qr} * \frac{D s}{D r} * \frac{A r}{A s} * \frac{I r}{I s} * \frac{\mathrm{ns}^{2}}{n r^{2}}
$$

The Table S1 and Table S2 show the reference data for two fluorescence references considered to carry out the quantum yield calculations and the refractive index of common solvents. 
Table S1. Quantum yield and refractive index of fluorescein and tryptophan

\begin{tabular}{|c|c|c|}
\cline { 2 - 3 } \multicolumn{1}{c|}{} & \multicolumn{2}{c|}{ References data } \\
\cline { 2 - 3 } \multicolumn{1}{c|}{} & Quantum yield $\mathrm{Q}_{\mathrm{r}}$ & Refractive index $\mathrm{n}_{\mathrm{r}}$ \\
\hline Fluorescein & 0.82 & 1.33 \\
\hline Tryptophan & 0.13 & 1.754 \\
\hline
\end{tabular}

Table S2. Refractive index of several solvents

\begin{tabular}{|c|c|}
\cline { 2 - 2 } \multicolumn{1}{c|}{} & Refractive index of solvents ( $\mathbf{n}_{\mathbf{s}}$ ) \\
\hline DMSO & 1.479 \\
\hline water & 1.33 \\
\hline toluene & 1.497 \\
\hline methanol & 1.329 \\
\hline
\end{tabular}

Table S3 lists the fluorescence data extracted from the fluorescence spectra of bulk powder particulate $\mathrm{Y}_{0.9} \mathrm{Eu}_{0.1} \mathrm{VO}_{4}$ (Figure S6b)

Table S3. Fluorescence data of bulk powder particulate $\mathrm{Y}_{0.9} \mathrm{Eu}_{0.1} \mathrm{VO}_{4}$ at different concentrations in water

\begin{tabular}{|c|c|c|c|c|c|c|}
\hline & $\lambda(\mathrm{nm})$ & A & Total area & I (excitation peak) & $\varphi s$ (without I) & $\varphi s$ \\
\hline Trp & 280 & 0.0555 & 2968.3981 & 37.98 & & \\
\hline $0.025 \mathrm{mg} / \mathrm{mL}$ & 280 & 0.1159 & 495.13 & 142.36 & 0.00551102 & 0.001470276 \\
\hline $0.05 \mathrm{mg} / \mathrm{mL}$ & 280 & 0.1159 & 549.2893 & 195.74 & 0.006113837 & 0.001186286 \\
\hline $0.01 \mathrm{mg} / \mathrm{mL}$ & 280 & 0.1328 & 430.1346 & 127.51 & 0.004178328 & 0.001244552 \\
\hline
\end{tabular}

\section{Stability of the luminescence with time}

a)

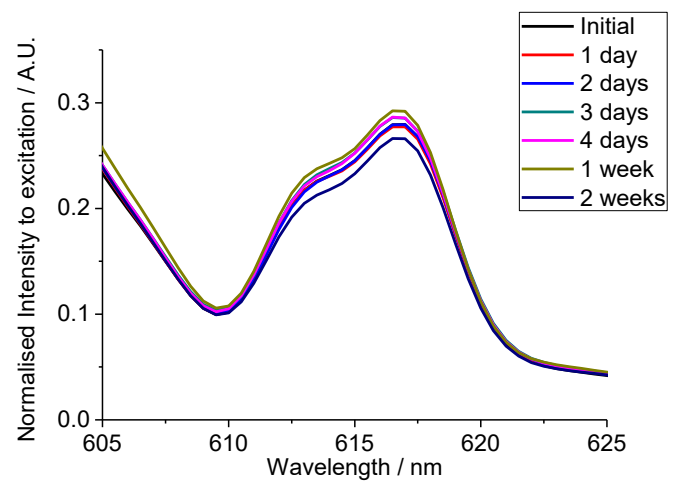

b)

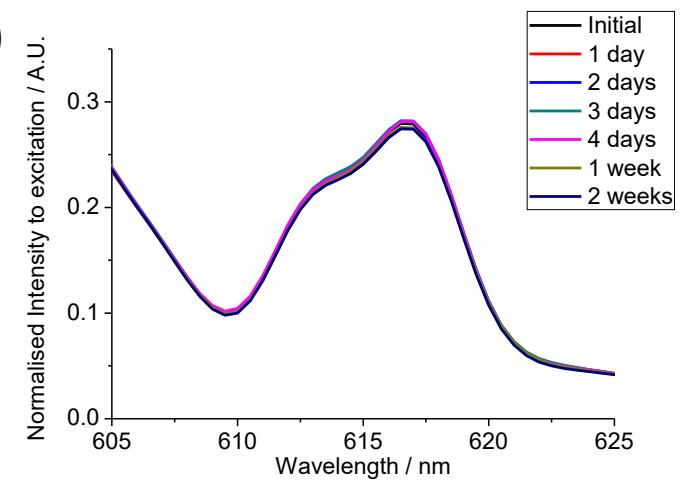

Figure S10. Luminescence spectra of bulk powder particulate $\mathrm{Y}_{0.9} \mathrm{Eu}_{0.1} \mathrm{VO}_{4}\left(\lambda_{\mathrm{ex}}=290 \mathrm{~nm}\right)$ in Milli-Q water $0.1 \mathrm{mg} / \mathrm{mL}$ stored in a glass vial, protected from light a) at room temperature and b) at $4{ }^{\circ} \mathrm{C}$ up to 2 weeks. 

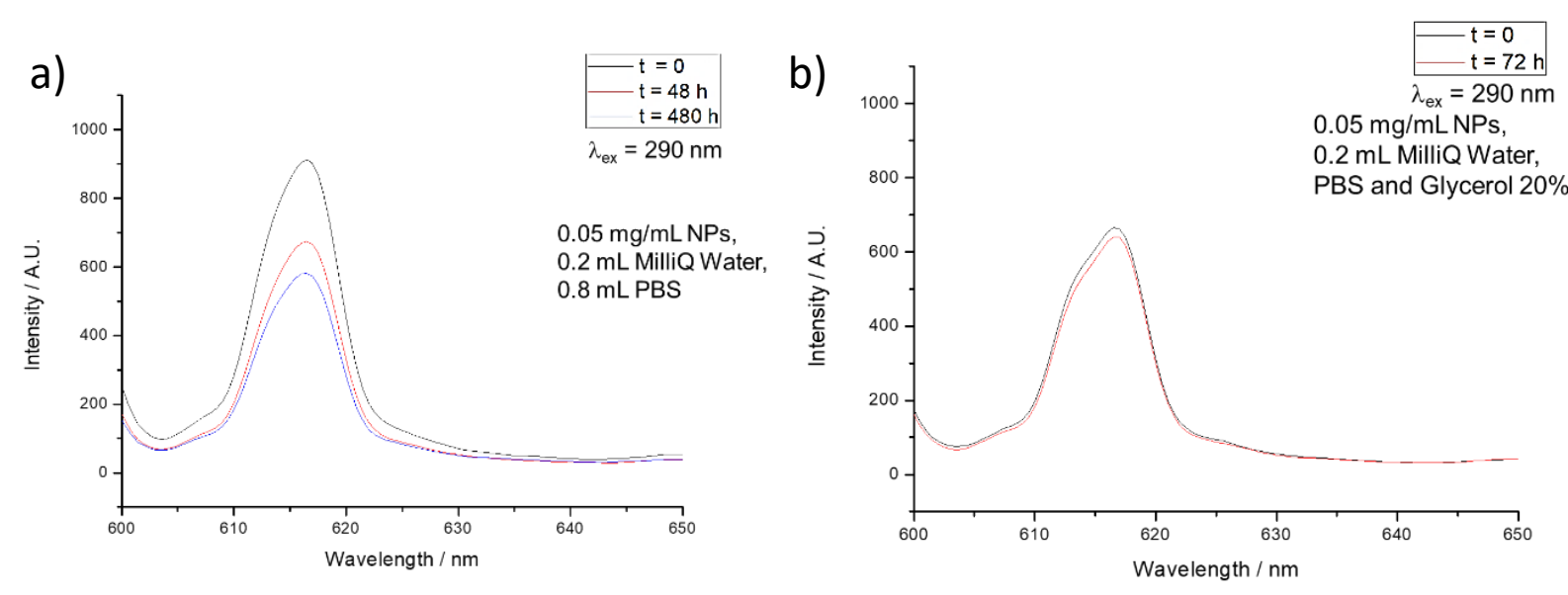

Figure S11. Luminescence spectra of bulk powder particulate $\mathrm{Y}_{0.9} \mathrm{Eu}_{0.1} \mathrm{VO}_{4}\left(\lambda_{\mathrm{ex}}=290 \mathrm{~nm}\right.$ ) in a) PBS $0.05 \mathrm{mg} / \mathrm{mL}$ stored in a glass vial, protected from light at room temperature up to 20 days and b) PBS with glycerol $20 \% 0.05 \mathrm{mg} / \mathrm{mL}$ stored in a glass vial, protected from light at room temperature up to 3 days.

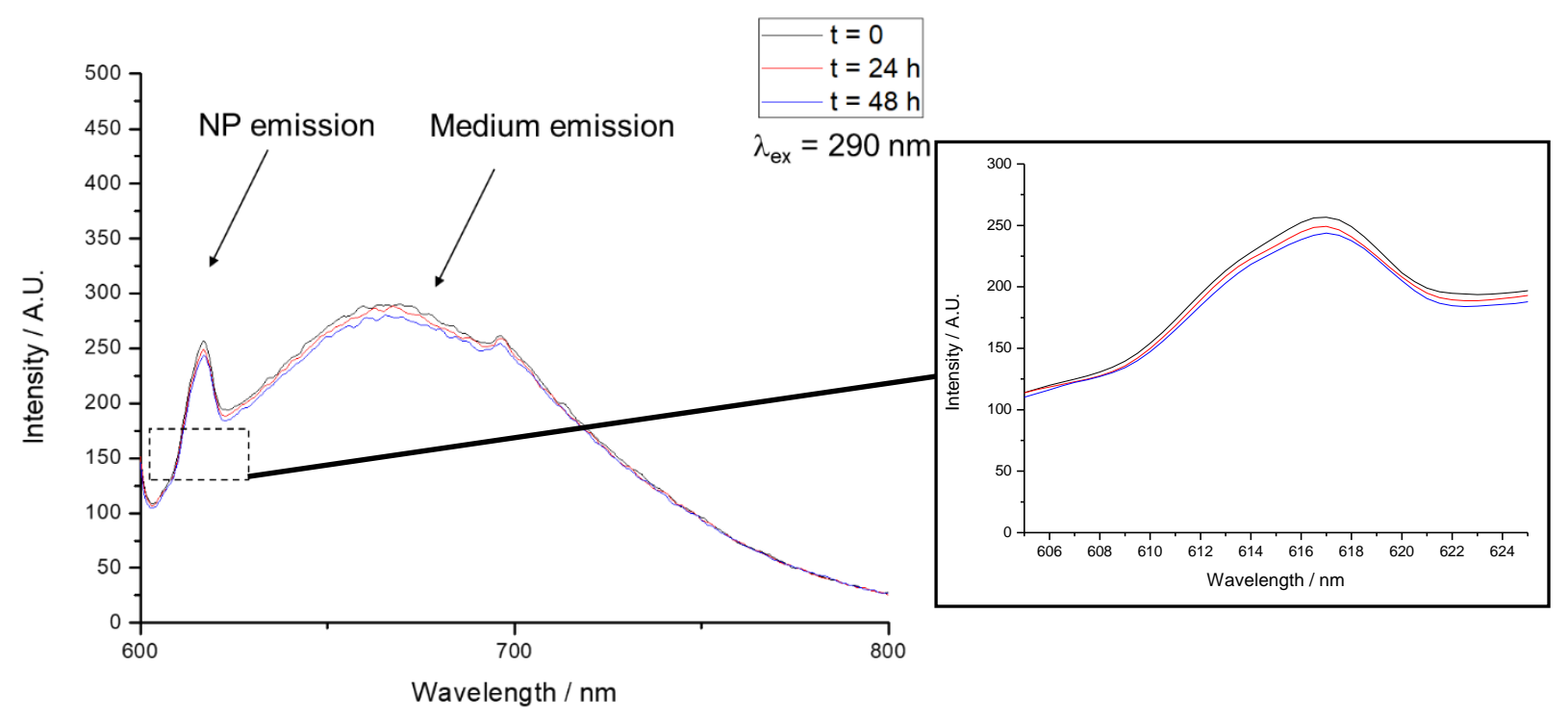

Figure S12. Luminescence spectra of bulk powder particulate $\mathrm{Y}_{0.9} \mathrm{Eu}_{0.1} \mathrm{VO}_{4}\left(\lambda_{\mathrm{ex}}=290 \mathrm{~nm}\right)$ in cell medium (MEM) (0.8 $\mathrm{mL} \mathrm{MEM}$ $10 \%$ FBS $+0.05 \mathrm{mg} / \mathrm{mL}$ NPs, $0.2 \mathrm{~mL}$ Milli-Q water) protected from light at room temperature up to 2 days.

\section{Fluorescence microscopy}

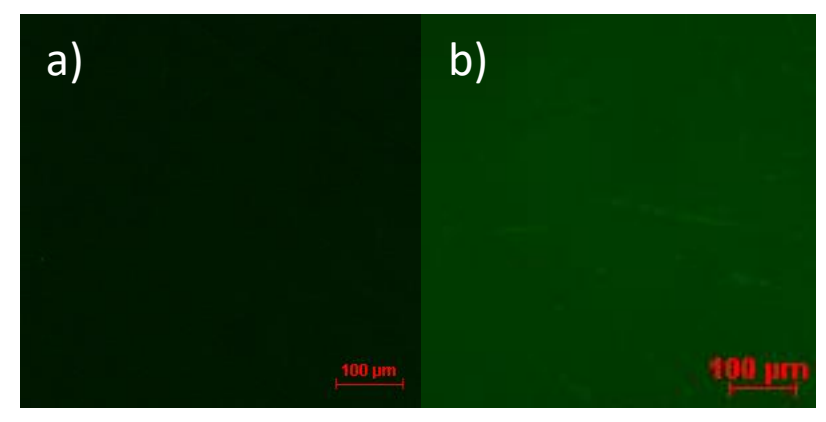

Figure S13. Representative fluorescence of a) Milli-Q water and b) Milli-Q water with $0.25 \mathrm{mg} / \mathrm{mL}$ of bulk powder particulate $\mathrm{Y}_{0.9} \mathrm{Eu}_{0.1} \mathrm{VO}_{4}$ nanomaterials (green channel, $\lambda_{\mathrm{ex}}=488 \mathrm{~nm}$ ). 

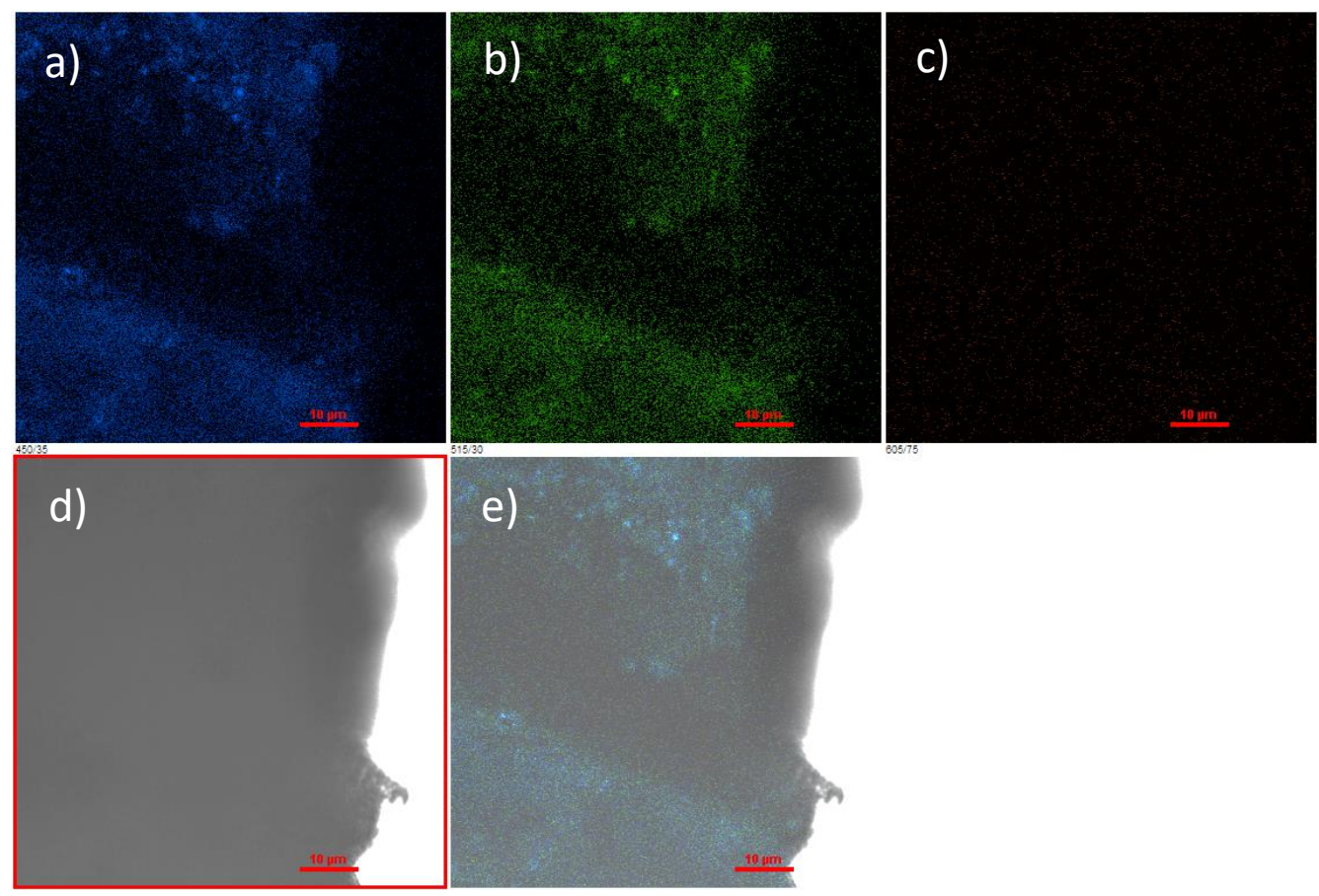

Figure S14. Representative confocal fluorescence of bulk powder particulate $\mathrm{Y}_{0.9} \mathrm{Eu}_{0.1} \mathrm{VO}_{4}$ nanomaterials deposited on a glass slide a) blue channel; b) green channel; c) red channel; d) DIC image and e) overlay of the blue-green channels; $\lambda_{\text {ex }}=488 \mathrm{~nm}$. Scale bar: $10 \mu \mathrm{m}$.

\section{Cell studies}

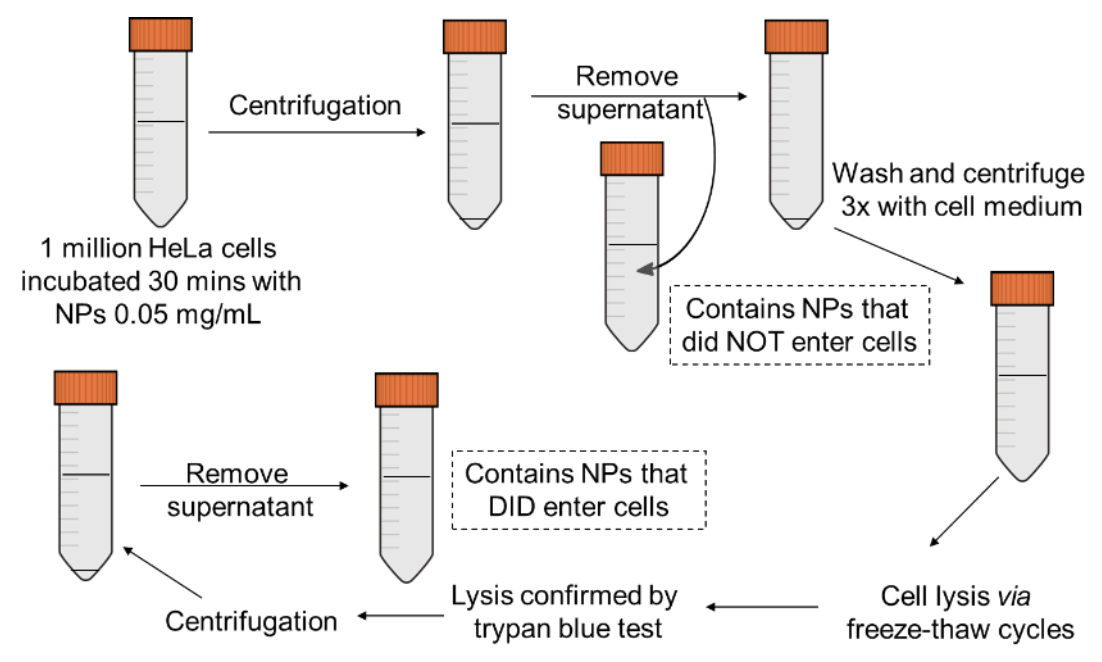

Scheme S1. Cell uptake experiment. 

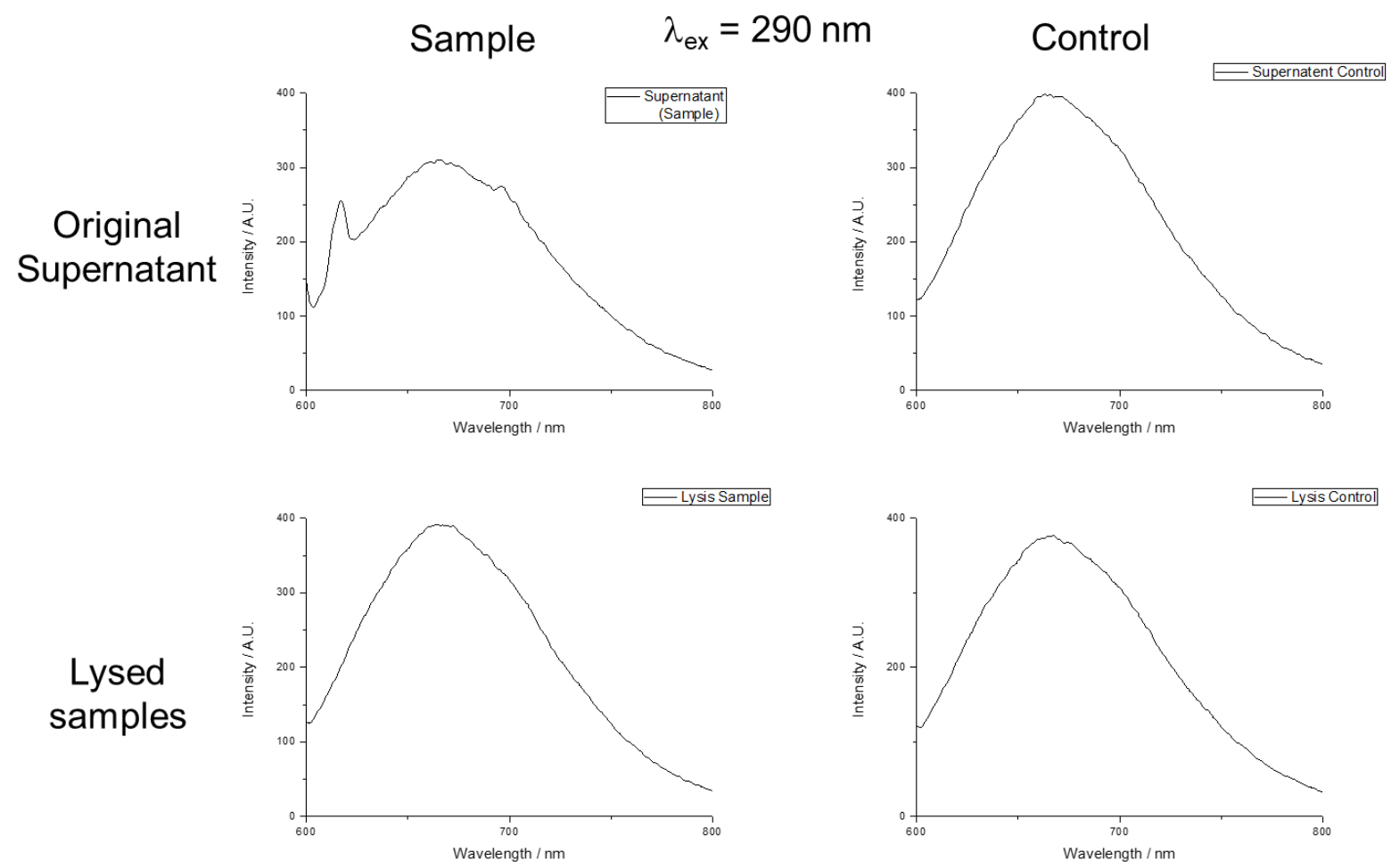

Figure S15. Luminescence spectra of bulk powder particulate $\mathrm{Y}_{0.9} \mathrm{Eu}_{0.1} \mathrm{VO}_{4}$ nanomaterials and control samples $\left(\lambda_{\mathrm{ex}}=290 \mathrm{~nm}\right)$.

As it can be observed in the Figure S16, no incorporation of bulk powder particulate $\mathrm{Y}_{0.9} \mathrm{Eu}_{0.1} \mathrm{VO}_{4}$ into the cell takes place. This was also confirmed by confocal fluorescence microscopy (Figure S17).

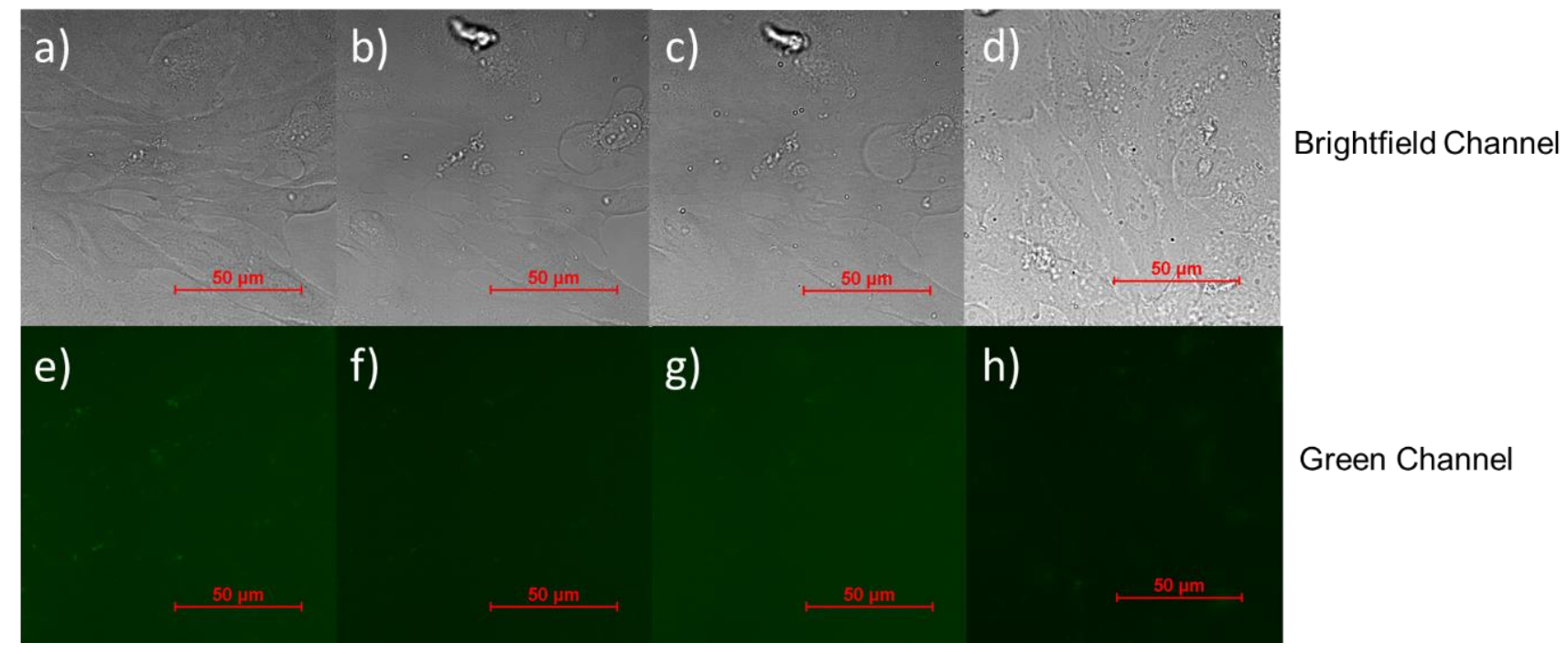

Figure S16. Fluorescence image of live HeLa cells incubated with bulk powder particulate $\mathrm{Y}_{0.9} \mathrm{Eu}_{0.1} \mathrm{VO}_{4}(0.05 \mathrm{mg} / \mathrm{mL})$ at a) and e) $t=0 \mathrm{~min}$ (without nanoparticles), b) and f) $t=15 \mathrm{~min}, \mathrm{c}$ ) and $\mathrm{g}) \mathrm{t}=60 \mathrm{~min}$, and d) and h) $\mathrm{t}=360 \mathrm{~min}$. $\lambda_{\mathrm{ex}}=488 \mathrm{~nm}$. Scale bar: $50 \mu \mathrm{m}$.

In addition, it has been proven experimentally that, after 6 hours of incubation, there is practically no incorporation of uncoated bulk powder particulate $\mathrm{Y}_{0.9} \mathrm{Eu}_{0.1} \mathrm{VO}_{4}$ into the cell, and the non-toxicity of the nanoparticles Figure S17. 

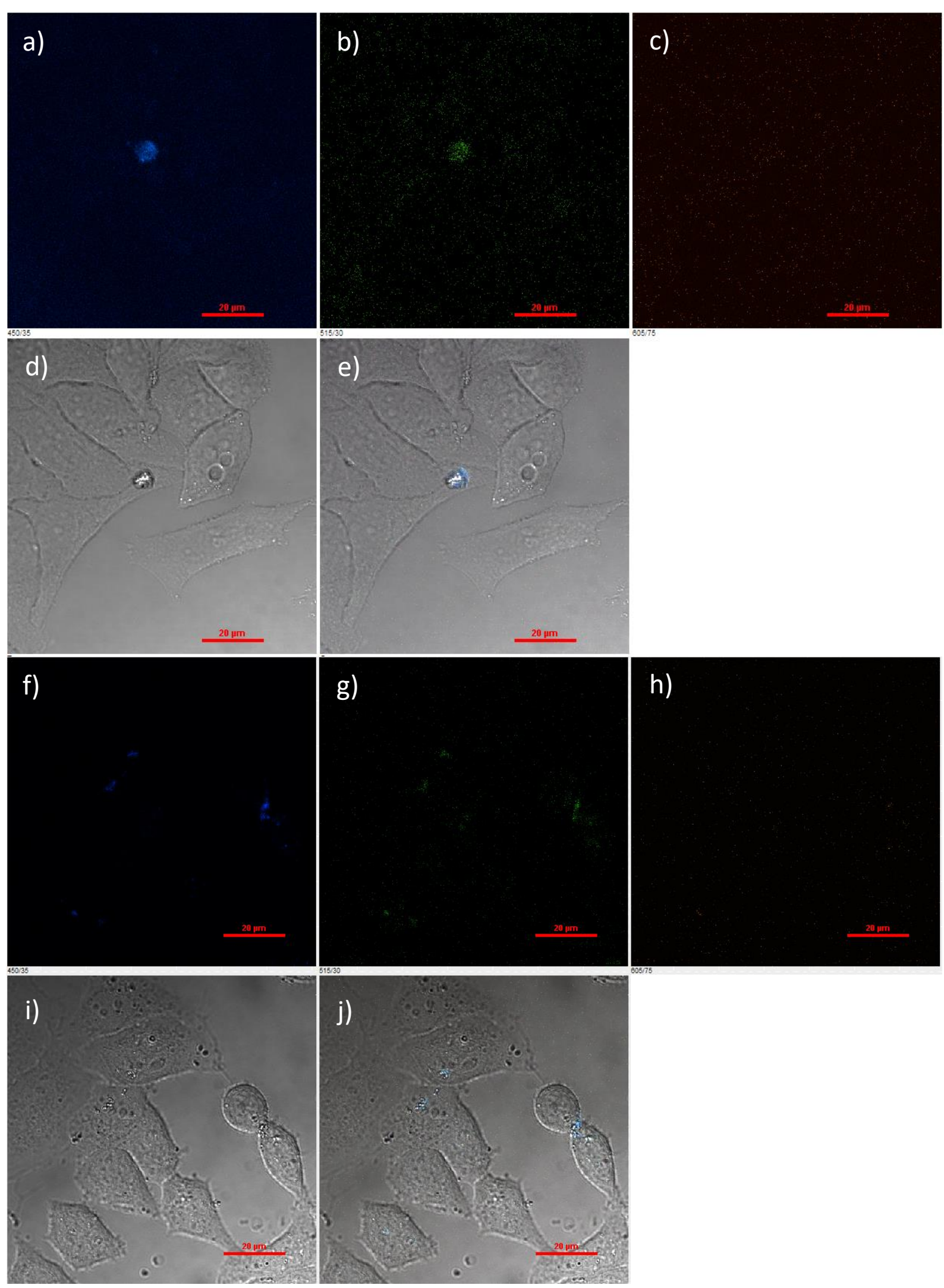

h)

Figure S17. Confocal image of live HeLa cells incubated (15 min) with bulk powder particulate $\mathrm{Y}_{0.9} \mathrm{Eu}_{0.1} \mathrm{VO}_{4}(0.05 \mathrm{mg} / \mathrm{mL})$ a) blue channel; b) green channel; c) red channel; d) DIC image and e) overlay of the blue-green channels and live HeLa cells incubated (360 min) with bulk powder particulate $\mathrm{Y}_{0.9} \mathrm{Eu}_{0.1} \mathrm{VO}_{4}(0.05 \mathrm{mg} / \mathrm{mL}) \mathrm{f}$ ) blue channel; g) green channel; $\left.\mathrm{h}\right)$ red channel; i) DIC image and j) overlay of the blue-green channels; $\lambda_{\mathrm{ex}}=488 \mathrm{~nm}$. Scale bar: $20 \mu \mathrm{m}$. 


\section{PEG-ylation Procedures}

The amino PEG precursors and the aminooxy $\mathrm{H}_{2} \mathrm{~N}-\mathrm{PEG}-\mathrm{OC}_{3} \mathrm{H}_{6}-\mathrm{COOH}$ polymer with Mw ca. $2000 \mathrm{~g} / \mathrm{mol}, 3000 \mathrm{~g} / \mathrm{mol}$ and 5000 $\mathrm{g} / \mathrm{mol}$ were purchased from Rapp Polymere or NanoCS and functionalised in-house through the synthetic approaches described below, giving rise to Compounds Type I and II below.

In parallel experiments the surface of the bulk powder material $\mathrm{Y}_{0.9} \mathrm{Ln}_{0.1} \mathrm{VO}_{4}$ (denoted Eu:YVO4) and of the core-shell $\mathrm{Y}_{0.9} \mathrm{Ln}_{0.1} \mathrm{VO}_{4} @ \mathrm{SiO}_{2}$ nanoparticles was functionalized with functional PEGylated silane polymers with Mw of ca. 2000, 3000 and $5000 \mathrm{Da}$, whereby $\mathrm{n}$ were of $40\left(\mathrm{C}_{7} \mathrm{H}_{16} \mathrm{NO}_{4} \mathrm{Si}\left(\mathrm{C}_{2} \mathrm{H}_{4} \mathrm{O}\right)_{40} \mathrm{CH}_{3} \mathrm{O}\right.$ ), 60 (for $\mathbf{C}_{7} \mathrm{H}_{17} \mathbf{N}_{2} \mathbf{O}_{4} \mathrm{Si}\left(\mathbf{C}_{2} \mathrm{H}_{4} \mathrm{O}_{60} \mathbf{C}_{4} \mathrm{H}_{7} \mathbf{O}_{3}\right.$ ), and finally $\mathrm{C}_{7} \mathrm{H}_{17} \mathrm{~N}_{2} \mathrm{O}_{4} \mathrm{Si}\left(\mathrm{C}_{2} \mathrm{H}_{4} \mathrm{O}_{100} \mathrm{C}_{4} \mathrm{H}_{7} \mathrm{O}_{3}\right.$ of ca. $100 \mathrm{PEG}$ mer units), through a number of optimised routes, described below. In case of the bulk powder material $\mathrm{Y}_{0.9} \mathrm{Ln}_{0.1} \mathrm{VO}_{4}$ (denoted Eu:YVO4) one-pot reaction functionalisation, to prevent the possibility that the -NCO functional reactants (2) may still be present on the NP surface, the quenching reaction with the amino PEG precursors (compounds Type I) were carried out in situ, aiming to attach these directly on the -NCO terminal groups on the NPs. These type of reactions were also carried out for the linker functionalisation optimisation strategies, applied in a stepwise reaching, after the isolation of the molecular compounds of types I and II, characterised by IR, mass spectrometry and GPC.

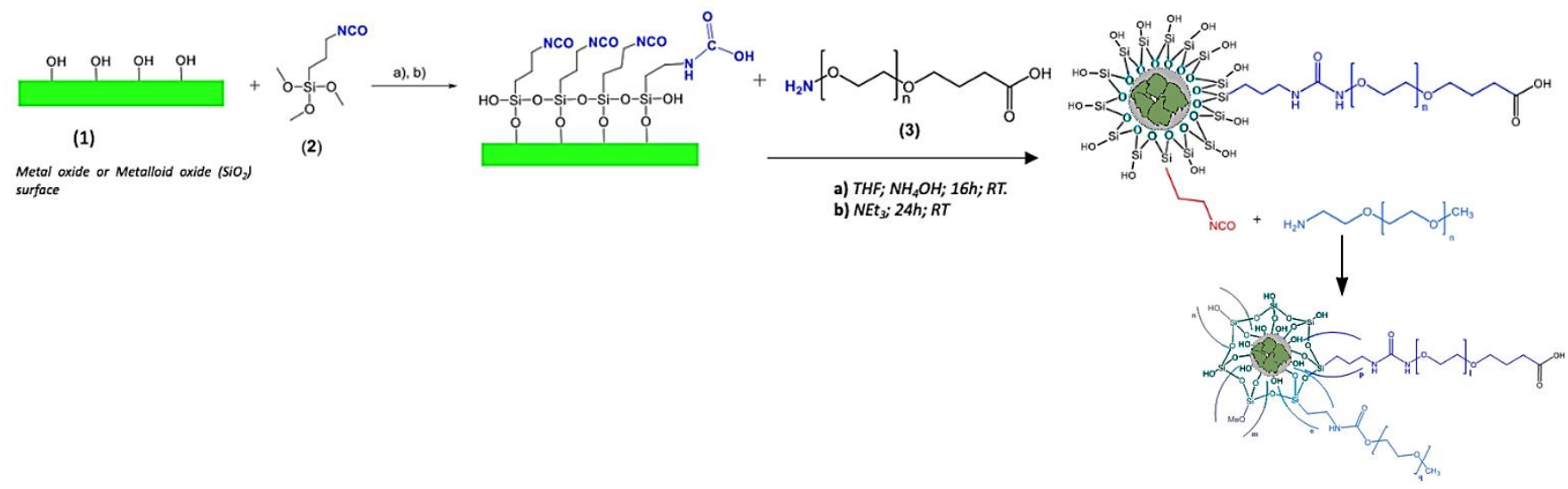

Scheme S1. General functionalisation of bulk powder materials, in one-pot reaction approach used for the optimization reactions for functionalization with $-\mathrm{COOH}$ groups followed by quenching in situ of -NCO residues.

(i)
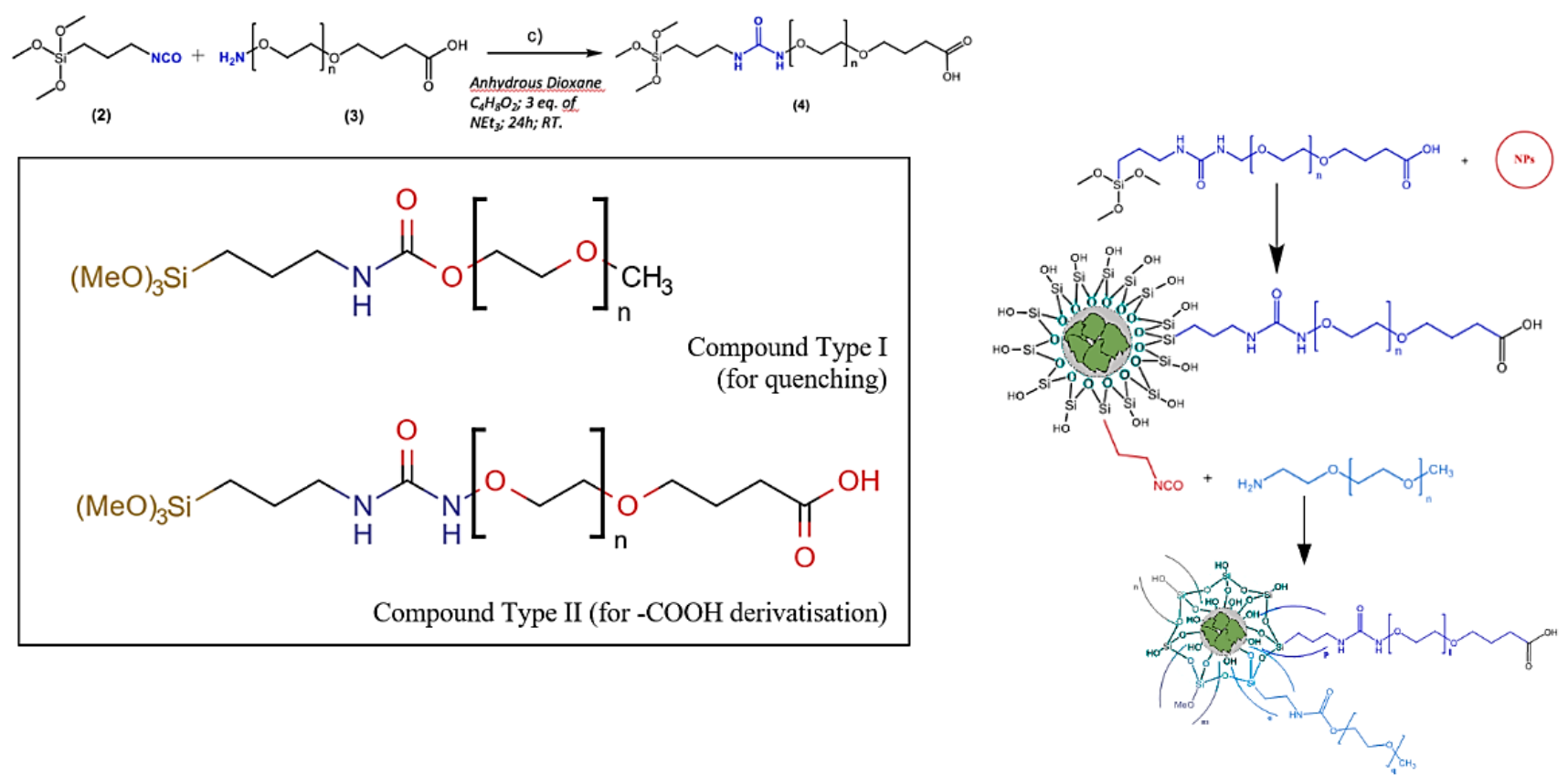

Scheme S2. Stepwise functionalization protocol for optimization reactions: (i) Formation of functional linker molecules followed by (ii) Direct NPs surface functionalization and quenching, adopted hereby as the functionalisation approach for direct functionalisation of $\mathrm{Y}_{0.9} \mathrm{Eu}_{0.1} \mathrm{VO}_{4}$ bulk powder nanomaterial used for kinetic stability investigations. Box: Structures of linkers precursors and quenchers isolated, Types I and II, whereby compounds type I ( $n=40,60$ or 100-111 range) were typically used in the quenching reactions. The functionalised linkers (with PEGs $2 \mathrm{kDa}, 3 \mathrm{kDa}$ and $5 \mathrm{kDa}$ ) denoted compounds type II and derived from the aminooxy $\mathrm{H}_{2} \mathrm{~N}-\mathrm{PEG}-\mathrm{O}-\mathrm{C}_{3} \mathrm{H}_{6}-\mathrm{COOH}$ (with $\mathrm{Mw}$ ca. $2 \mathrm{kDa}, 3 \mathrm{kDa}$ and $5 \mathrm{kDa}$ ) were isolated and characterised and used directly as molecular linkers for the nanophosphors conjugation and introduction of $-\mathrm{COOH}$ units. 


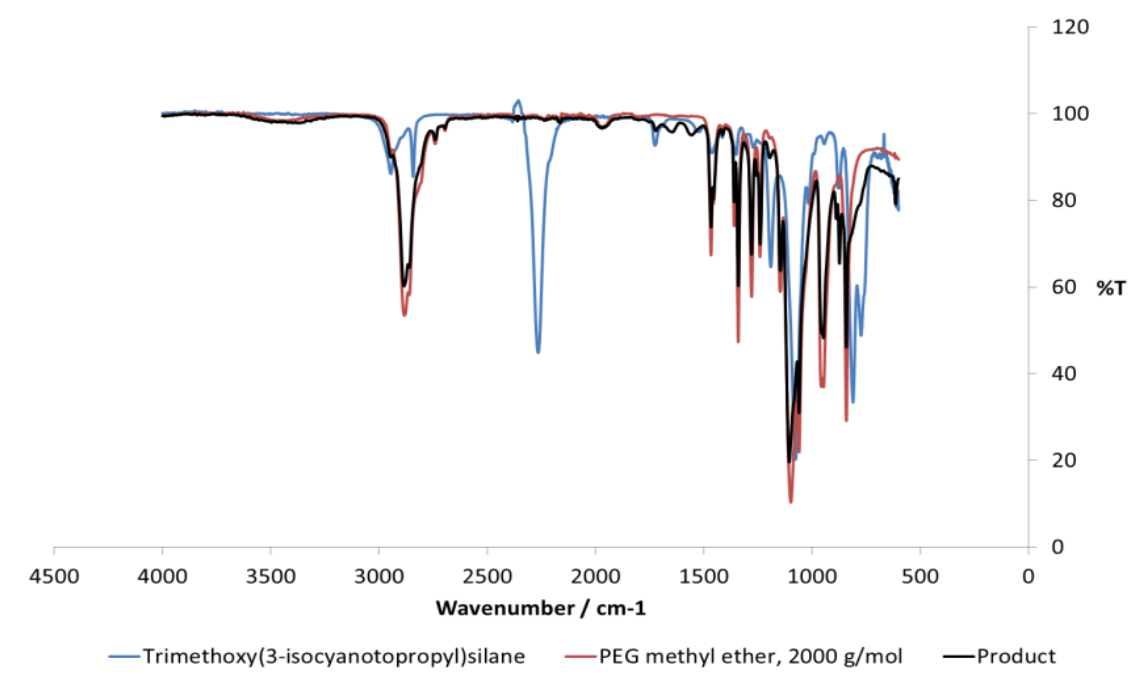

Figure S18. FT-IR spectra of Polyethylene methyl ester (red line), Trimethoxy(3-isocynotopropyl)silane (blue line) and Trimethoxy(3-ureapropyl)polyethylene glycol-silane (black line).

\section{$\underline{\text { Reaction approach } 1}$}

$100 \mathrm{mg}$ nanophosphor (bulk, solid powder) was placed in a pressure tube, $10 \mathrm{~mL}$ dry, degassed THF and $10 \mu \mathrm{L}$ aqueous ammonia (34\%) was added and stirred for 10 minutes. $1.1 \mathrm{~g}$ Trimethoxy(3-isocyanotopropyl)silane was added and the reaction mixture was stirred overnight at $66^{\circ} \mathrm{C}$. The product was centrifuged at $3000 \mathrm{rpm}$ for 10 minutes and subsequently washed $3 x$ with dry THF. After removal of THF the nanophosphors were analysed by IR:

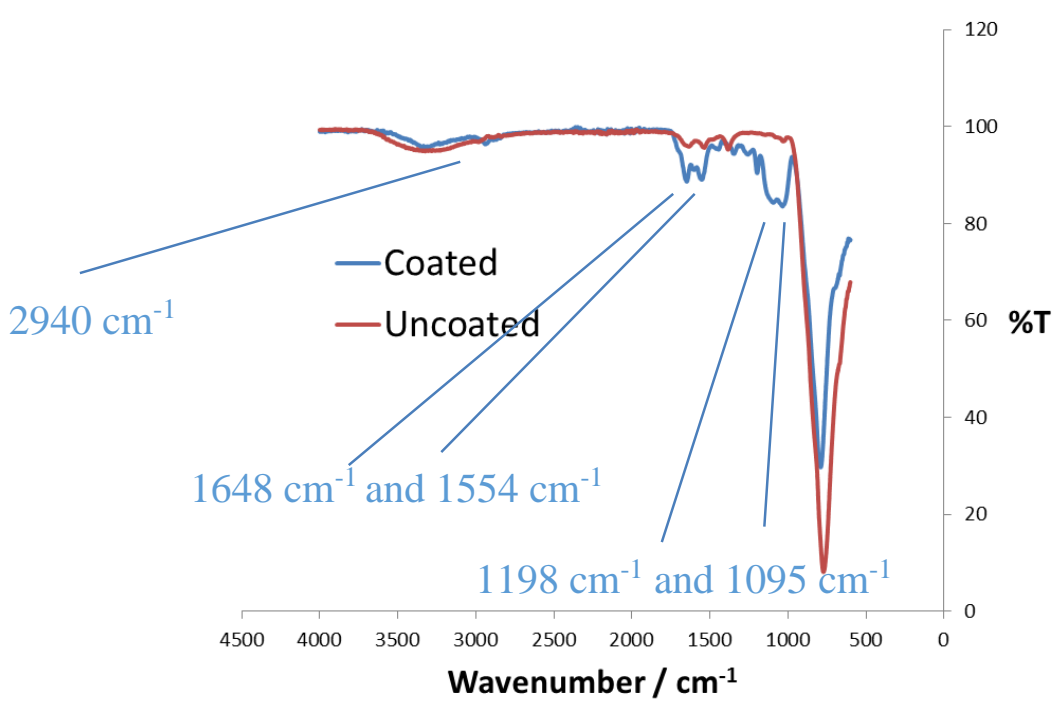

Figure S19. FT-IR of coated and uncoated $\mathrm{Y}_{0.9} \mathrm{EU}_{0.1} \mathrm{VO}_{4}$ nanoparticles, whereby for the coated nanoparticle IR(neat): 3328 2940, 1648, 1601, 1554, 1445, 1409, 1378, 1347, 1309, 1257, 1198, 1095, 1035, 791, 701, 669. Uncoated, IR(neat): 3324 , $1634,1536,1384,1030,773 \mathrm{~cm}^{-1}$.

A band at ca. $2300 \mathrm{~cm}^{-1}$ would be expected for an isocyanate group, which is clearly not present. However, a band and $1095 \mathrm{~cm}^{-1}$ were detected which are indicative of Si-O, showing that coating has occurred (Figure S19). Therefore, it appears that the -NCO group has hydrolysed, leaving an amine group. Bands at $1648 \mathrm{~cm}^{-1}$ and 1554 $\mathrm{cm}^{-1}$ (N-H bend region) and at $1198 \mathrm{~cm}^{-1}$ (C-N stretch region) are confirmative of the presence of a $-\mathrm{NH}_{2}$ group. There is also a band at $2940 \mathrm{~cm}^{-1}$ not visible in the uncoated, which could be indicative of one of the two expected the $\mathrm{N}-\mathrm{H}$ stretch (despite being a little low). The other $\mathrm{N}-\mathrm{H}$ stretch may be overlapping with the broad band occurring 
in the uncoated nanophosphors and is therefore not easily visible. To avoid the observed hydrolysis a one-pot approach and pre-reacting approach were carried out.

A Schlenk was pre-silylated using dimethyldichloride silane in vacuo using a desiccator for 2 hours and was then moved to an oven for $2 \mathrm{~h}$ at $200^{\circ} \mathrm{C}$. $10 \mathrm{~mL}$ dry, THF and $10 \mu \mathrm{L}$ aqueous ammonia (34\%) was added followed by $100 \mathrm{mg} \mathrm{Eu}: \mathrm{YVO}_{4}$ nanophosphor under a flow of nitrogen and stirred for $1 \mathrm{~h} .1 \mathrm{~mL}$

Trimethoxy(3-isocyanotopropyl)silane was added and the reaction mixture was stirred overnight at room temperature. $100 \mathrm{mg}$ of the $5,000 \mathrm{~g} / \mathrm{mol}\left(\mathrm{NH}_{2}-\mathrm{PEG}-\mathrm{COOH}\right) \mathrm{HCl}$ was added followed by $1 \mathrm{eq}$. of triethylamine under a flow of nitrogen. After $20 \mathrm{~h} 250 \mathrm{mg}$ of Poly(ethylene glycol) monomethyl ether $(5,000 \mathrm{~g} / \mathrm{mol})$ was added under a flow of nitrogen (Scheme S3). This was allowed to react for $5 \mathrm{~h}$ and then was centrifuged at $3000 \mathrm{rpm}$ for 5 minutes and subsequently washed $3 x$ with dry THF. After removal of THF the nanophosphors, the supernatant was analyzed by fluorimetry in Milli-Q water (Figure S19). The characteristic spectrum can be visualized here $\left(\lambda_{\text {ex }}=\right.$ $290 \mathrm{~nm}$ ), where there was an absence of the emission peak observed in poorly dispersed coated nanoparticle (a broad peak ca. $350 \mathrm{~nm}$ ). This therefore indicates that there is a good dispersability in THF and in water.

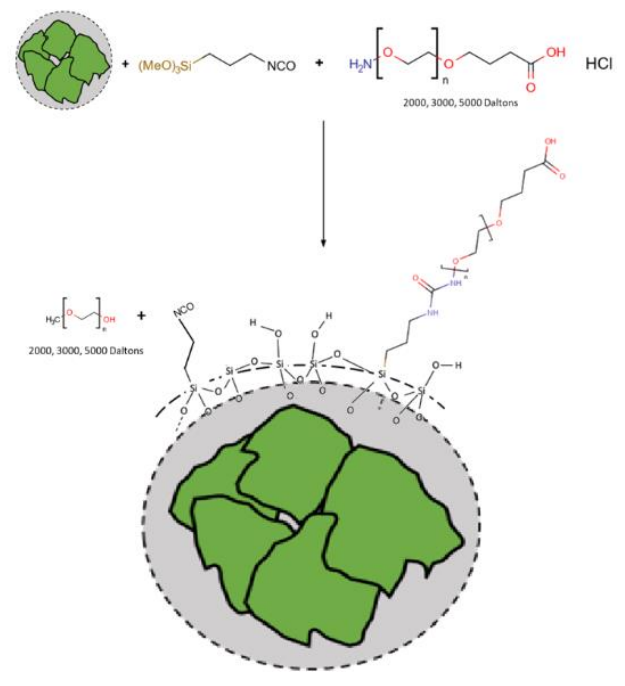

Scheme S3. Reaction scheme for the optimised 1-pot synthesis to yield coated $\mathrm{Y}_{0.9} \mathrm{Eu}_{0.1} \mathrm{VO}_{4}$ nanoparticles via an isocyanate functionalized silane, and generalised to the range of functional PEG linkers.

a)

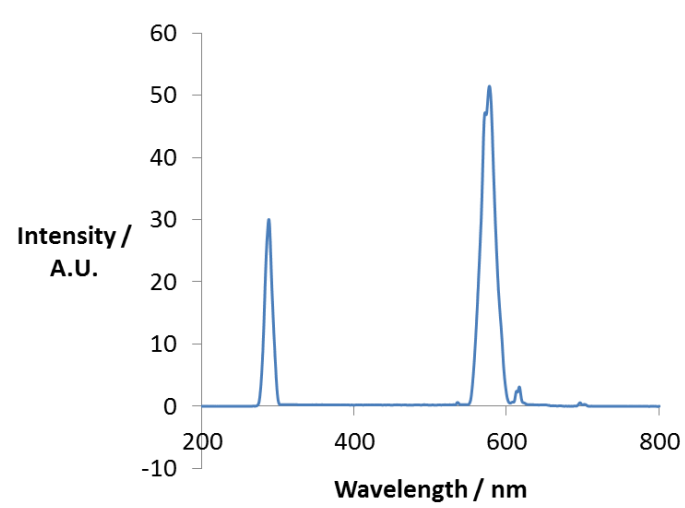

b)

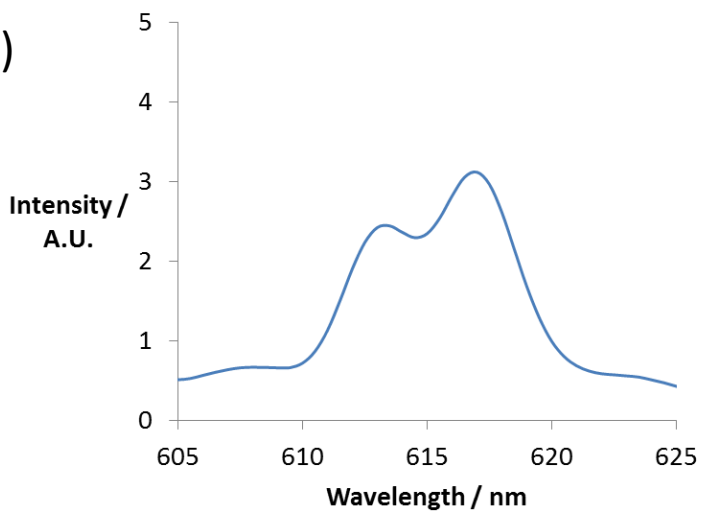

Figure S20. Luminescence spectra of the $\mathrm{Y}_{0.9} \mathrm{Eu}_{0.1} \mathrm{VO}_{4}$ product, coated with PEG5000 linker in $2 \mathrm{mg} / \mathrm{mL}$ in Milli-Q water of scheme 1, a) $200 \mathrm{~nm}$ to $800 \mathrm{~nm}$, b) $605 \mathrm{~nm}$ to $625 \mathrm{~nm}, \lambda_{\mathrm{ex}}=290 \mathrm{~nm}$. 


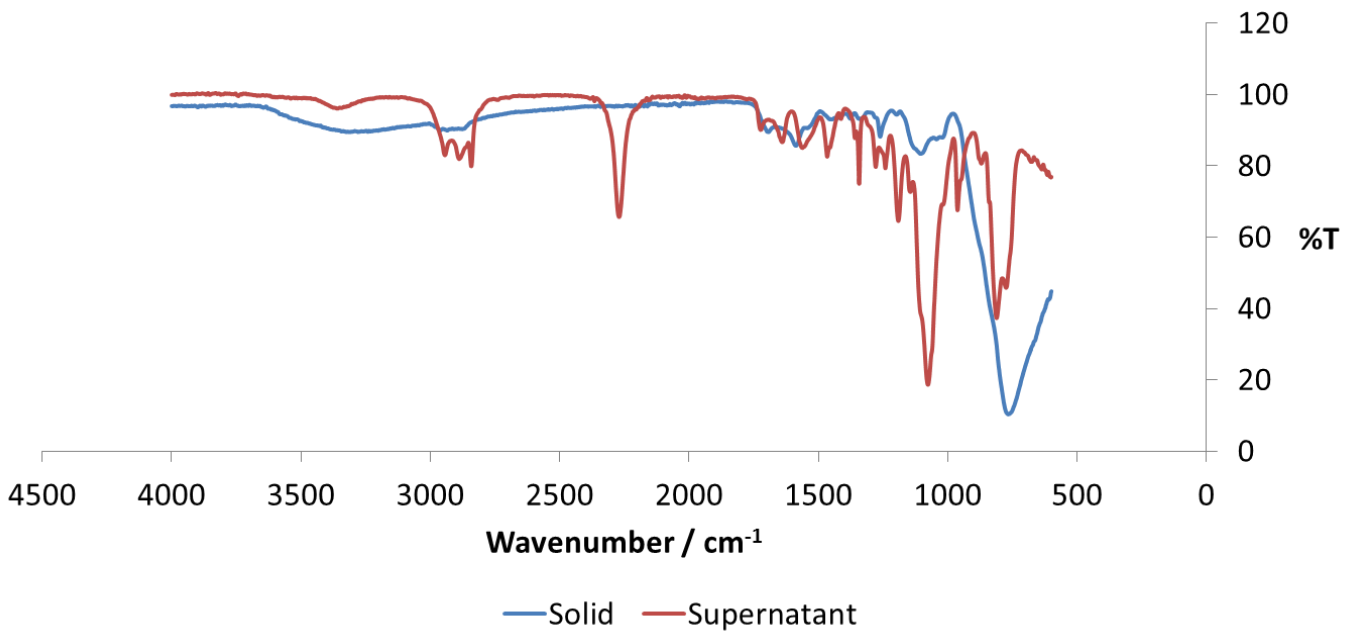

Figure 21. IR spectra of the supernatant (IR(neat): 3361, 2944, 2889, 2842, 2271, 1723, 1640, 1563, 1466, 1413, 1360, 1343, 1279, 1242, 1192, 1145, 1077, 963, 871, 812, 775, 676, 638, $616 \mathrm{~cm}^{-1}$ ) and of the solid (IR(neat): 3315, 2963, 2935, 2877, $1693,1587,1542,1448,1420,1377,1339,1262,1198,1106,1044,1021,767$ ) from the reaction described in Scheme S3 (for PEG5000).

\section{Quenching of reaction shown in Scheme S3:}

To the supernatant a further $250 \mathrm{mg}$ of Poly(ethylene glycol) monomethyl ether (ca. 5,000 g/mol, denoted MeOfunctional PEG5000) and $10 \mathrm{~mL}$ of anhydrous dioxane. This was gently heated into solution and stirred at $\mathrm{rt}$ for 24h. The flask was dried in vacuo and an IR spectrum was measured. The resultant product was not found to be fully reacted (due to the presence of the isocyanate peak at $2271 \mathrm{~cm}^{-1}$ ), therefore the process above was repeated with another $250 \mathrm{mg}$ of Poly(ethylene glycol) monomethyl ether $(5,000 \mathrm{~g} / \mathrm{mol})$ in anhydrous dioxane. After drying, the IR spectrum showed that no isocyanate remained (Figure S22).

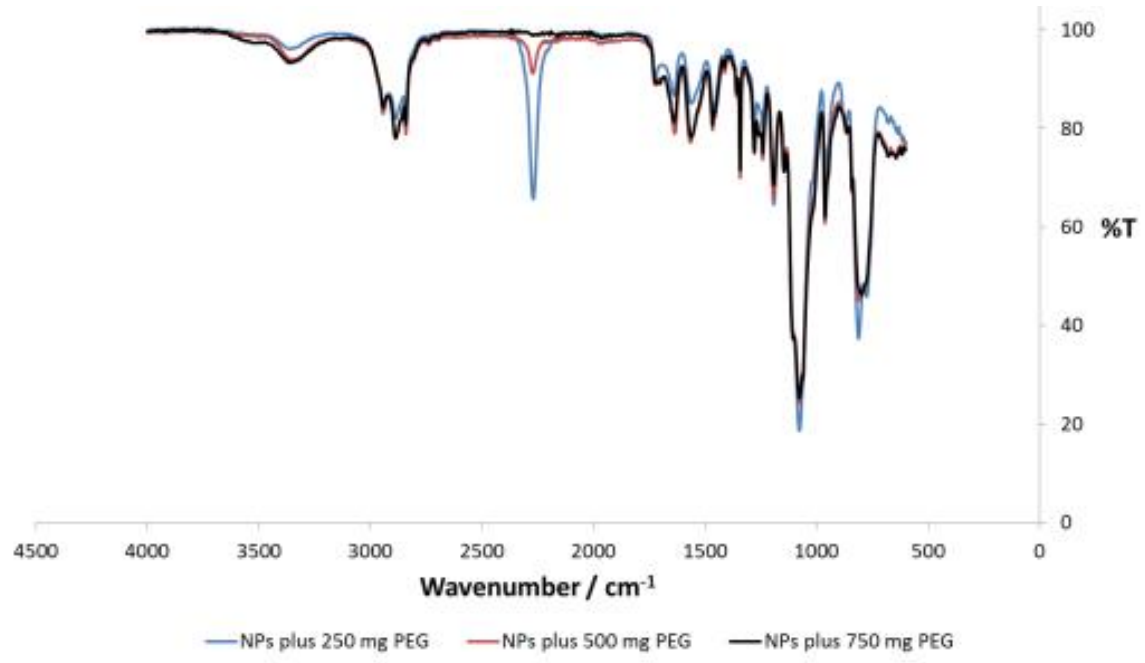

Figure S22. FTIR spectra of product of reaction described in Scheme S2 (blue), with an extra 250 mg of PEG methyl ether added (totalling $500 \mathrm{mg}$ ) (red) IR(neat): 3354, 2943, 2888, 2841, 2741,2695, 2272, 1724, 1636, 1566, 1466, 1455, 1413, 1360, $\left.1343,1279,1242,1192,1147,1106,1078,962,866,841,811,676,643,617 \mathrm{~cm}^{-1}\right)$ and with a total of $750 \mathrm{mg}$ (black) (IR(neat): 3369, 2942, 2888, 2842, 2741, 2696, 1723, 1705, 1639, 1562, 1466, 1413, 1360, 1343, 1279, 1257, 1242, 1192, 1146, 1106, $\left.1077,1061,962,864,841,799,679,644,616 \mathrm{~cm}^{-1}\right)$.

The product from the reaction illustrated in Scheme S3, which was fully quenched, was dialysed using 7 rounds of washing with Milli-Q water, using $250 \mathrm{~mL}$ each, whereby each $250 \mathrm{~mL}$ portion was exposed to the dialysis membrane for ca. 60 minutes and collected. 
a)

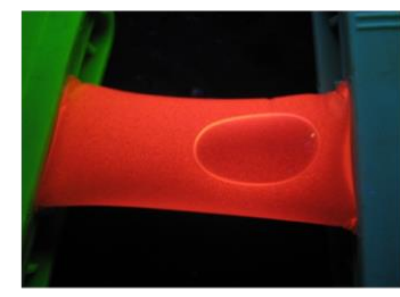

Stayed within dialysis membrane $>12,000$ Daltons $\uparrow$

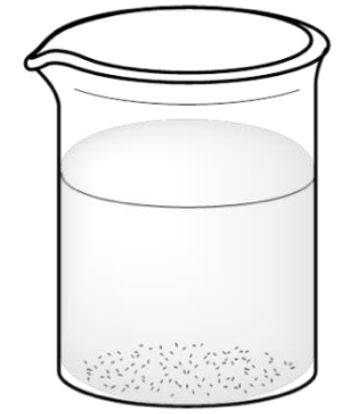

b)

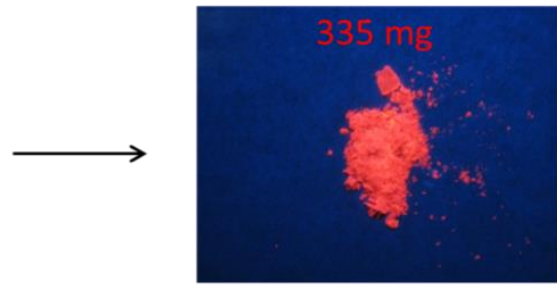

Exposed to short UV

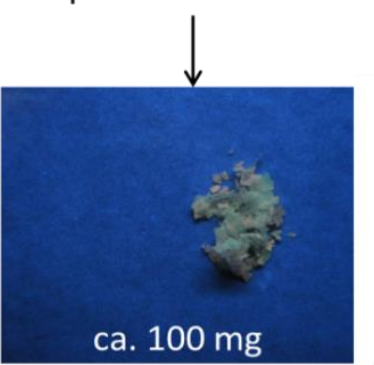

c)
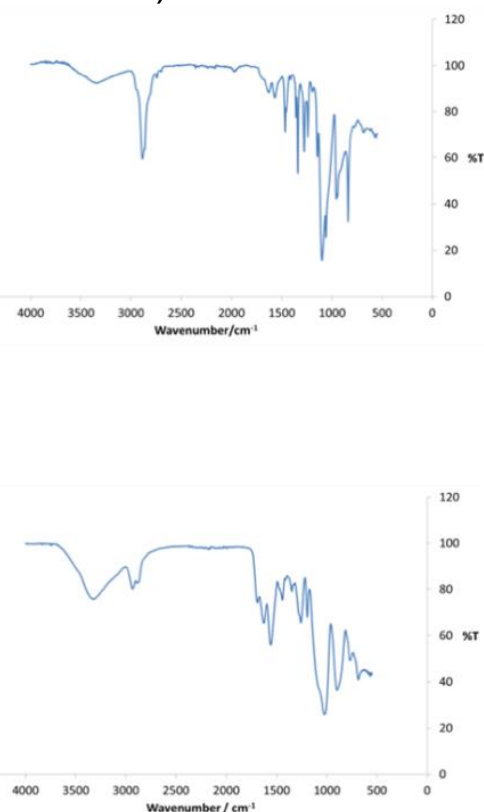

Crossed dialysis membrane $<12,000$ Daltons

Figure S23. Overview of purification process of PEG5000-linked bulk-powder nanophosphors, a) dialysis, b) UV exposure, c) IR spectroscopy. Within the dialysis membrane IR (neat): 3347, 2943, 2885, 2742, 2696, 1700, 1628, 1568, 1467, 1455, 1413, $1360,1341,1279,1241,1196,1146,1100,1060,958,947,842,777,685 \mathrm{~cm}^{-1}$; dialysate IR(neat): 3329, 2931, 2883, 1690, $1628,1558,1474,1444,1413,1349,1330,1260,1196,1024,899,767,686 \mathrm{~cm}^{-1}$.

Both the liquid which remained within the dialysis membrane and the dialysate were isolated in vacuo (Figure S23). The IR spectra of the un-purified product, the dialysate and that, which stayed within the membrane, are compared below (Figure S24). Importantly the FTIR spectrum of the purified product is notably different from the unreacted nanophosphor and contains a significant band at $2890 \mathrm{~cm}^{-1}$ (Figure S24) which is attributable to the carboxylic acid. Furthermore, the intense luminescence of which stayed within the membrane when irradiated with short UV light (ca. $254 \mathrm{~nm}$ ) indicates that this reaction was successful and yielded $335 \mathrm{mg}$ of coated $\mathrm{Y}_{0.9} \mathrm{Eu}_{0.1} \mathrm{VO}_{4}$ nanoparticles.

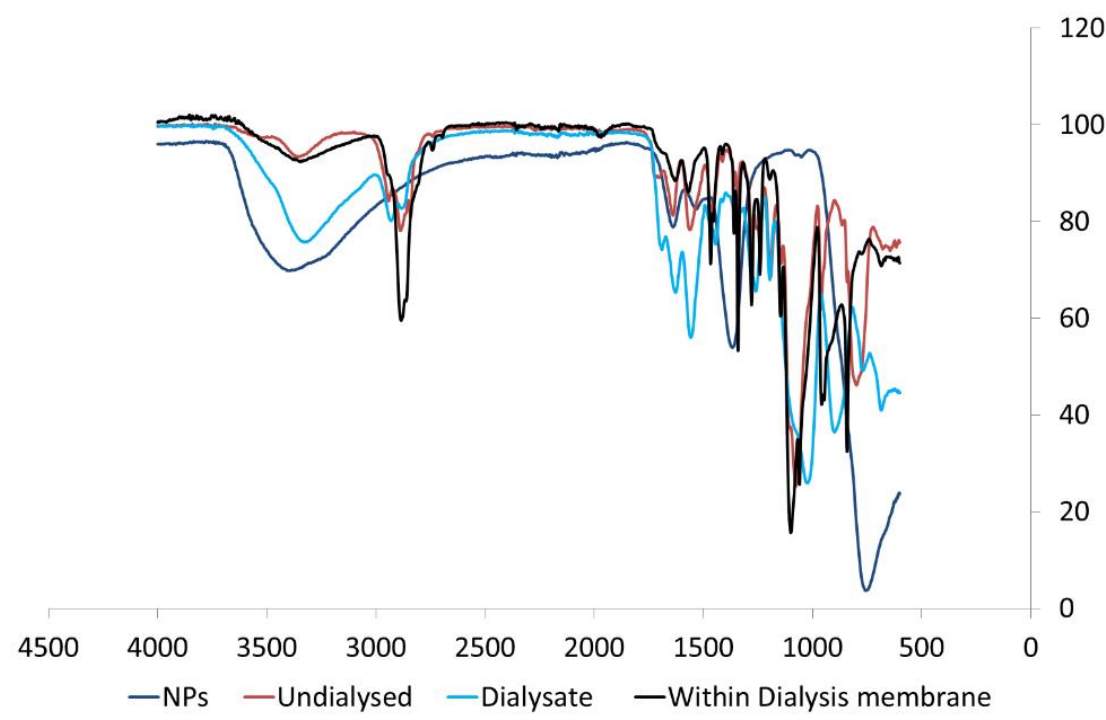

Figure S24. IR spectra of bulk powder particulate $\mathrm{Y}_{0.9} \mathrm{Eu}_{0.1} \mathrm{VO}_{4}$ (dark blue), undialyzed solid (red), dialysate (light blue), the isolate remaining within the dialysis membrane. IR bands listed in Figures S22-S23. 

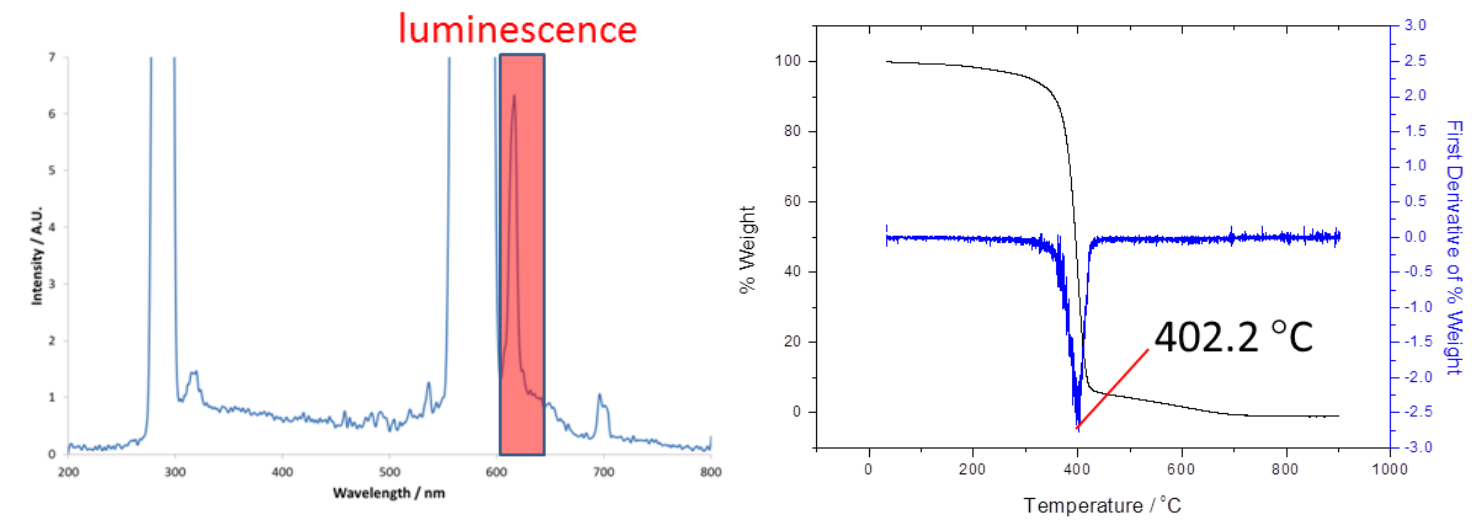

Figure S25. (left) Luminescence emission spectrum of coated bulk powder particulate $\mathrm{Y}_{0.9} \mathrm{Eu}_{0.1} \mathrm{VO}_{4}$ with the functional $5 \mathrm{kDa}$ PEG at $0.1 \mathrm{mg} / \mathrm{mL}$ (after dialysis), with an emission intensity of 6.3 A.U. (Right) TGA of coated bulk powder particulate $\mathrm{Y}_{0.9} \mathrm{Eu}_{0.1} \mathrm{VO}_{4}$ with 5 the kDa PEG.

\section{Approach 2: Test reaction approach for alternative PEG linkers functionalisation}
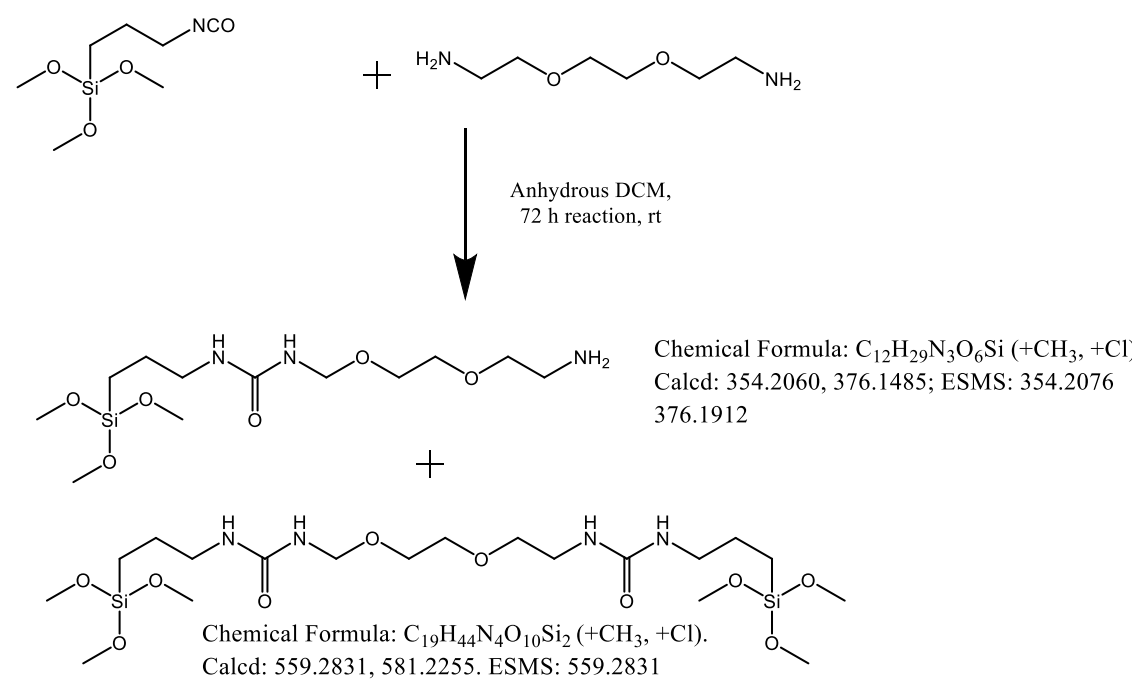

581.2698

Scheme S4. A model reaction with a short amine-functionalised PEG, leading to a mono-substituted siloxane compound.

Another approach was attempted whereby reacting the silane isocyanate with the $\mathrm{NH}_{2}$-PEG-tBoc protected amine prior to coating to the nanophosphor. Trimethoxy(3-isocyanotopropyl)silane, $1.084 \mathrm{~g}(0.0053 \mathrm{mmols})$ was diluted in $100 \mathrm{~mL}$ anhydrous DCM and added dropwise (over $8 \mathrm{~h})$ to $0.783 \mathrm{~g}(0.0053 \mathrm{mmols})$ and allowed to stir over weekend (Scheme S4). DCM was removed in vacuo and an oily product was analysed by ESMS and ${ }^{1} \mathrm{H}$ and ${ }^{13} \mathrm{C}$ NMR. Mass spectrometry confirmed that there was a mixture of the mono(substituted) and di(substituted) silane (peaks ionised in positive mode as in the reaction scheme above). Importantly, there was no significant peak according to MS corresponding to the silane starting material (or its hydrolysed form) (Figure S26) as was there no peak in the region of $120 \mathrm{ppm}$ in the ${ }^{13} \mathrm{C}$ NMR $(75.5 \mathrm{MHz})$. 
+MS, 1.0-1.3min \#(47-60), -Spectral Bkgrnd

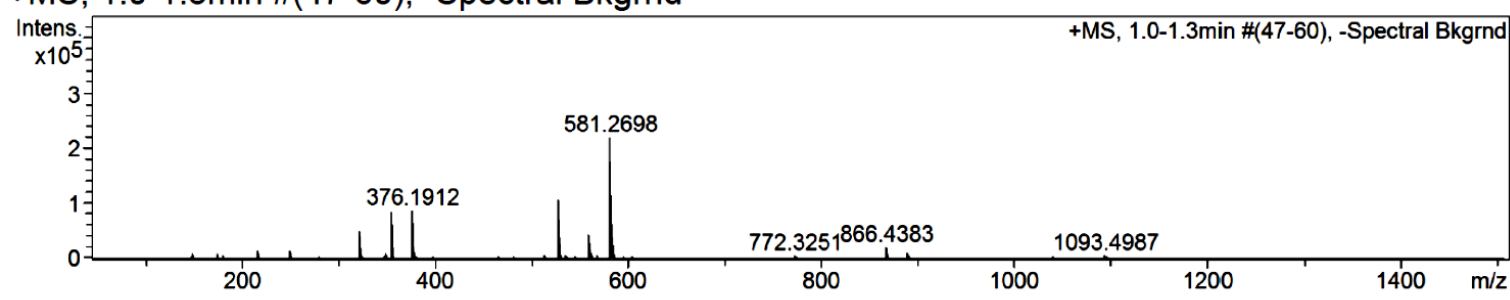

Figure S26. ES-MS spectrum of the obtained product.

\section{Alternative functionalisation of linkers - reaction approach 3}
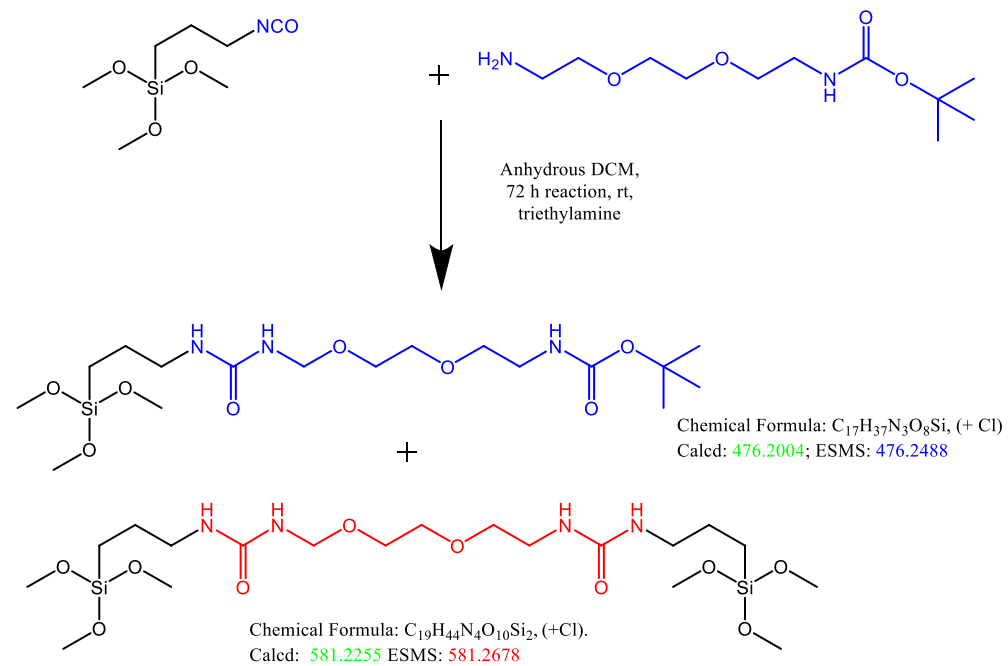

Scheme S5. A model reaction with a short t-boc protected-amine-functionalised PEG, with the purpose of synthesising a monosubstituted siloxane compound.

$277.3 \mathrm{mg}$ (1.351 mmols) Trimethoxy(3-isocyanotopropyl)silane, was added to $335.4 \mathrm{mg}$ (1.351 mmols) of a short t-Butoxycarbonyl-Amine-PEG-Amine, with vast excess of triethylamine $(136.8 \mathrm{mg})$ in anhydrous dichloromethane (Scheme S5). A preliminary ES-MS demonstrated that a mixture of the desired product and undesirable bis(substituted) product were formed (Figure S27).

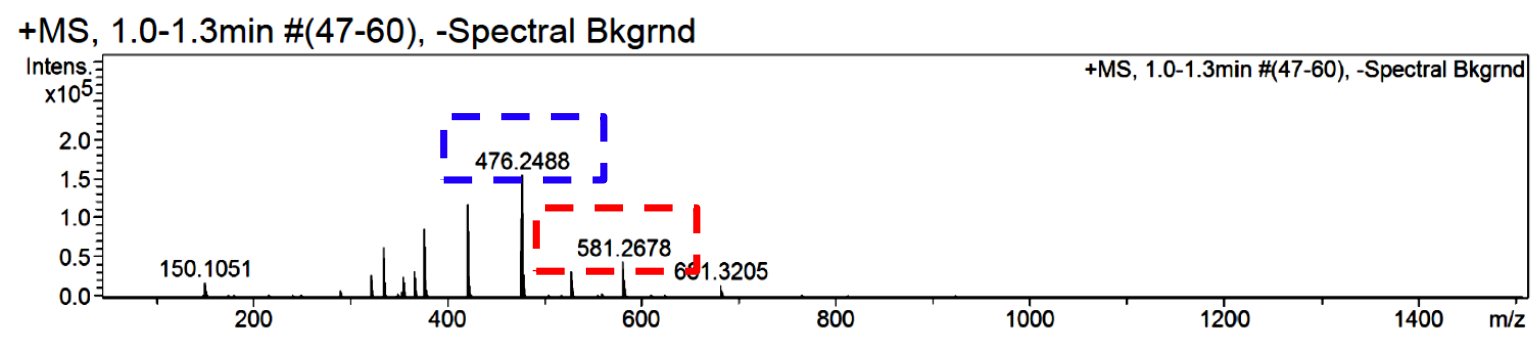

Figure S27. ES-MS of the product from reaction approach 3, showing a mixture of the desired mono(substituted) product (blue) and the by-product (red). 


\section{Alternative reaction approach 4}

$31.8 \mathrm{mg}(29.4 \mu \mathrm{L}, 0.1551 \mathrm{mmols})$ trimethoxy(3-isocyanotopropyl)silane was added to $0.1 \mathrm{~g}(0.1551 \mathrm{mmols})$ of tButoxycarbonyl-Amine-PEG-Amine ( $\left.\mathrm{M}_{\mathrm{r}}=644.7 \mathrm{~g} / \mathrm{mols}\right)$ and to 3 equivalents of triethylamine. As was observed with model reaction 3 a preliminary ES-MS demonstrated that a mixture of the desired product and undesirable bis(substituted) product were formed (Figure S28).

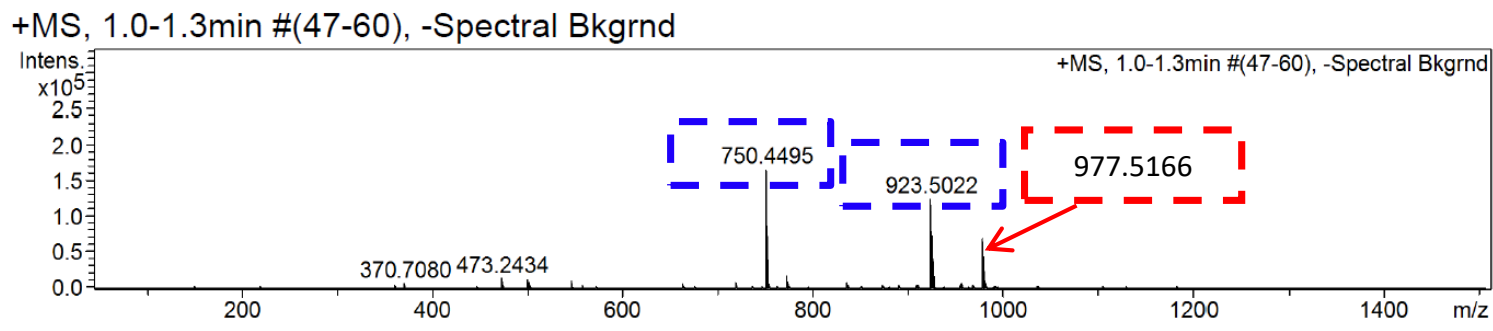

Figure S28. ES-MS of reaction approach 4, showing a mixture of the desired mono(substituted) products (protected and deprotected) (blue) and a small amount of the by-product (red).

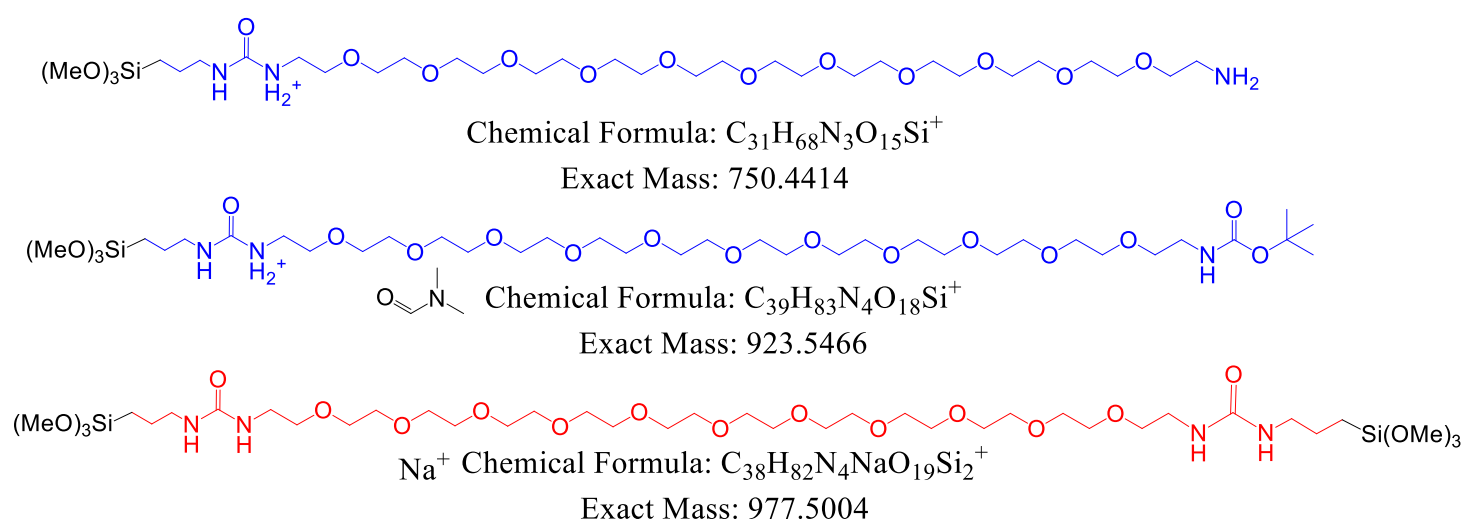

Figure S29. Figure outlining the likely products of reaction approach 4

Both t-Boc protected amine reaction approaches 3 and 4 resulted in deprotection, despite being carried out under basic conditions. It can be speculated that improved results may be achieved, by rinsing glassware with base prior to the start of the reaction and addition of the t-boc protected amine as the last component.

\section{Alternative reaction - approach 5}

Following the method of Lam et al. ${ }^{1}$, succinic anhydride $(1.0 \mathrm{~g}, 9.99 \mathrm{mmols})$ in $100 \mathrm{~mL}$ 1,4-dioxane was added dropwise on ice to 2,2'-(Ethylenedioxy)bis(ethylamine) $(1.703 \mathrm{~g}, 11.5 \mathrm{mmols})$ over 30 minutes. This was allowed to warm to room temperature and rotary evaporated. Saturated aqueous $\mathrm{Na}_{2} \mathrm{CO}_{3}$ was added followed by $200 \mathrm{~mL}$ of diethyl ether. The following mixture was extracted and washed a second time with ether. The aqueous phase was dried in vacuo and a mixture of 1:1 acetone: ethanol was added $(100 \mathrm{~mL})$. This was subsequently filtered and washed again with 1:1 acetone: ethanol $(100 \mathrm{~mL})$. The solvent was removed in vacuo leaving an oily solid. ES-MS appears to show that the most significant peak was the unwanted di-substituted PEG, the length of PEG may be important in selectivity of this reaction (Figure S30). The peak shown is in negative mode showing the peak expected in positive mode - the spectrum may require re-calibration. It also includes the peak plus a sodium accurate to 2 decimal places. 


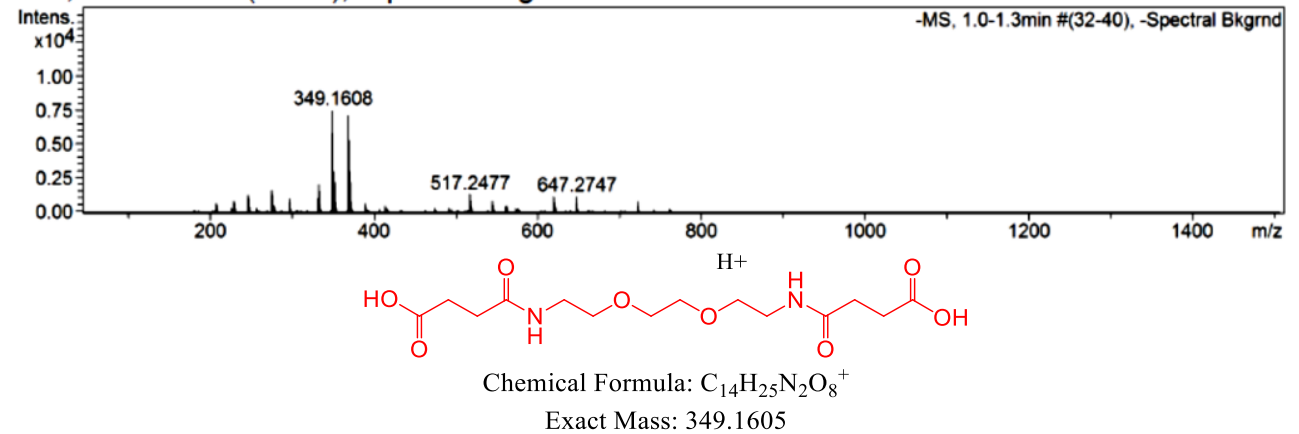

Figure S30. ES-MS of model reaction approach 5, which appears to show the presence of the di-substituted PEG Composites - with $3 \mathrm{kDa}$ PEG and 5 kDa PEG - and which were characterised by IR (figure S31).

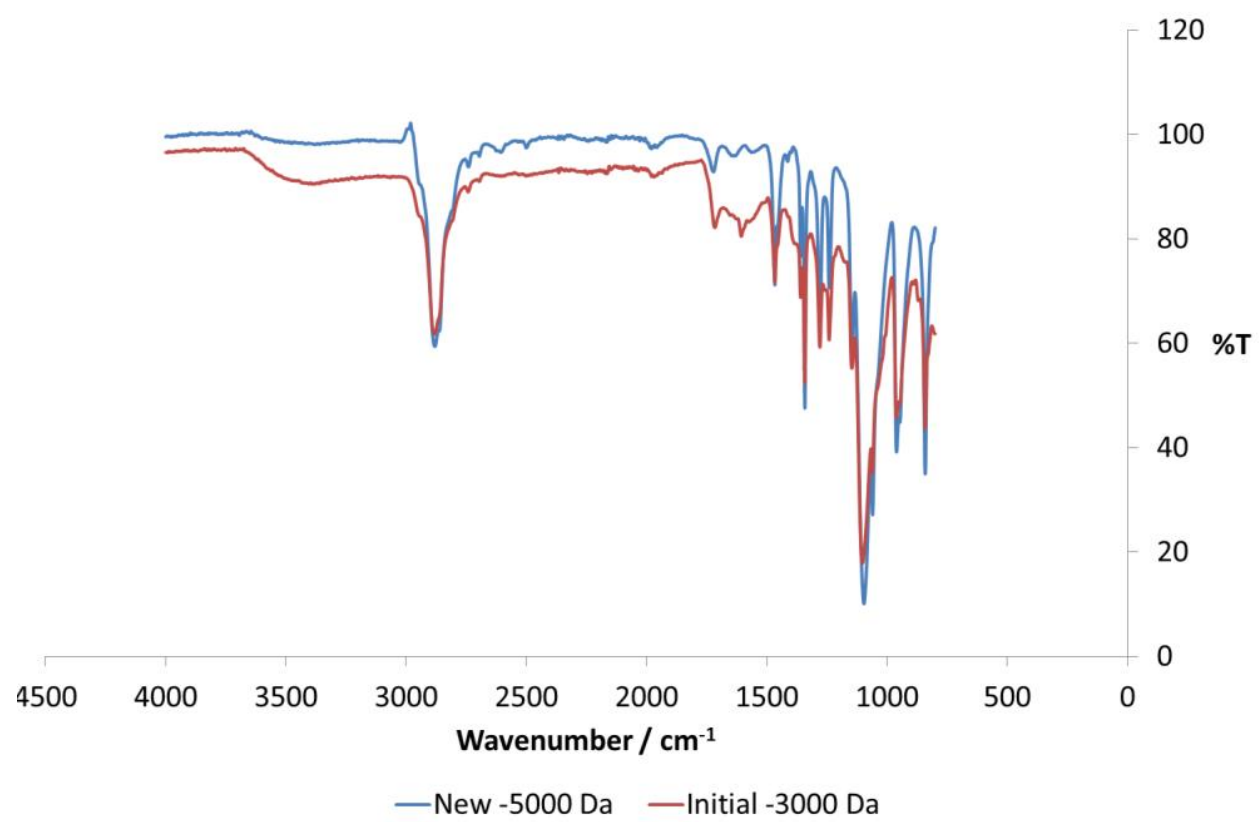

Figure S31. FT-IR spectra of trimethoxy(3-isocyanotopropyl)silane and product of reaction B: Compound with $3 \mathrm{kDaPEG}$ IR(neat): 3426, 2884, 2743, 2696, 1717, 1653, 1606, 1575, 1467, 1360, 1342, 1280, 1241, 1147, 1103, 1061, 961, 870, 841, $801,771,746,731,696 \mathrm{~cm}^{-1}$. Compound with 5 kDaPEG IR(neat): 2944, 2881, 2863, 2741, 2696, 2606, 2500, 1980, 1722, $1640,1559,1467,1456,1360,1342,1279,1241,1146,1096,1060,961,947,841 \mathrm{~cm}^{-1}$.

\section{$\underline{\text { Reactions using protocols involving a pre-reacting to silane step }}$}

To allow both more control over the reaction and analysis via additional methods an approach whereby the silane was reacted to the PEG prior to coating was explored. 


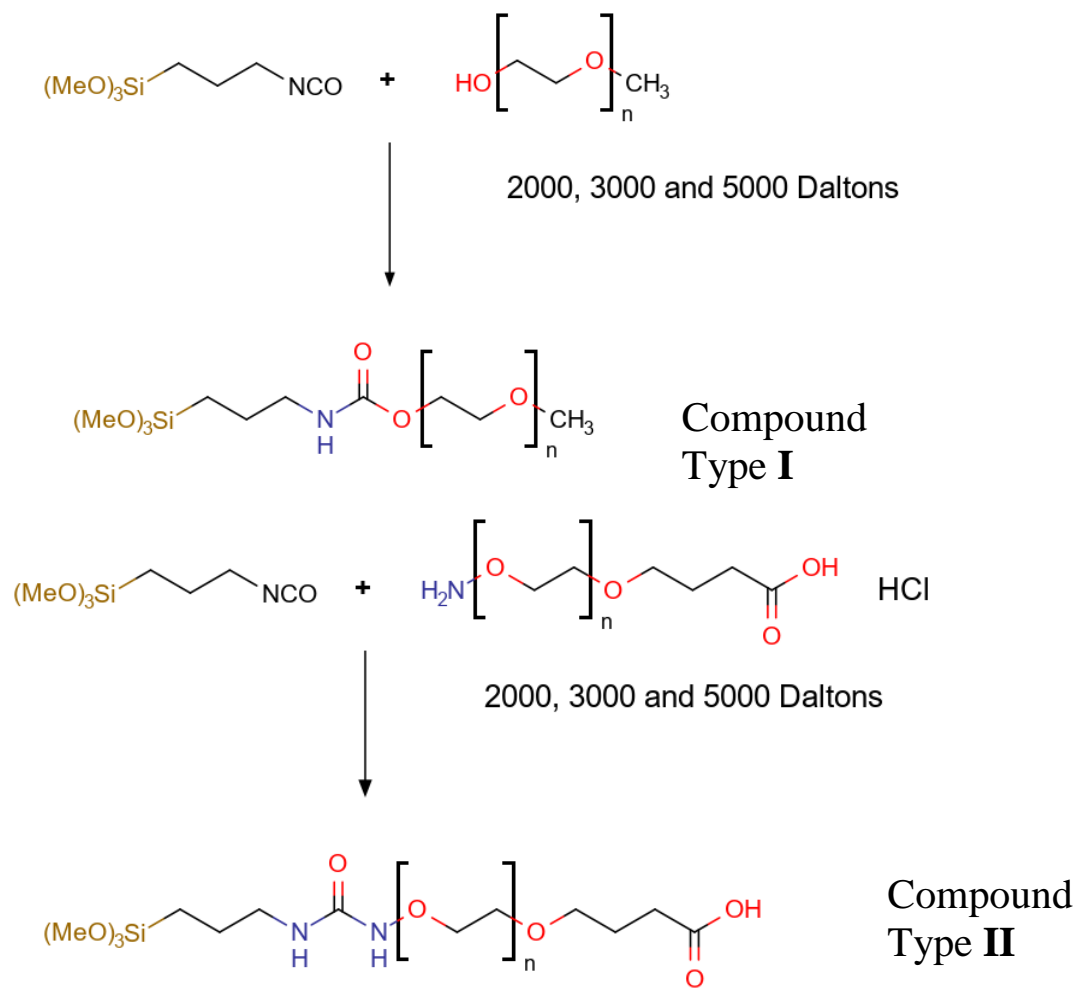

Scheme S6. Reaction to enable a controlled ratio of non-reacting PEG and to hetero-labelled PEG-amine.

Reaction A: A Schlenk was pre-silylated using dimethyldichloride silane in vacuo using a desiccator for 2 hours and was then moved to an oven for $2 \mathrm{~h}$ at $200^{\circ} \mathrm{C} .10 \mathrm{~mL}$ anhydrous dioxane was added under a flow of nitrogen to which, $150 \mathrm{mg}$ (0.73067 mmols) of Trimethoxy(3-isocyanotopropyl)silane and $1.607 \mathrm{~g}$ (ca $0.8 \mathrm{mmols})$ of PEG methyl ether $(2,000 \mathrm{~g} / \mathrm{mol})$ were added, with the reaction mixture stirred for $24 \mathrm{~h}$ at room temperature, and dried in vacuo yielding $1.7221 \mathrm{~g}, 96 \%$ (Scheme S6). The reactants and the product were analysed by FT-IR (Figure S32), TGA and GPC. TGA of the compound 1 possessed a first derivative at $251.94{ }^{\circ} \mathrm{C}$, and plateaued at ca. $600{ }^{\circ} \mathrm{C}$, with $7.4 \%$ remaining at $900{ }^{\circ} \mathrm{C}$. PEG methyl ether $(2,000 \mathrm{~g} / \mathrm{mol})$ contained two $M_{\mathrm{n}}(\mathrm{GPC})$ of $=2423$ and 667 , with the $M_{\mathrm{n}}$ (theoretical) $=2014$ (see 4.6 GPC section, Figure S47). GPC showed that compound 1 has three $M_{\mathrm{n}}$ of 5073,2374 and 674, $M_{n}$ (theoretical) $=2234$ (see 4.6 GPC section, Figure S48). The major peak of the $M_{n}(\mathrm{GPC}$ ) for PEG methyl ether $(2,000 \mathrm{~g} / \mathrm{mol})$ was slightly smaller than that of compound $\mathbf{1}$, which is expected suggesting that the reaction took place. The disappearance of the isocyanate peak in the FT-IR spectrum at $2265 \mathrm{~cm}^{-1}$ and the presence of $1663 \mathrm{~cm}^{-1}$ and $1556 \mathrm{~cm}^{-1}$, which indicate $\mathrm{O}-\mathrm{C}$ and $\mathrm{C}=\mathrm{O}$ respectively and would likewise suggest that the reaction happened. Preliminary experiments have been carried out using NMR on compound 1 . Without suppression, the $\mathrm{CH}_{2}$ groups of the polyethylene glycol chain it was not possible to observe the other peaks within this polymer (see 4.4 NMR section Figure S43). With suppression, however in the region of $\mathrm{CH}_{2}$ groups of the polyethylene glycol chain, it was possible to presence of shifts at $\delta=0.49\left(\mathrm{SiCH}_{2} \mathrm{CH}_{2} \mathrm{CH}_{2}, 2 \mathrm{H}, \mathrm{m}\right), 1.47$ $\left(\mathrm{SiCH} \mathrm{CH}_{2} \mathrm{CH}_{2}, 2 \mathrm{H}, \mathrm{m}\right)$ (see NMR section Figure S44). 


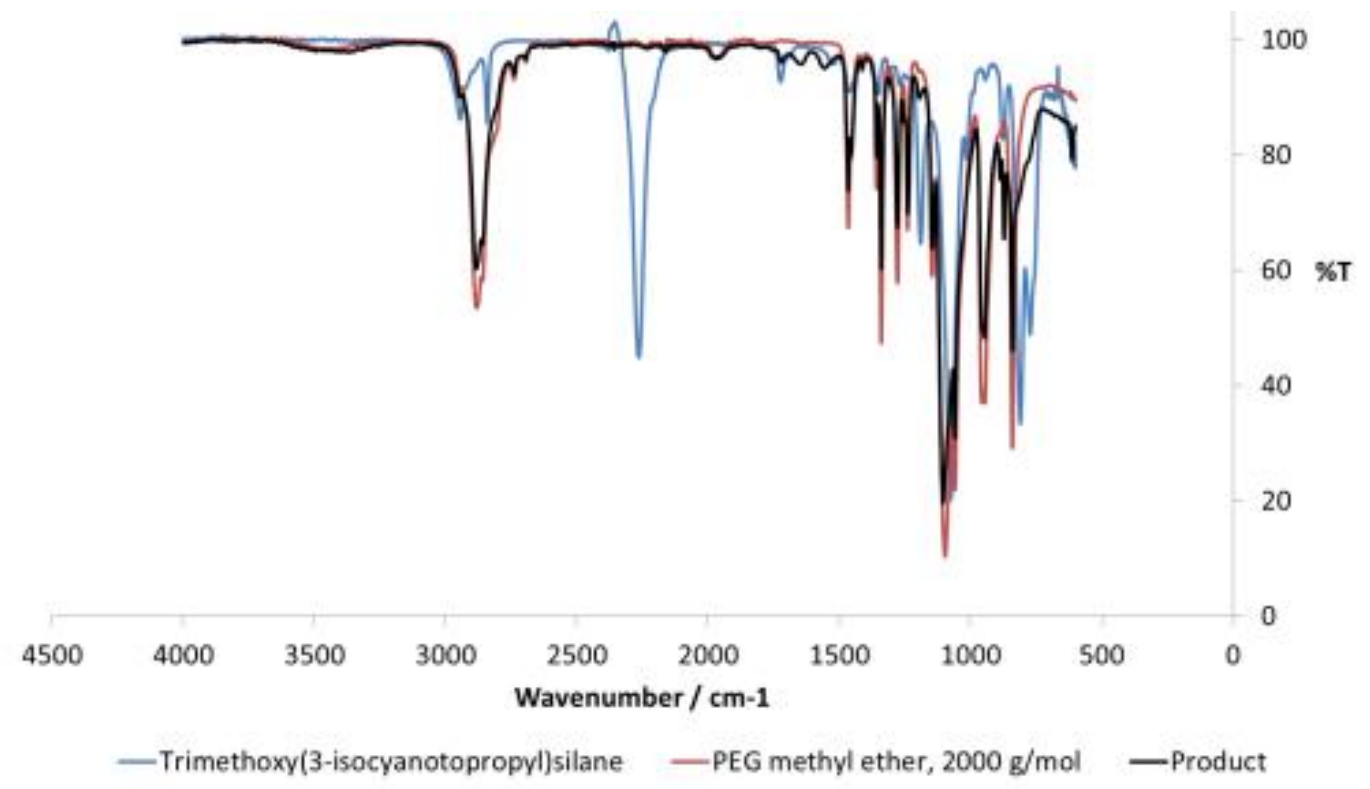

Figure S32. FTIR spectra of the product of the reaction (IR(neat): 2946, 2884, 2860, 2741, 2695, 1721, 1647, 1556, 1467, $1455,1413,1360,1340,1279,1254,1240,1195,1146,1106,1060,947,889,873,842,614 \mathrm{~cm}^{-1}$ ) compared to the starting materials Trimethoxy(3-isocyanotopropyl)silane IR (neat): 2945, 2843, 2265, 1725, 1693, 1525, 1462, 1414, 1350, 1310, 1270, 1191, 1153, 1077, 1016, 990, 947, 879, 811, $774 \mathrm{~cm}^{-1}$ and PEG methyl ether (2,000 g/mol) (IR(neat): 2946, 2883, 2861, 2741, 2695, 1970, 1467, 1455, 1413, 1360, 1341, 1279, 1241, 1196, 1147, 1098, 1060, 957, 947, 841, $\left.623,615 \mathrm{~cm}^{-1}\right)$.

Reaction B: The same protocol was followed for the synthesis of compounds Type II using the $3 \mathrm{kDa}$ and $5 \mathrm{kDa}$ PEGs. A Schlenk was pre-silylated using dimethyldichloride silane in vacuo using a desiccator for 2 hours and was then moved to an oven for $2 \mathrm{~h}$ at $200^{\circ} \mathrm{C} .20 \mathrm{~mL}$ anhydrous dioxane was added under a flow of nitrogen to which, $15 \mathrm{mg}$ ( $0.073 \mathrm{mmols})$ of Trimethoxy(3-isocyanotopropyl)silane and $240.7 \mathrm{mg}$ (ca. $0.08 \mathrm{mmols}$ ) ( $\mathrm{NH}_{2}-\mathrm{PEG}$ $\mathrm{COOH}) \mathrm{HCl}(3,000 \mathrm{~g} / \mathrm{mol})$ and 3 equivalents of trietheylamine $(22.6 \mathrm{mg})$ were added, with the reaction mixture stirred for $24 \mathrm{~h}$ at room temperature. The reactants and the product (yielding $231 \mathrm{mg}$ ) were analysed by FT-IR (Figure S33), GPC and TGA. The TGA of compound $2(3 \mathrm{kDa})$ possessed first derivatives at $340{ }^{\circ} \mathrm{C}, 371.86{ }^{\circ} \mathrm{C}$, $390.5{ }^{\circ} \mathrm{C}$ and plateaued at $600^{\circ} \mathrm{C}$, with $10.5 \%$ remaining at $900{ }^{\circ} \mathrm{C}$ (see 4.3 TGA analyses section, Table S4). This was significantly different from the starting materials, trimethoxy(3-isocyanotopropyl)silane (first derivative $157.26{ }^{\circ} \mathrm{C}$, plateau $400{ }^{\circ} \mathrm{C}, 1.6 \%$ remaining at $900 \stackrel{\circ}{\circ}$ ) and $\mathrm{NH}_{2}-\mathrm{PEG}-\mathrm{COOH}, 3 \mathrm{kDa}$ (first derivative $251.94{ }^{\circ} \mathrm{C}$, plateau $600{ }^{\circ} \mathrm{C}, 9.2 \%$ remaining at $900{ }^{\circ} \mathrm{C}$ ) (see TGA analyses section, Table S4).

Starting reagent, $\mathrm{NH}_{2}-\mathrm{PEG}-\mathrm{COOH}, 3 \mathrm{kDa}$ possessed two peaks, with a $M_{\mathrm{n}}(\mathrm{GPC})=3234$, which compares well to the $M_{n}$ (theoretical) $=3000$, and a second at 660 (see 4.6 GPC section, Figure S49). Compound $2(3 \mathrm{kDa})$ possessed a single $M_{\mathrm{n}}(\mathrm{GPC})=3180$, with a $M_{\mathrm{n}}$ (theoretical) $=3325$ (see $4.6 \mathrm{GPC}$ section,, Figure S50). Likewise $\mathrm{NH}_{2}$-PEG-COOH, $5 \mathrm{kDa}$ contained two peaks, with the major at $M_{\mathrm{n}}(\mathrm{GPC})=4148$ and 671 and the $M_{\mathrm{n}}$ (theoretical) $=5006$ (see 4.6 GPC section, Figure S51). Compound 2 (5 kDa) possessed two $M_{n}(\mathrm{GPC})$ of 4302, 685, with a $M_{\mathrm{n}}$ (theoretical) $=5331$ (see GPC section, Figure S52). Two peaks in the starting material may indicate that decomposition is occurring, despite storage at $-20^{\circ} \mathrm{C}$. 


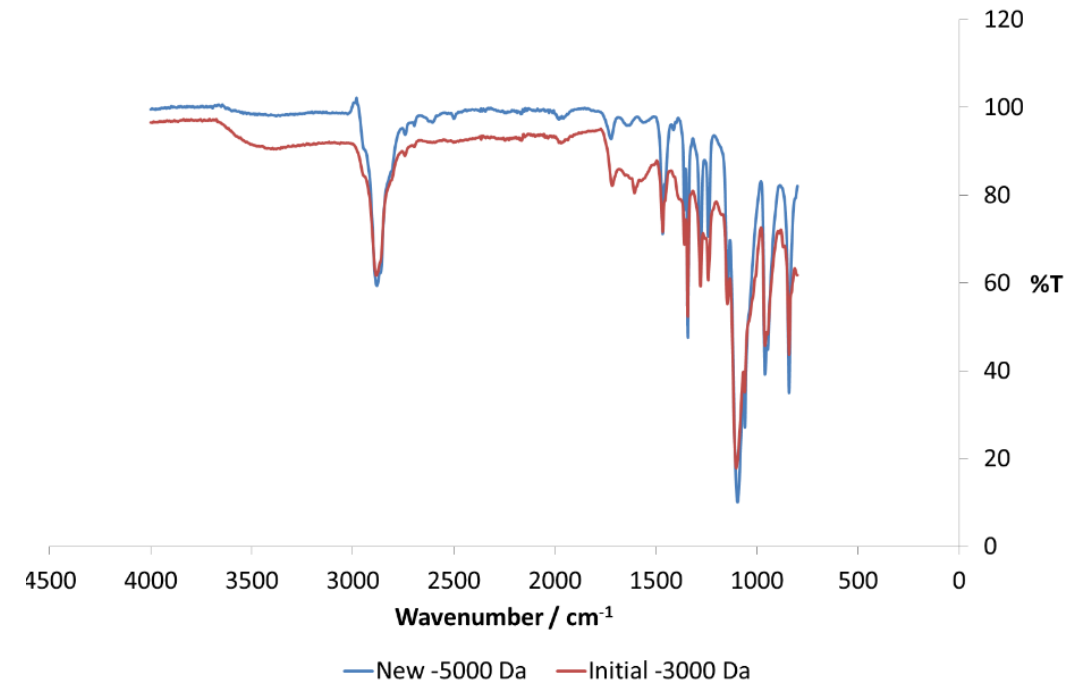

Figure S33. FT-IR spectra of trimethoxy(3-isocyanotopropyl)silane and product of reaction B: Compound 2 (3 kDa) IR(neat): 3426, 2884, 2743, 2696, 1717, 1653, 1606, 1575, 1467, 1360, 1342, 1280, 1241, 1147, 1103, 1061, 961, 870, 841, 801, 771, $746,731,696 \mathrm{~cm}^{-1}$. Compound 2 (5 kDa) IR(neat): 2944, 2881, 2863, 2741, 2696, 2606, 2500, 1980, 1722, 1640, 1559, 1467, $1456,1360,1342,1279,1241,1146,1096,1060,961,947,841 \mathrm{~cm}^{-1}$.

Reaction C: A Schlenk was pre-silylated using dimethyldichloride silane in vacuo using a desiccator for 2 hours and was then moved to an oven for $2 \mathrm{~h}$ at $200^{\circ} \mathrm{C} .10 \mathrm{~mL}$ dry, THF and $10 \mu \mathrm{L}$ aqueous ammonia (34\%) was added followed by $99.6 \mathrm{mg} \mathrm{Eu}: \mathrm{YVO}_{4}$ nanophosphor under a flow of nitrogen and stirred for $1 \mathrm{~h} .850 .9 \mathrm{mg}$ of compound 1 and $150.5 \mathrm{mg}$ of compound $2(3 \mathrm{kDa})$ were added under a flow of nitrogen and the reaction mixture was stirred overnight at room temperature. Subsequently this it was centrifuged at $3000 \mathrm{rpm}$ for 5 minutes and washed $3 \mathrm{x}$ with dry THF. The solid and supernatant were dialysed yielding $31.8 \mathrm{mg}$ and 647.9 respectively and analysed by FT-IR (Figure S34) and TGA. Both solid and supernatant from this reaction were analysed by TGA. The solid displayed first derivatives at $230.81^{\circ} \mathrm{C}$ and spike at $352.97^{\circ} \mathrm{C}$, whereas the supernatant possessed first derivatives at 247.3 ${ }^{\circ} \mathrm{C}$ and $364.56{ }^{\circ} \mathrm{C}$. TGA investigations on the solid showed a plateau at ca. $450{ }^{\circ} \mathrm{C}$ (see TGA analyses section, in Table S4).

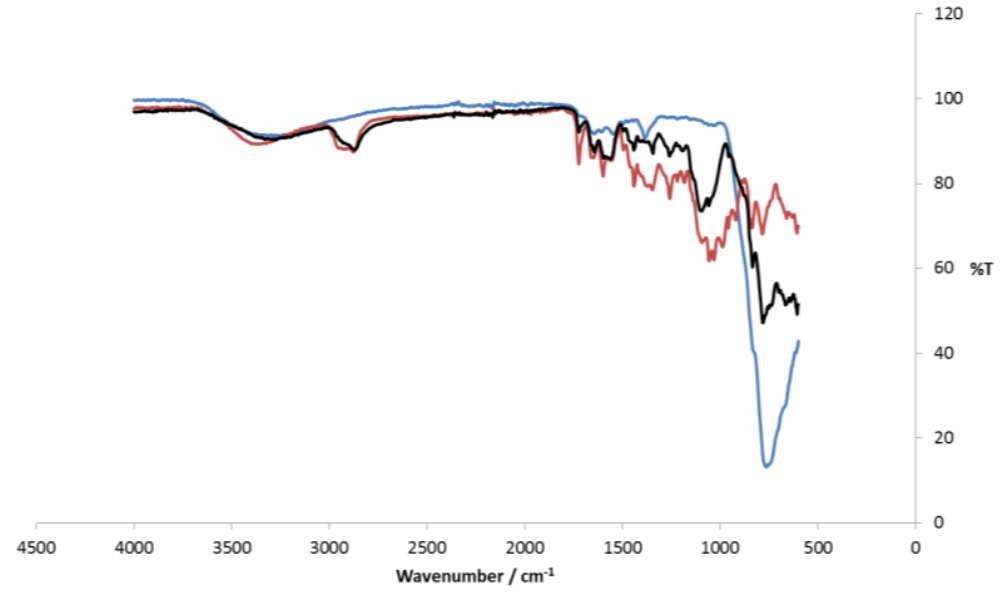

-NPs - Supernatant - - solid

Figure S34. IR spectra of uncoated nanoparticles (IR(neat): $\left.3289,1724,1643,1608,1551,1385,763,675 \mathrm{~cm}^{-1}\right)$ and the supernatant (IR(neat): 3375, 2951, 2927, 2877, 1724, 1648, 1599, 1560, 1496, 1442, 1403, 1347, 1258, 1220, 1184, 1094, 1058, 1032, 988, 958, 920, 881, 836, 784, 753, 701, 661, 633, $607 \mathrm{~cm}^{-1}$ ) and of the solid (IR(neat): 3278, 2871, 1724, 1643, $\left.1563,1442,1344,1260,1191,1097,1059,957,834,782,752,737,700,667,639,607 \mathrm{~cm}^{-1}\right)$

\section{$\underline{\text { Thermogravimetric analysis }}$}

Thermogravimetric analysis is a technique whereby the mass of a sample is measured according to an increase in temperature. This approach was designed whereby a decrease in mass of coated nanophosphor can be correlated 
to the mass of the coated material. If the molecular weight of the coating material is known, the number of moles required to coat a given mass of nanoparticle can therefore be calculated.

The mass of the coating material can be calculated by:

$$
\%_{C}=100 \%-\left[\%_{R} \div 100\right]
$$

Where $\%_{c}$ is the estimated percentage mass of coating material and $\%_{R}$ is the remaining percentage mass of sample

Table S4. Table of TGA data including the first derivative peaks, point of plateau and the percentage mass remaining at $900{ }^{\circ} \mathrm{C}$

\begin{tabular}{|c|c|c|c|}
\hline Sample & First Derivative Peak(s) $/{ }^{\circ} \mathbf{C}$ & Point of Plateau & $\%$ at $900{ }^{\circ} \mathrm{C}$ \\
\hline Bulk powder particulate $\mathrm{Y}_{0.9} \mathrm{Eu}_{0.1} \mathrm{VO}_{4}$ & $\mathrm{~N} / \mathrm{A}$ & Not clear & 96.1 \\
\hline Trimethoxy(3-isocyanotopropyl)silane & 157.26 & $400{ }^{\circ} \mathrm{C}, 2.2 \%$ & 1.6 \\
\hline $\mathrm{NH}_{2}$-PEG-COOH (3 kDa) & $259.32,320.26$ & $550{ }^{\circ} \mathrm{C}, 7.8 \%$ & 9.2 \\
\hline Compound 5 (3 kDa) & 340 (s), 371.86, $390.5(\mathrm{~s})$ & $600{ }^{\circ} \mathrm{C}, 12 \%$ & 10.5 \\
\hline $\mathrm{NH}_{2}-\mathrm{PEG}-\mathrm{COOH}(5 \mathrm{kDa})$ & $247.74,313.54$ & $500^{\circ} \mathrm{C}, 6.80$ & 6.33 \\
\hline $\begin{array}{l}\text { Solid fraction of coated nanoparticle with } \\
\text { compound } 1 \text { ( } 3 \mathrm{kDa})\end{array}$ & 230.81 and spike at 352.97 & $450{ }^{\circ} \mathrm{C}, 73 \%$ & 71.0 \\
\hline $\begin{array}{c}\text { Supernatant fraction of coated } \\
\text { nanoparticle with compound } 1(3 \mathrm{kDa})\end{array}$ & $247.3,364.56$ & ca. $700^{\circ} \mathrm{C}, 9 \%$ & 8.0 \\
\hline $\mathrm{NH}_{2}-\mathrm{PEG}-\mathrm{COOH}(5 \mathrm{kDa})$ & $247.74,313.54$ & $500^{\circ} \mathrm{C}, 6.80$ & 6.33 \\
\hline
\end{tabular}

To calculate the number of moles of coating material required, coated nanoparticle with compound $\mathbf{1}(3 \mathrm{kDa})$. Using the equation above gives $26.12 \%$ and $91.68 \%$ for the solid and supernatant fractions of coated nanoparticle with compound $1(3 \mathrm{kDa})$ respectively.

The supernatant fraction was integrated using ACD labs software, whereby integration of the first derivatives indicates that the peak at $364.56{ }^{\circ} \mathrm{C}$ is $22 \%$ mass, representing $\mathrm{SiO}_{2}-\mathrm{PEG}-\mathrm{COOH}(\mathrm{Mr} \approx 3250 \mathrm{Da}$ ). Correspondingly the peak at $247.3{ }^{\circ} \mathrm{C}$ is $70 \%$ mass, representing $\mathrm{SiO}_{2}$-PEG-Me ether $(\mathrm{Mr} \approx 2250 \mathrm{Da})$. Considering that $91.68 \%$ corresponds to coating material these numbers can be more accurately calculated as $21.92 \%$ and $69.76 \%$ for $\mathrm{SiO}_{2-}$ PEG-COOH and $\mathrm{SiO}_{2}-\mathrm{PEG}-\mathrm{Me}$ ether respectively.

Therefore, for $100 \mathrm{mg}$ of NP (representing $8.32 \%$ of coated material), total mass required is $1201.25 \mathrm{mg}^{-\mathrm{SiO}_{2-}}$ PEG-COOH (21.92\%) would be $263.3 \mathrm{mg}, 0.0810 \mathrm{~m}$ moles and $\mathrm{SiO}_{2}$-PEG-Me ether $69.76 \%$ would be $838.0 \mathrm{mg}$, $0.372 \mathrm{~m}$ moles. The total number of moles required is thus $0.453 \mathrm{~m}$ moles siloxane per $100 \mathrm{mg}$ of NP. This therefore could be used for EDC coupling reactions and for using only the required number of moles of coating agent. Interestingly, the calculated molar ratio is 1:4.6, interestingly the ratio added was $1: 8.17$.

\section{Probing the stability of the luminescence with time in aqueous media}

The luminescence of coated and uncoated bulk powder particulate $\mathrm{Y}_{0.9} \mathrm{Eu}_{0.1} \mathrm{VO}_{4}$ nanophosphors, $0.1 \mathrm{mg} / \mathrm{mL}$ in Milli-Q water was tested using excitation at $290 \mathrm{~nm}$ (Figures S10, S35-S37). This was carried out in glass vials and in Eppendorfs tubes to assess the suitability of these coated materials under biological testing conditions, whereby 
plastic Eppendorf tubes were used as standard. These were also assessed at room temperature and at $4{ }^{\circ} \mathrm{C}$. Uncoated materials were investigated as a control at the same $\mathrm{w} / \mathrm{v}$ concentration (Figure S10 and S32). A luminescence emission was detectable up to 4 weeks under all conditions, with data gathered comparable at room temperature and at $4{ }^{\circ} \mathrm{C}$ as it was in glass vials and in plastic Eppendorf tubes. The luminescence of these samples was monitored over the two weeks.

a)

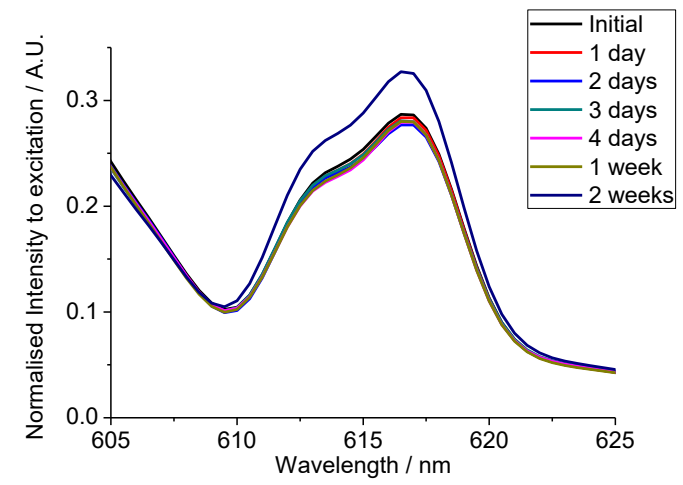

b)

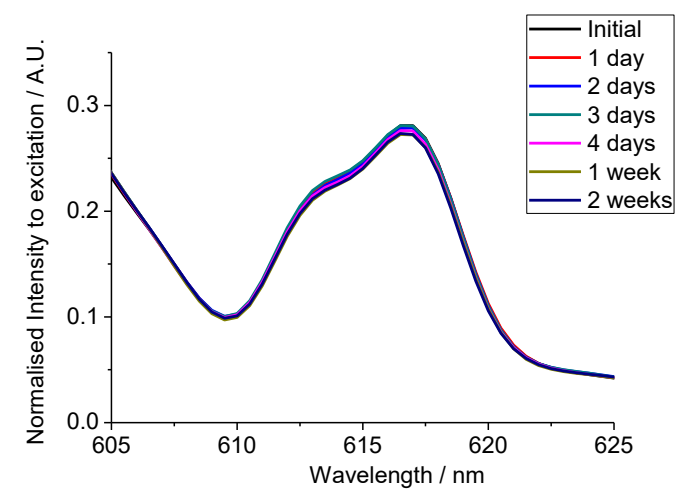

Figure S35. Luminescence spectra of uncoated bulk powder particulate $\mathrm{Y}_{0.9} \mathrm{Eu}_{0.1} \mathrm{VO}_{4}$ nanomaterials $\left(\lambda_{\mathrm{ex}}=290 \mathrm{~nm}\right)$ dispersed in Milli-Q water $0.1 \mathrm{mg} / \mathrm{mL}$ stored in an Eppendorf tube, protected from light a) at room temperature and b) at $4{ }^{\circ} \mathrm{C}$ up to 2 weeks.
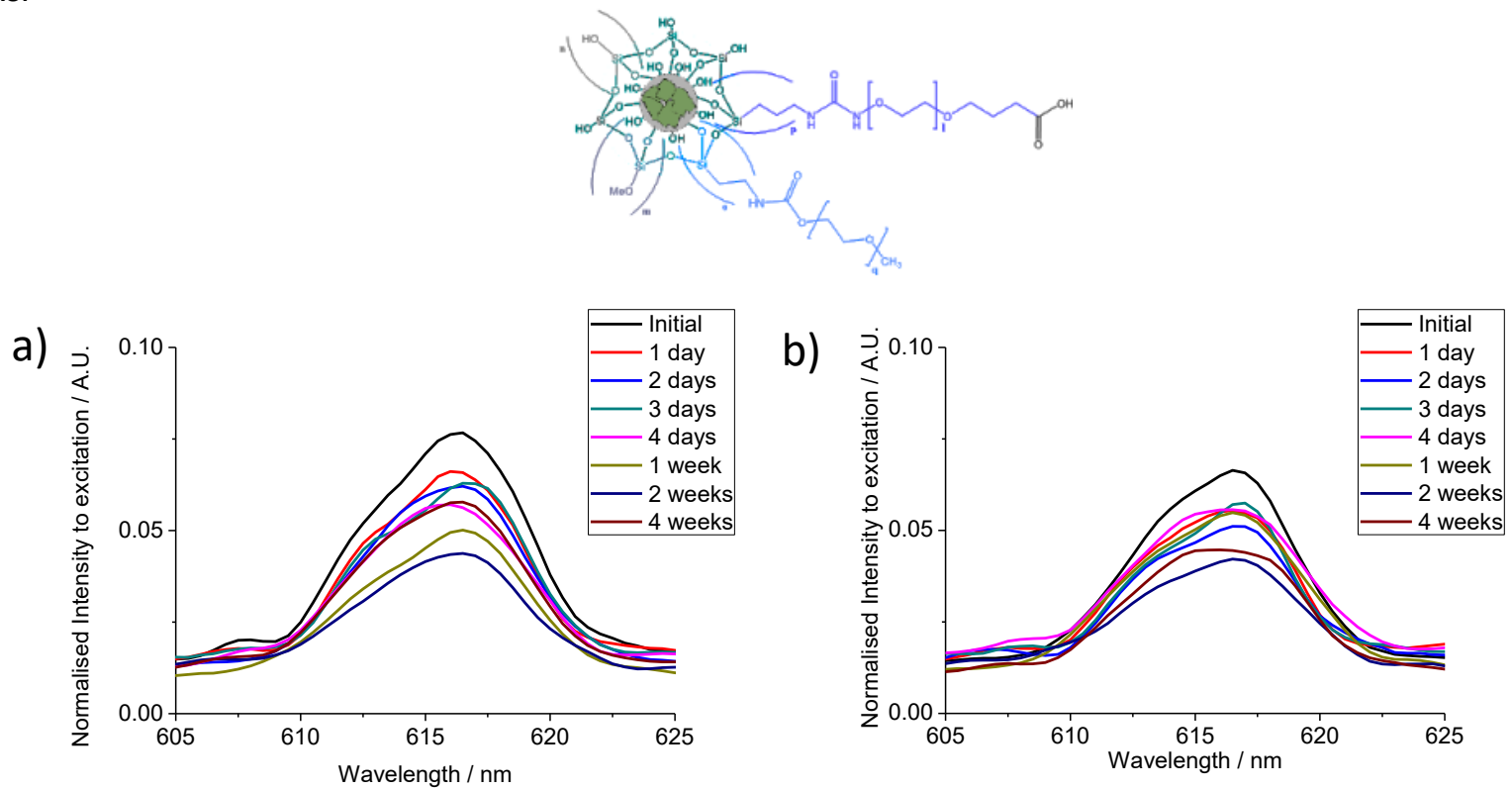

Figure S36. Luminescence spectra of PEG-coated bulk powder particulate $\mathrm{Y}_{0.9} \mathrm{Eu}_{0.1} \mathrm{VO}_{4}$ nanomaterials $\left(\lambda_{\mathrm{ex}}=290 \mathrm{~nm}\right)$ in Milli$\mathrm{Q}$ water $0.1 \mathrm{mg} / \mathrm{mL}$ stored in a glass vial, protected from light a) at room temperature and b) at $4{ }^{\circ} \mathrm{C}$ up to 4 weeks. In this typical example, $\mathrm{l}=60$ and $\mathrm{q}=40$.
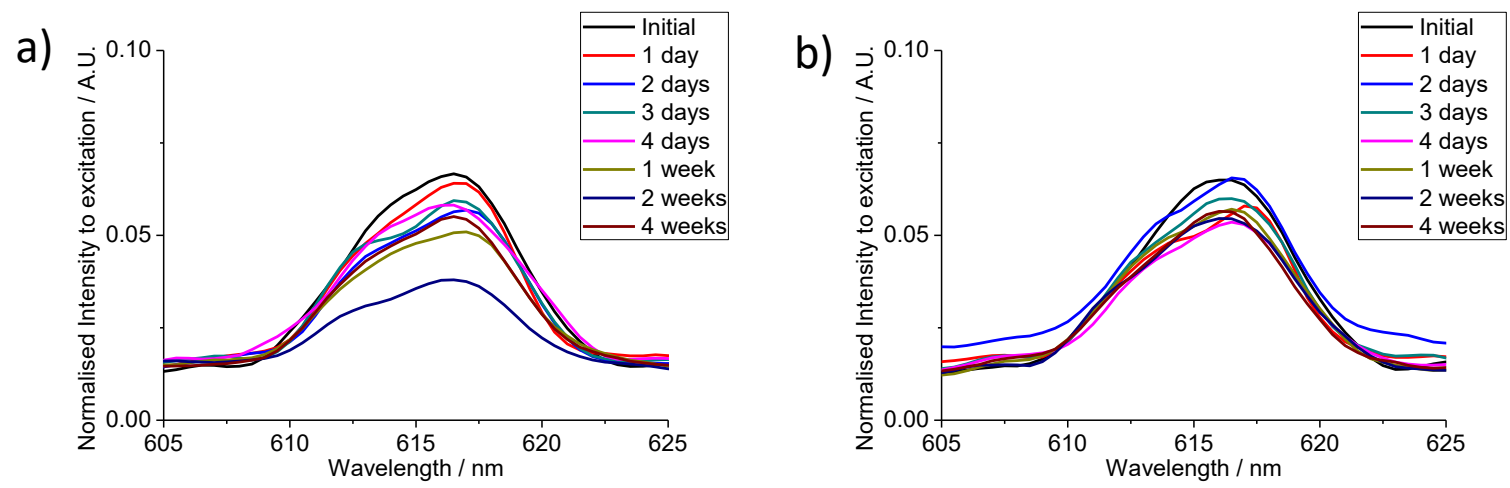

Figure S37. Luminescence spectra of PEG-coated bulk powder particulate $\mathrm{Y}_{0.9} \mathrm{Eu}_{0.1} \mathrm{VO}_{4}$ nanomaterials $\left(\lambda_{\mathrm{ex}}=290 \mathrm{~nm}\right)$ in Milli$\mathrm{Q}$ water $0.1 \mathrm{mg} / \mathrm{mL}$ stored in an Eppendorf tube, protected from light a) at room temperature and b) at $4{ }^{\circ} \mathrm{C}$ for 4 weeks. In this typical example, $\mathrm{l}=60$ and $\mathrm{q}=40$. 
a)

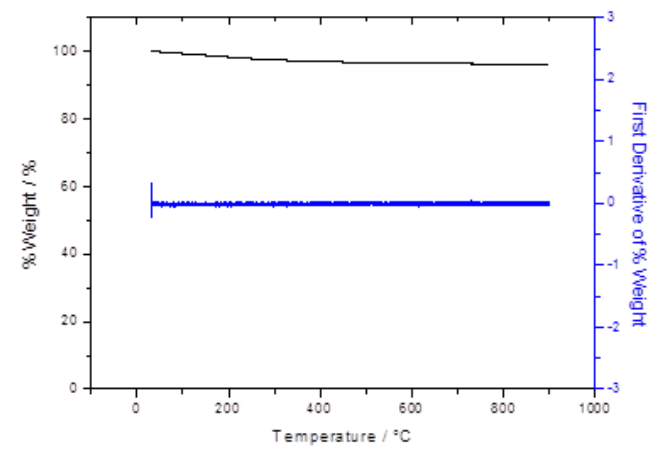

b)

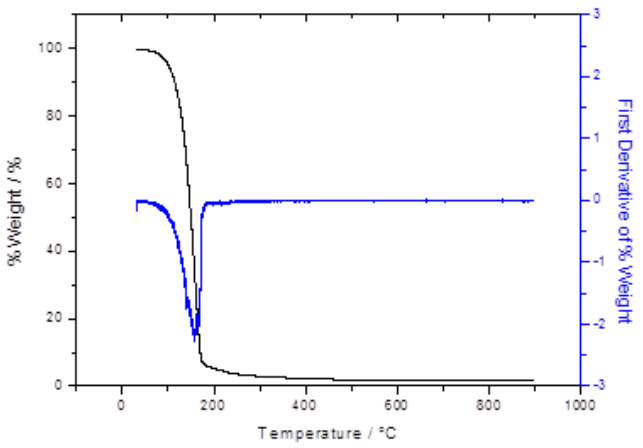

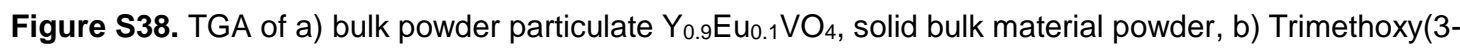
isocyanotopropyl)silane

a)

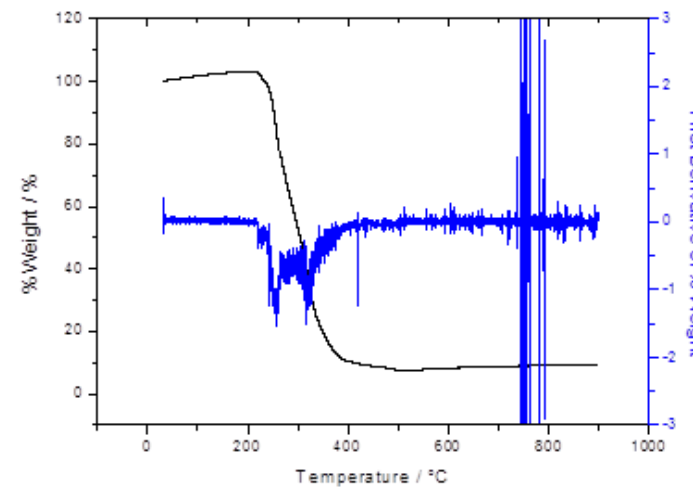

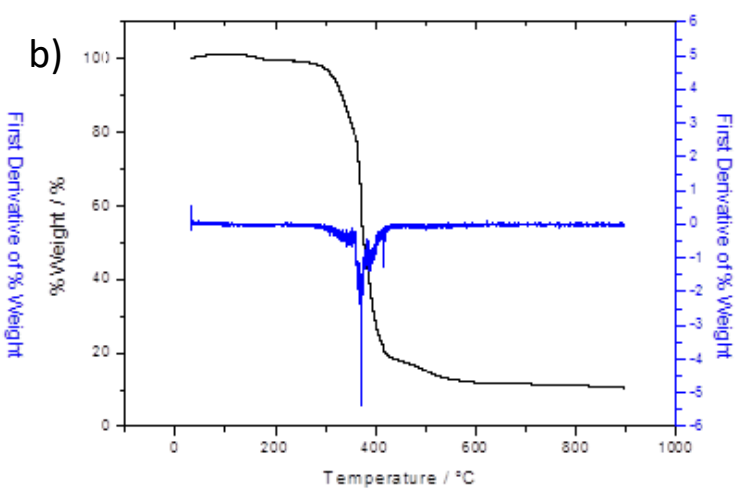

Figure S39. TGA of a) aminooxy $\mathrm{NH}_{2}-\mathrm{PEG}-\mathrm{COOH}(3 \mathrm{kDa})$, b) coated bulk powder particulate $\mathrm{Y}_{0.9} \mathrm{Eu}_{0.1} \mathrm{VO}_{4}$ nanophosphors with compound $2(3 \mathrm{kDa})$

a)

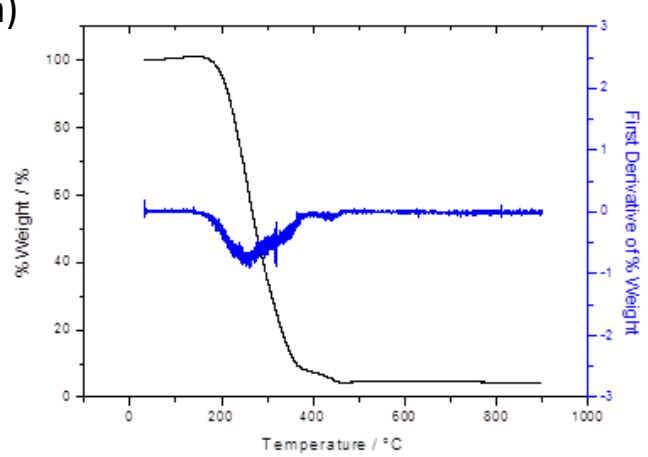

b)

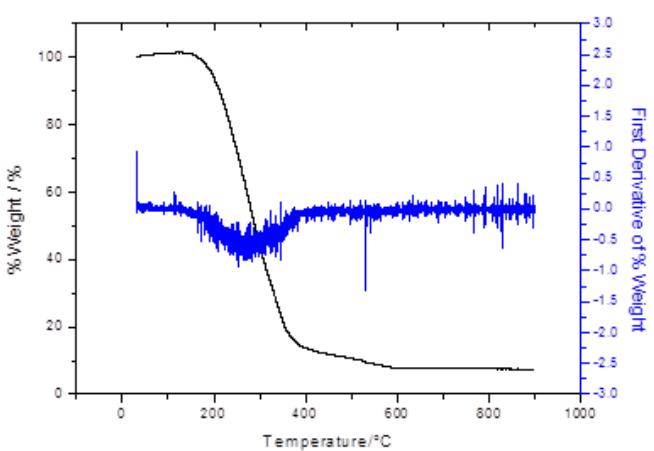

Figure S40. TGA of a) PEG-Me ether, b) Compound Type I 
a)

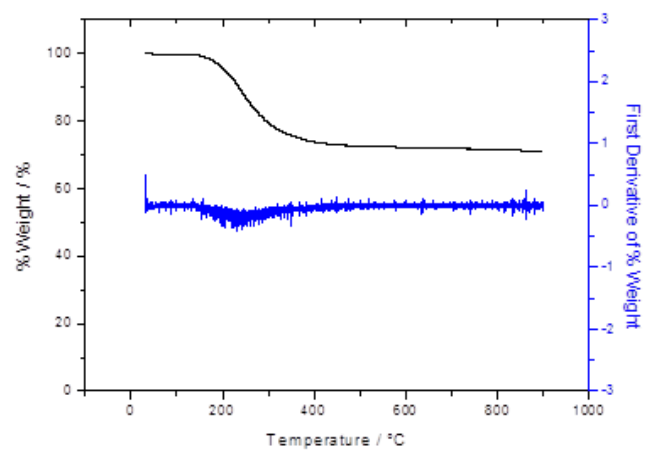

b)

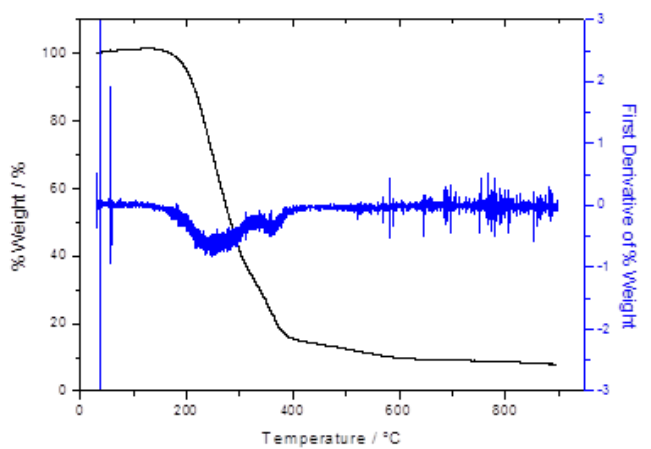

Figure S41. TGA of a) Solid fraction of coated bulk powder particulate $\mathrm{Y}_{0.9} \mathrm{Eu}_{0.1} \mathrm{VO}_{4}$ with compound Type I (3 kDa), b) Supernatant fraction of coated nanoparticle with compound I ( $3 \mathrm{kDa})$

a)

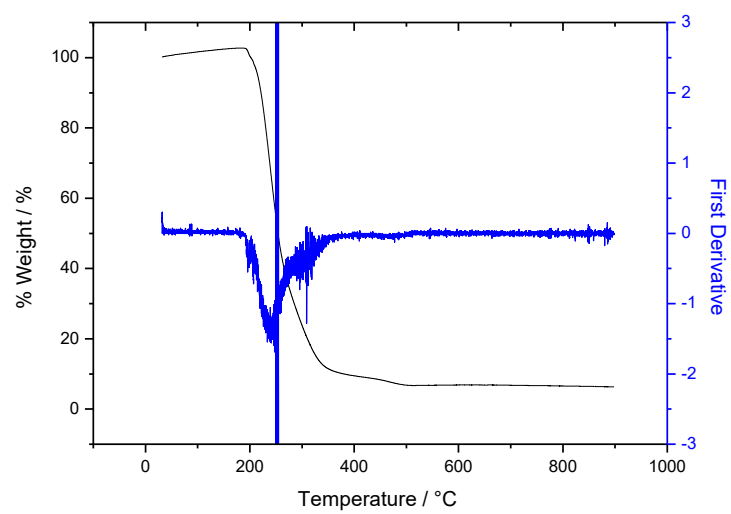

b)

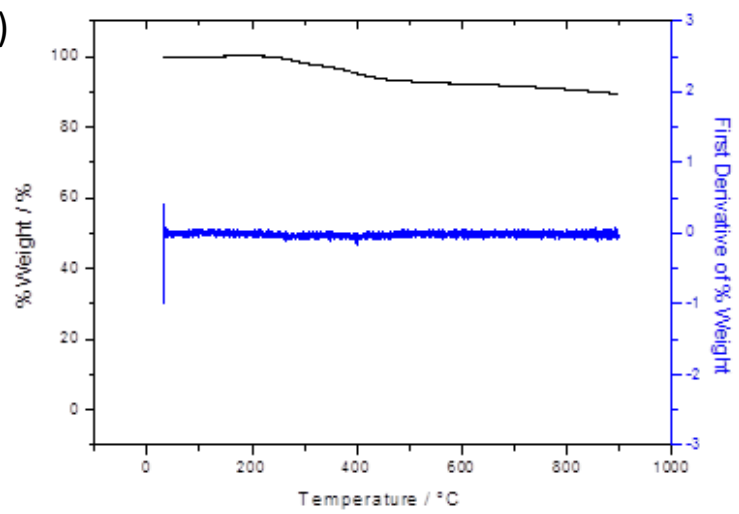

Figure S42. TGA of a) aminooxy $\mathrm{NH}_{2}-\mathrm{PEG}-\mathrm{COOH}(5 \mathrm{kDa})$, b) Coated bulk powder particulate $\mathrm{Y}_{0.9} \mathrm{Eu}_{0.1} \mathrm{VO}_{4}$

\section{NMR spectroscopy for model linkers studies}

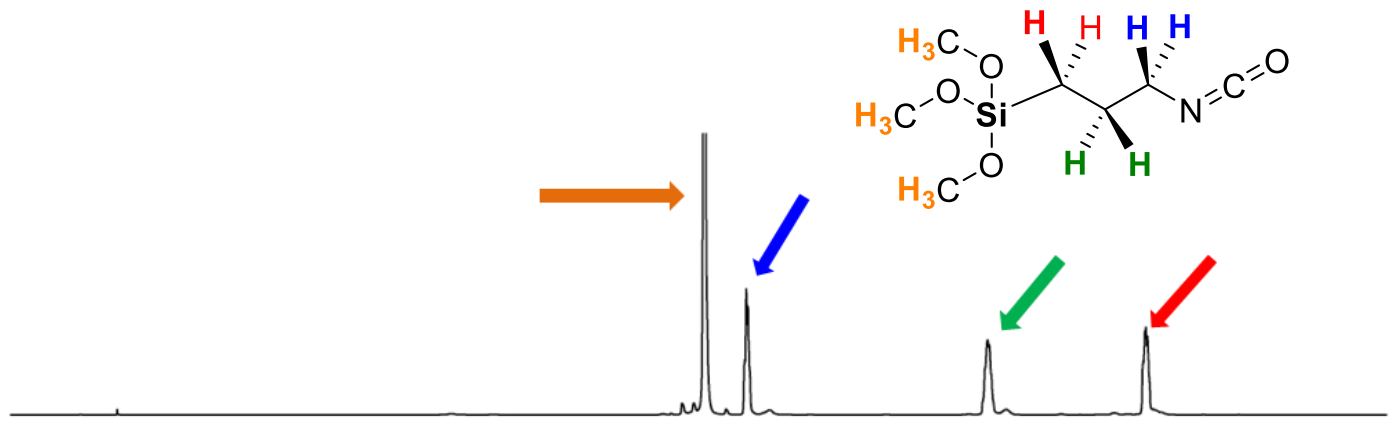

\begin{tabular}{llllllllll}
\hline & 7 & 6 & 5 & 4 & 3 & 2 & 1 & 0 & $\mathrm{ppm}$
\end{tabular}

Figure S43. ${ }^{1} \mathrm{H}$ NMR $500 \mathrm{MHz}$ spectrum of Trimethoxy(3-isocyanotopropyl)silane 

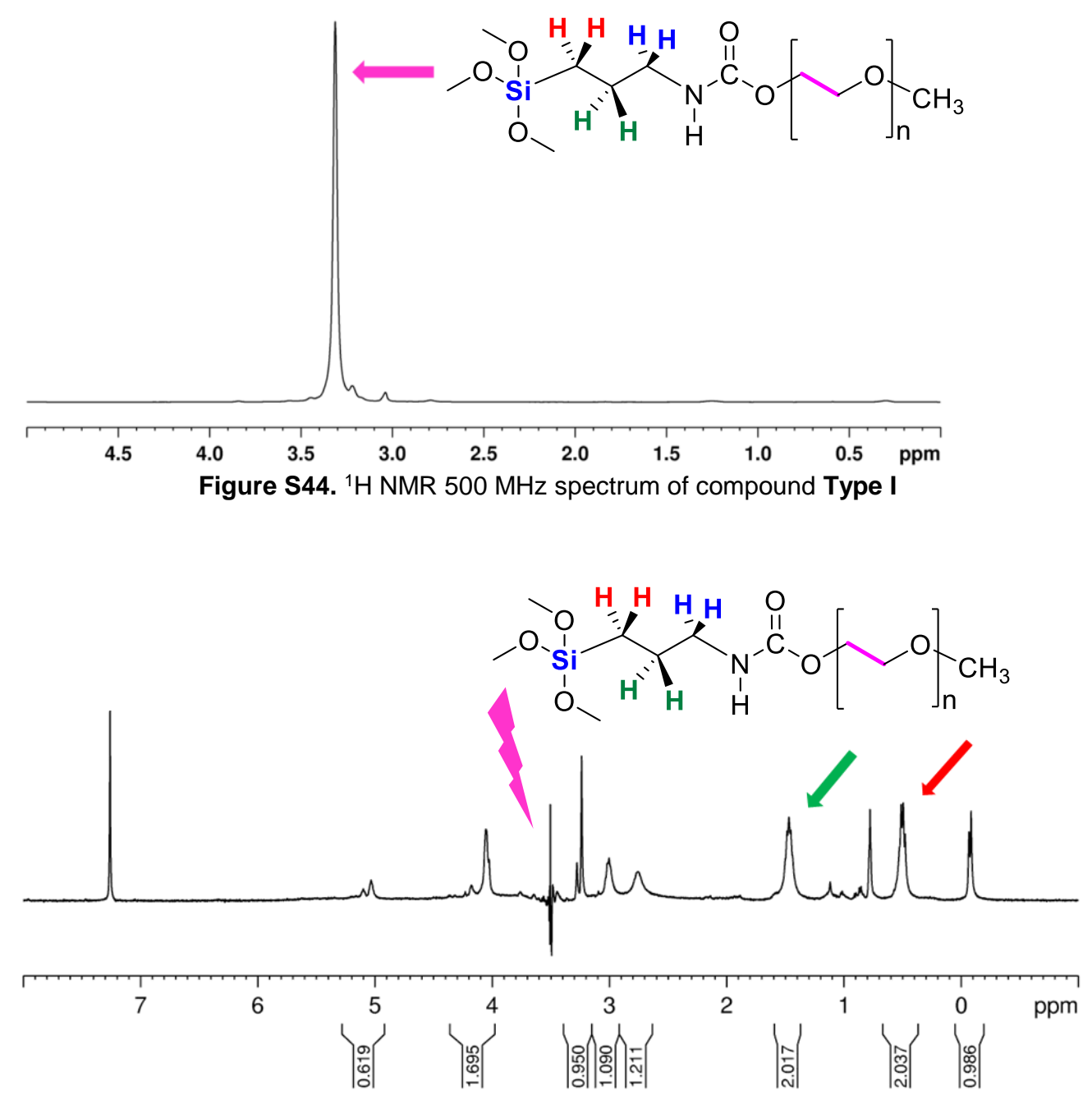

Figure S45. ${ }^{1} \mathrm{H}$ NMR $500 \mathrm{MHz}$ spectrum of compound Type I, with suppression in the region of $\mathrm{CH}_{2}$ groups of the polyethylene glycol chain, showing presence of shifts at $\delta=0.49\left(\mathrm{CH}_{2} \mathrm{CH}_{2} \mathrm{CH}_{2}, 2 \mathrm{H}, \mathrm{m}\right), 1.47\left(\mathrm{CH}_{2} \mathrm{CH}_{2} \mathrm{CH}_{2}, 2 \mathrm{H}\right.$, m), highlighted in red and green respectively.

\section{Raman Spectroscopy:}

a)

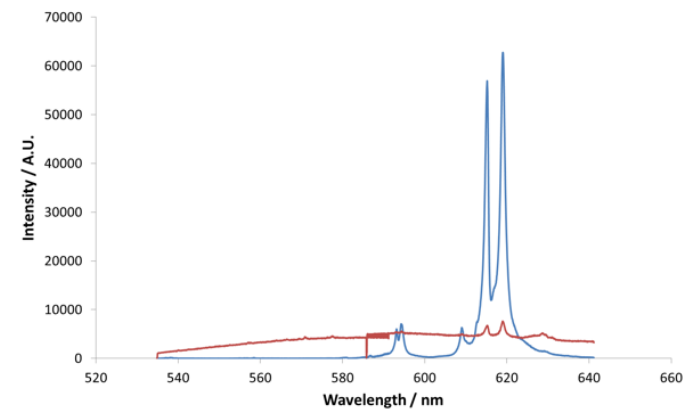

b)

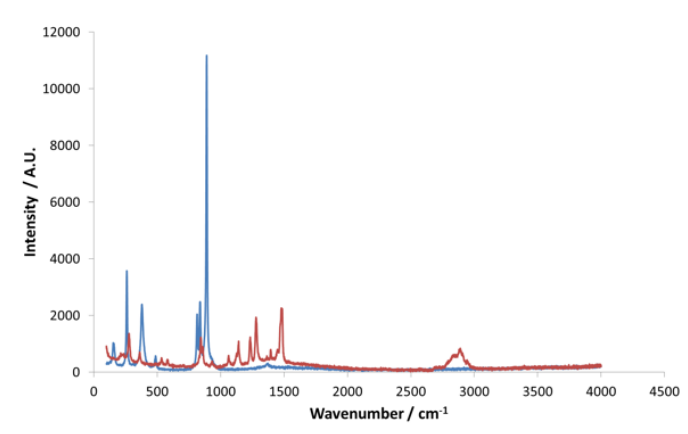

Figure S46. Raman investigations of functionalised NPs resulting from the method optimised by coating NPs via pre-reacting to silane and capping with Me-PEG ester, where the PEG used had Mw ca. $5000 \mathrm{~g} / \mathrm{mol}, \mathrm{l}=\mathrm{q}=100$. Blue line: coated NPs; red line $\mathrm{H}_{2} \mathrm{~N}-\mathrm{PEG}-\mathrm{COOH}$; a) green laser $532 \mathrm{~nm}$ and b) red laser, $785 \mathrm{~nm}$ 


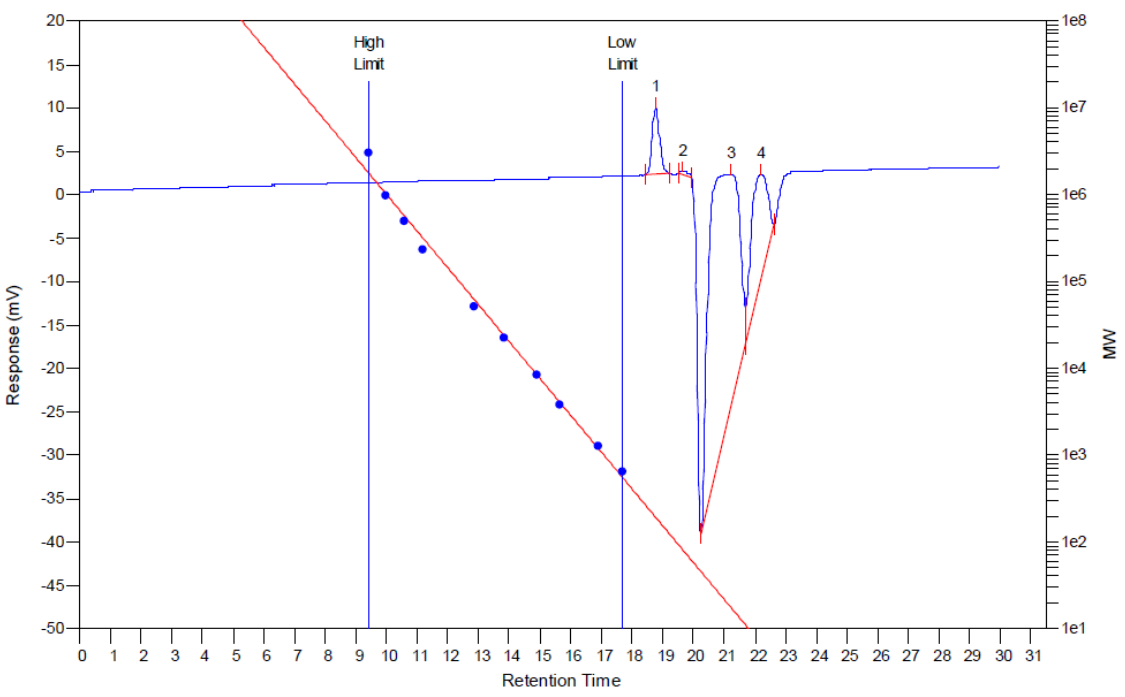

Figure S47. GPC of THF blank.
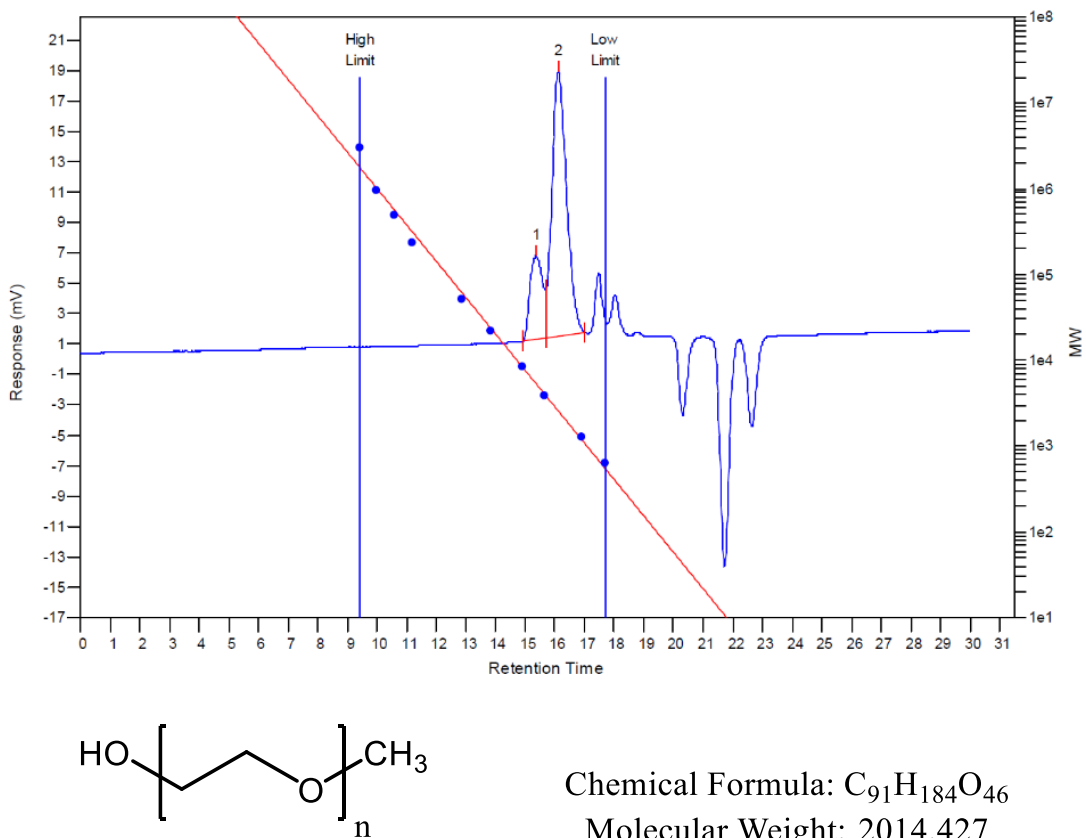

Chemical Formula: $\mathrm{C}_{91} \mathrm{H}_{184} \mathrm{O}_{46}$ Molecular Weight: 2014.427

2000 Daltons $n=45$

Figure S48. GPC of PEG methyl ether, $M_{n}($ GPC of 1$)=5208$ and $M_{n}($ GPC of 2$)=2366, M_{n}$ (theoretical) $=2014$. 

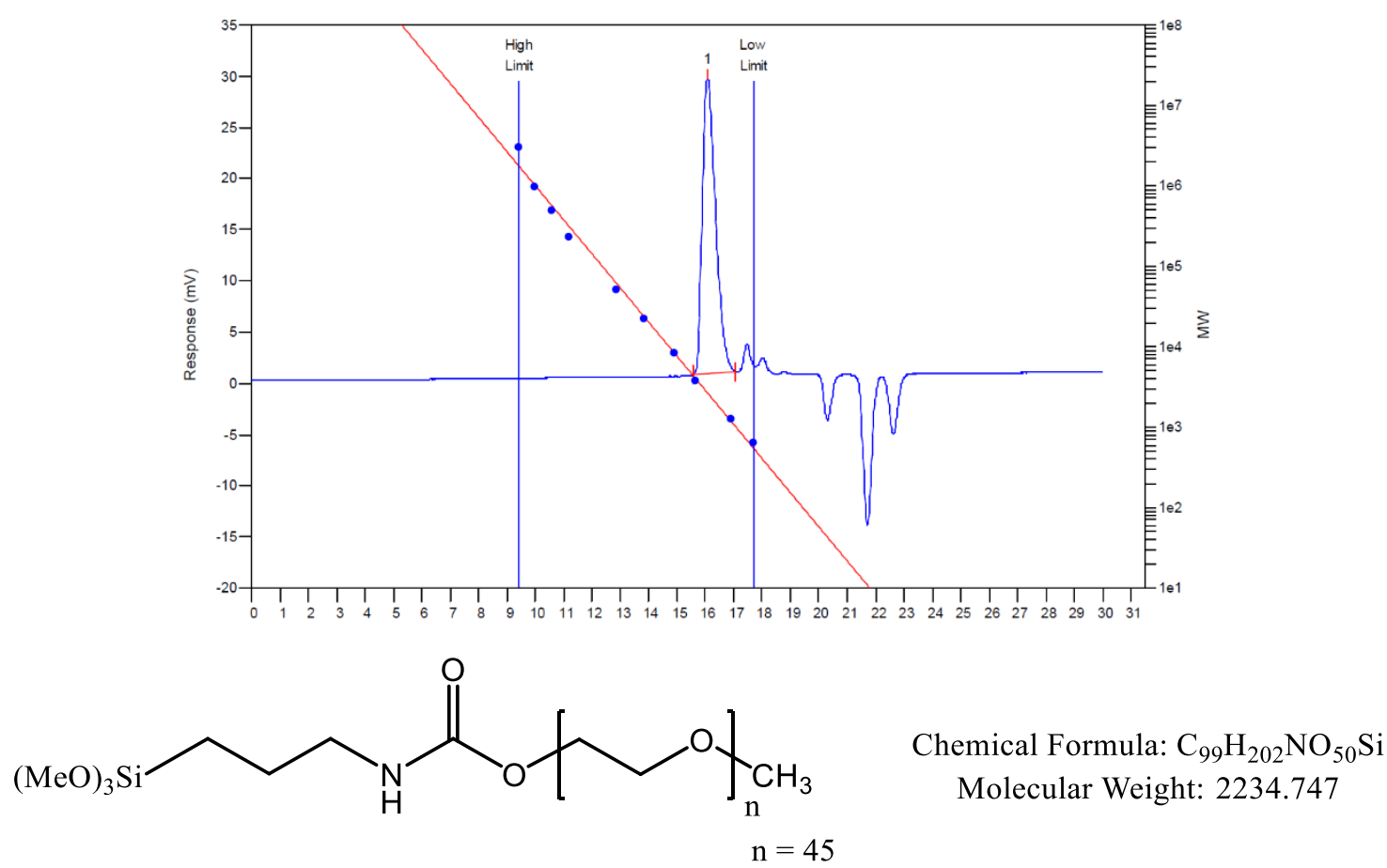

Figure S49. GPC of Compound Type I , $M_{\mathrm{n}}(\mathrm{GPC}$ of 1$)=2387, M_{\mathrm{n}}$ (theoretical) $=2235$.

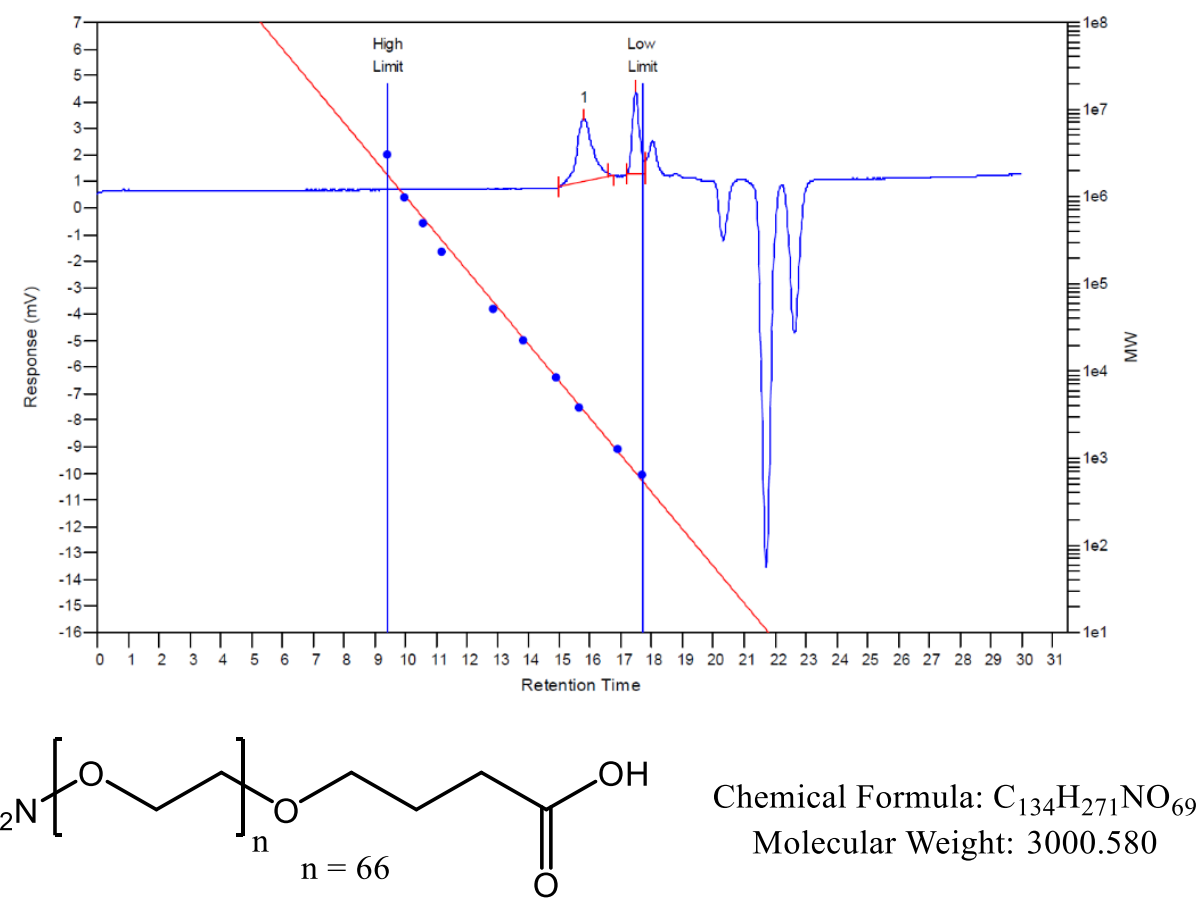

Figure S50. GPC of $\mathrm{NH}_{2}-\mathrm{PEG}-\mathrm{COOH}(3 \mathrm{kDa}) M_{N}(\mathrm{GPC}$ OF 1$)=3234$ and $M_{N}(\mathrm{GPC}$ OF 2$)=660, M_{N}($ THEORETICAL $)=3001$. 


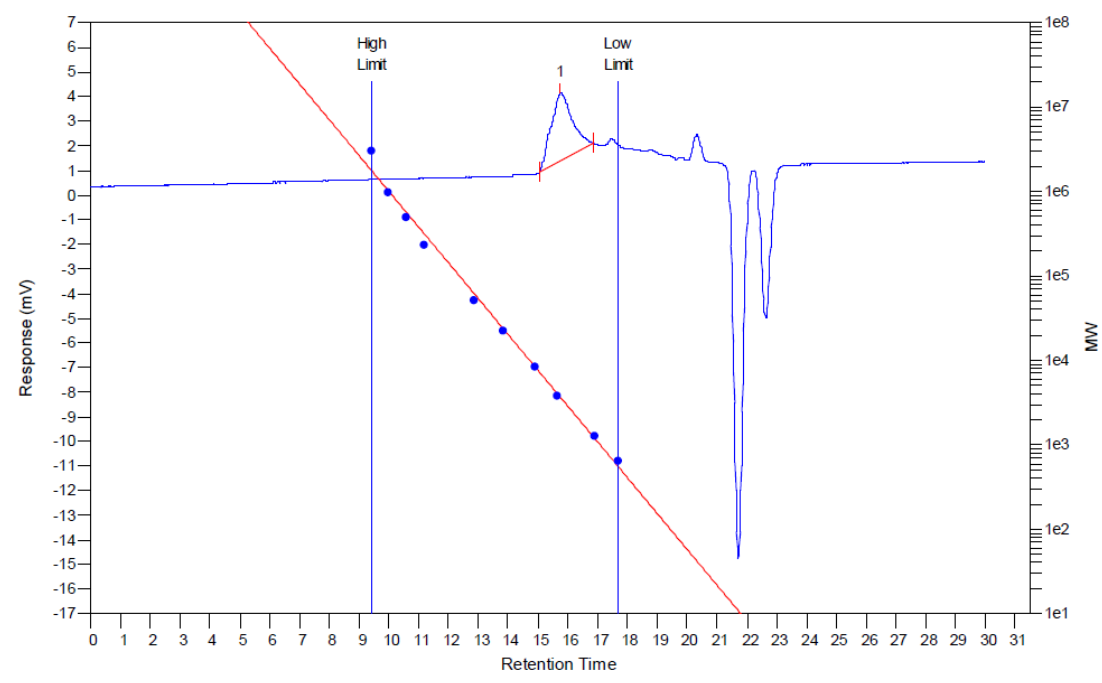

$\overbrace{\mathrm{MeO})_{3} \mathrm{Si}}^{\|} \overbrace{\mathrm{N}=66}^{\mathrm{O}}$

Figure S51. GPC of Compound Type II $(3 \mathrm{kDa}), M_{n}(\mathrm{GPC})=3180, M_{\mathrm{n}}$ (theoretical) $=3325$.
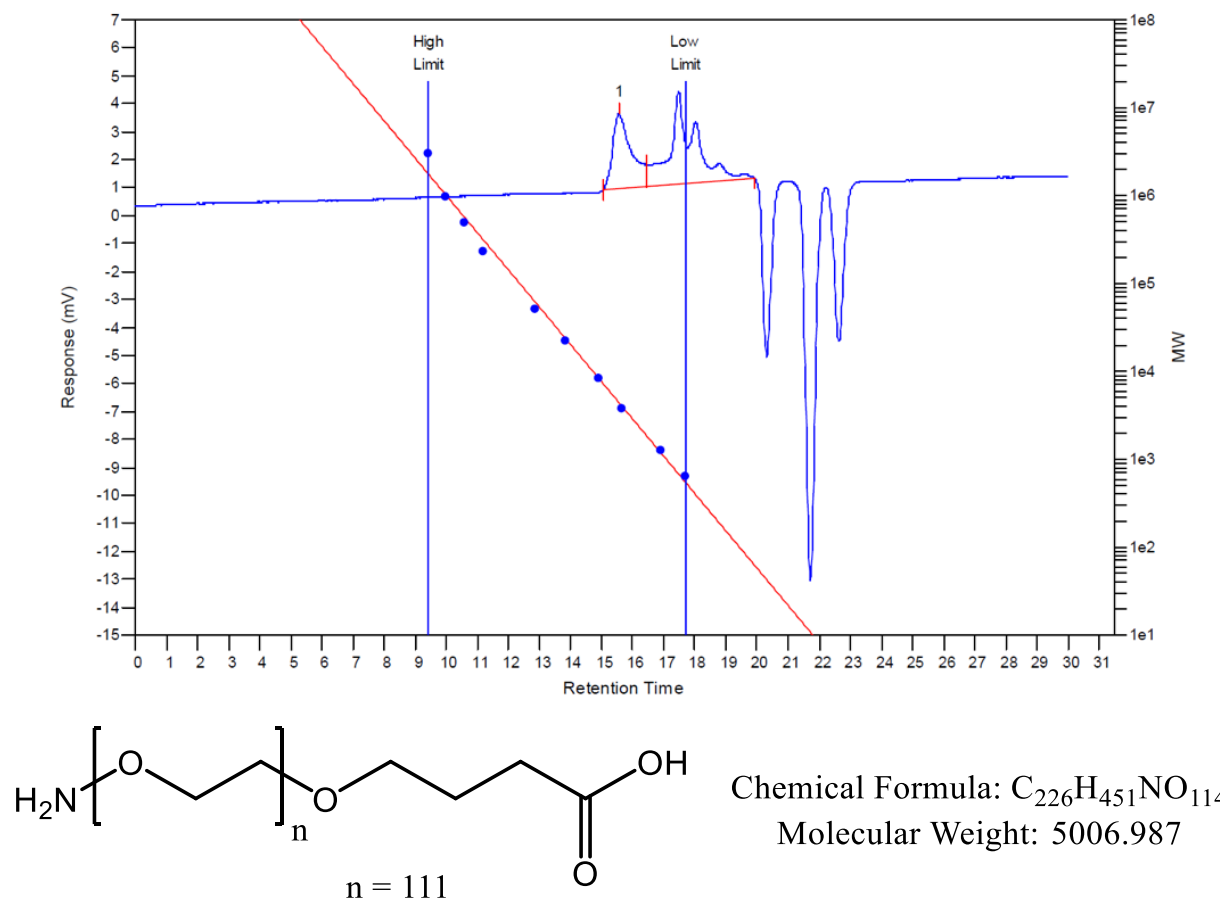

Figure S52. GPC of $\mathrm{NH}_{2}-\mathrm{PEG}-\mathrm{COOH}(5 \mathrm{kDa}) M_{N}(\mathrm{GPC}$ OF 1$)=3544, M_{n}$ (theoretical) $=5007$. 

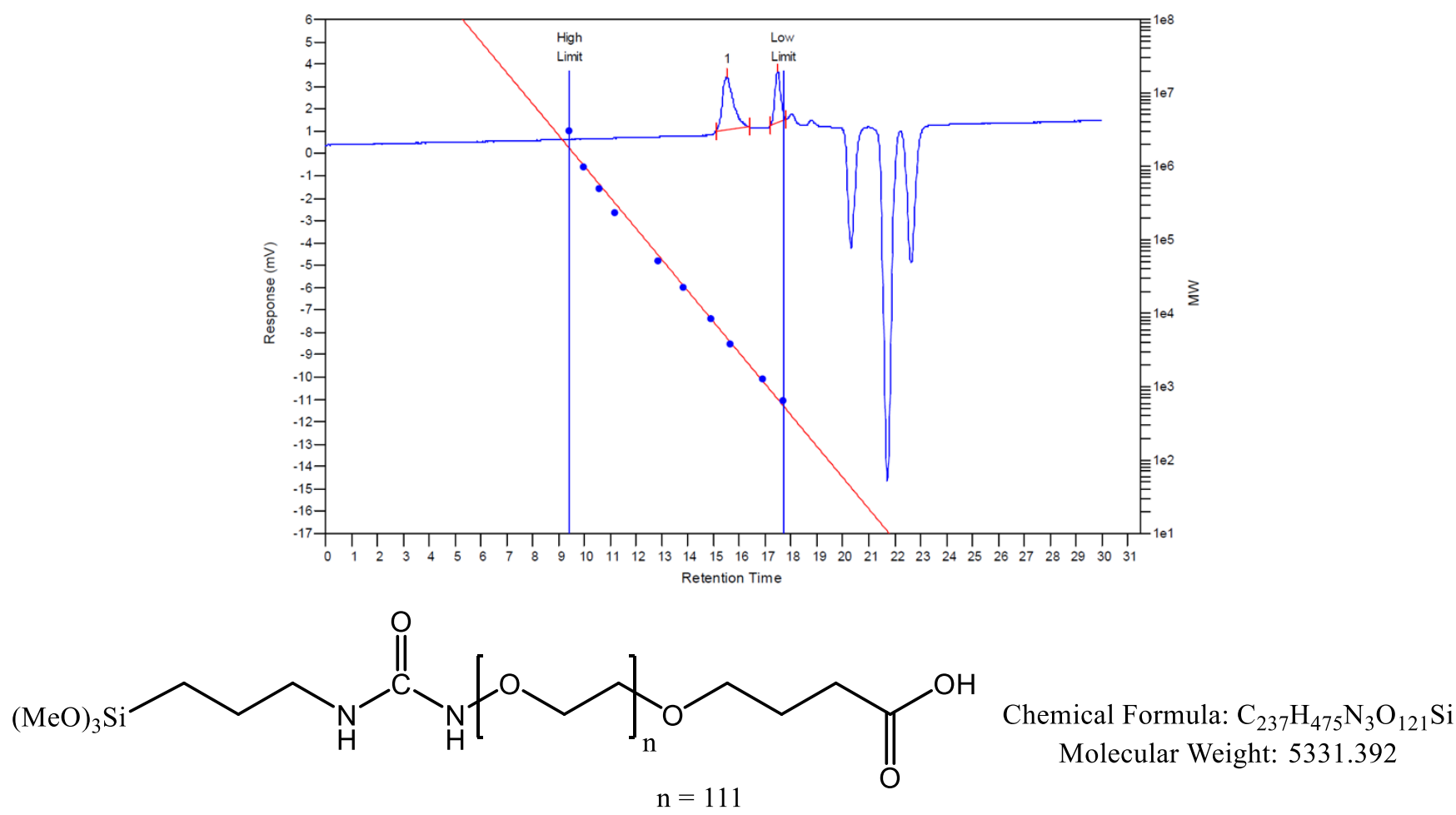

Figure S53. GPC of Compound Type II $(5 \mathrm{kDa}), M_{n}(\mathrm{GPC}$ of 1$)=4148$ and $M_{n}(\mathrm{GPC}$ of 2$)=671, M_{n}$ (theoretical $)=5331$.

\section{Mass Spectrometry}

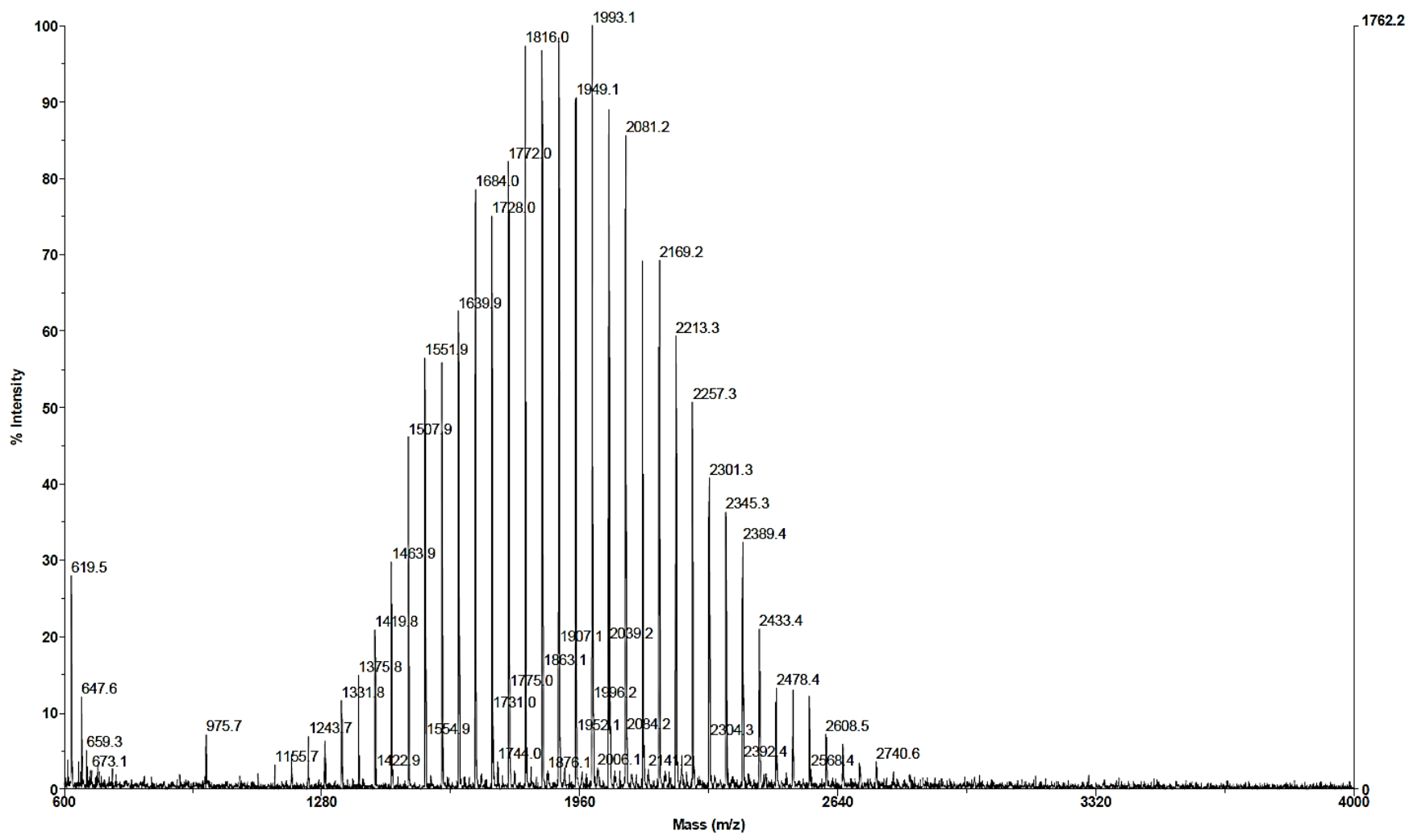



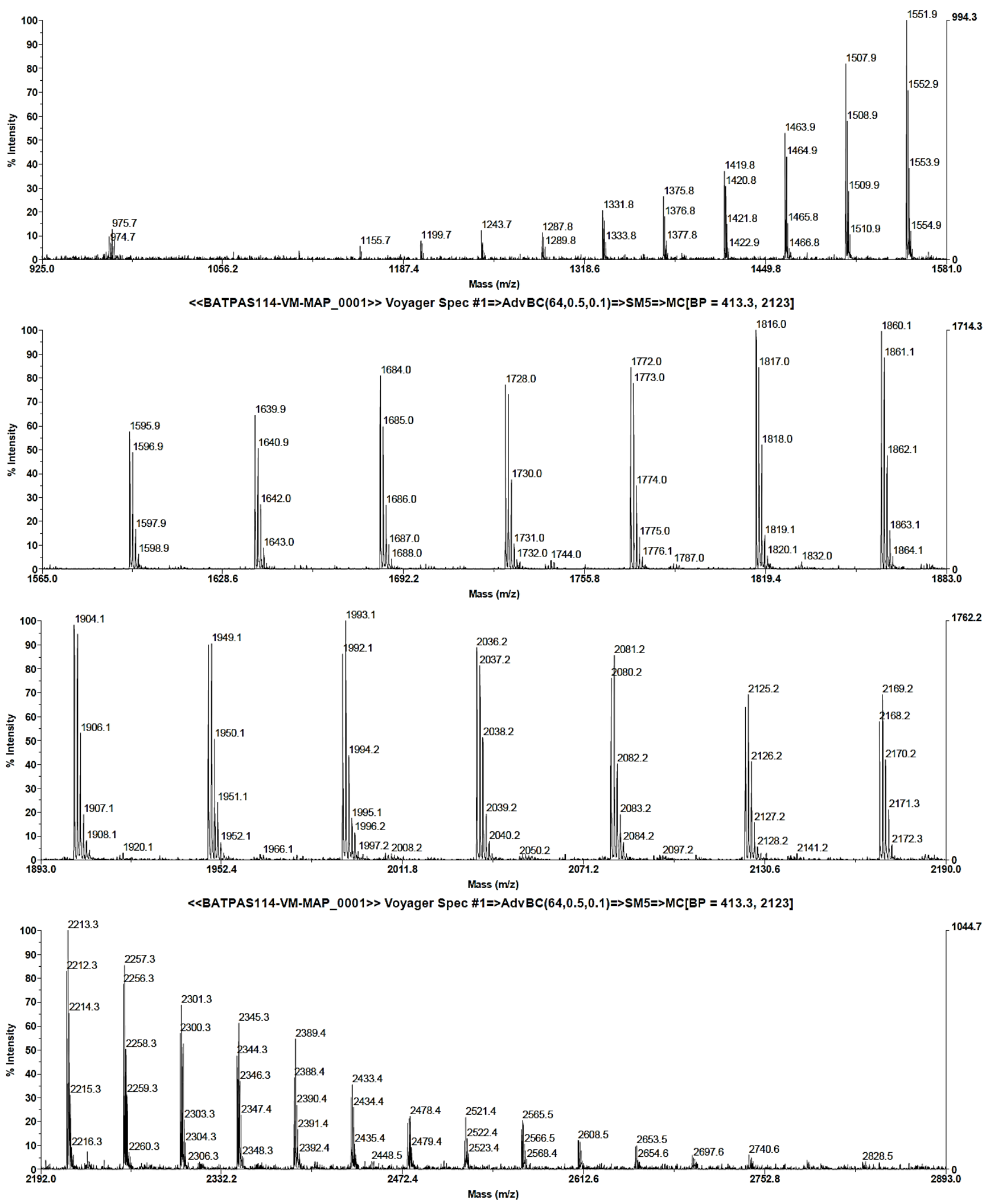

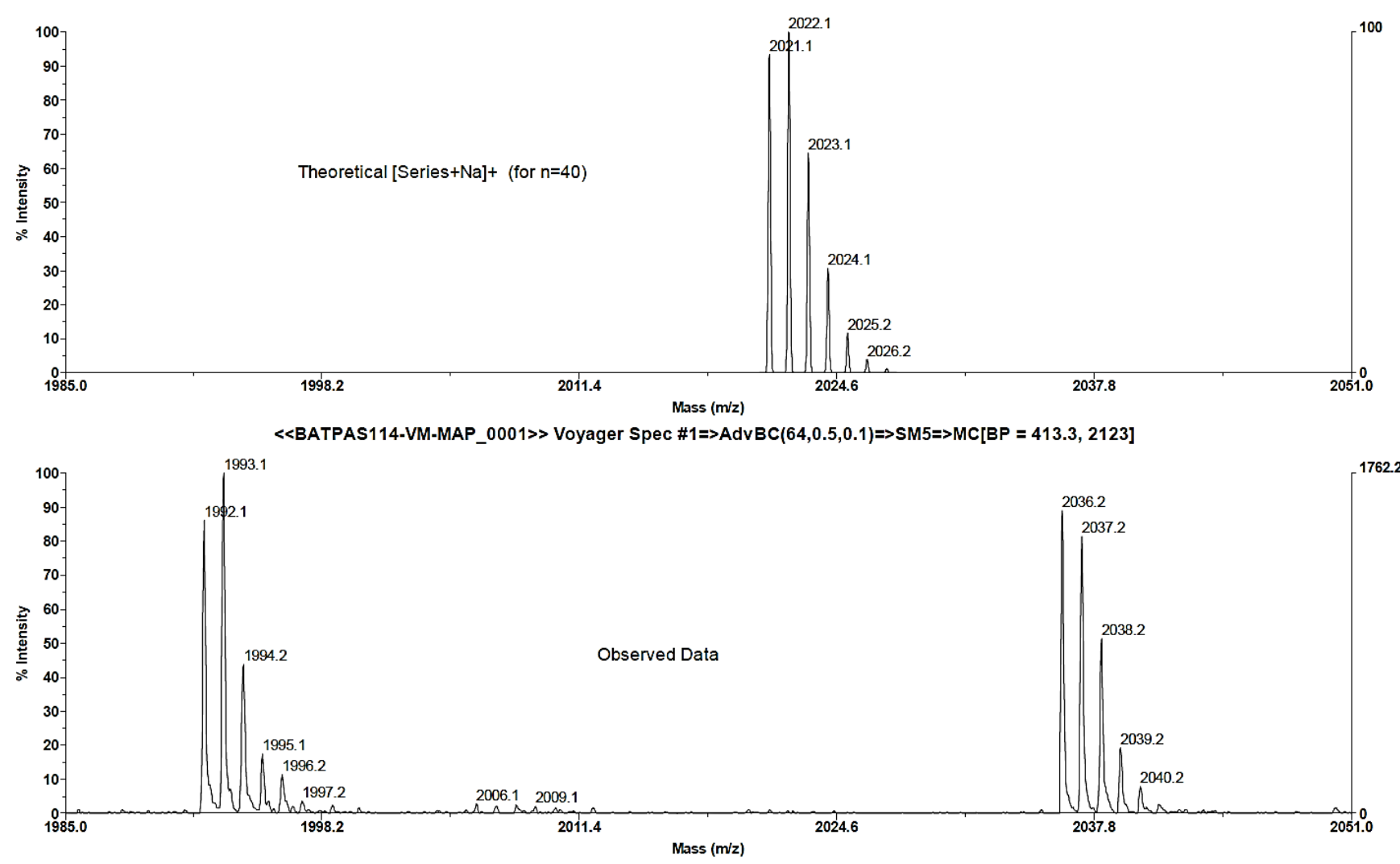

Figure S54. Mass spectra of GPC of Compound 1 (2 kDa). (THF PosRef [1:5] (Dith;THF) +NaOAc)

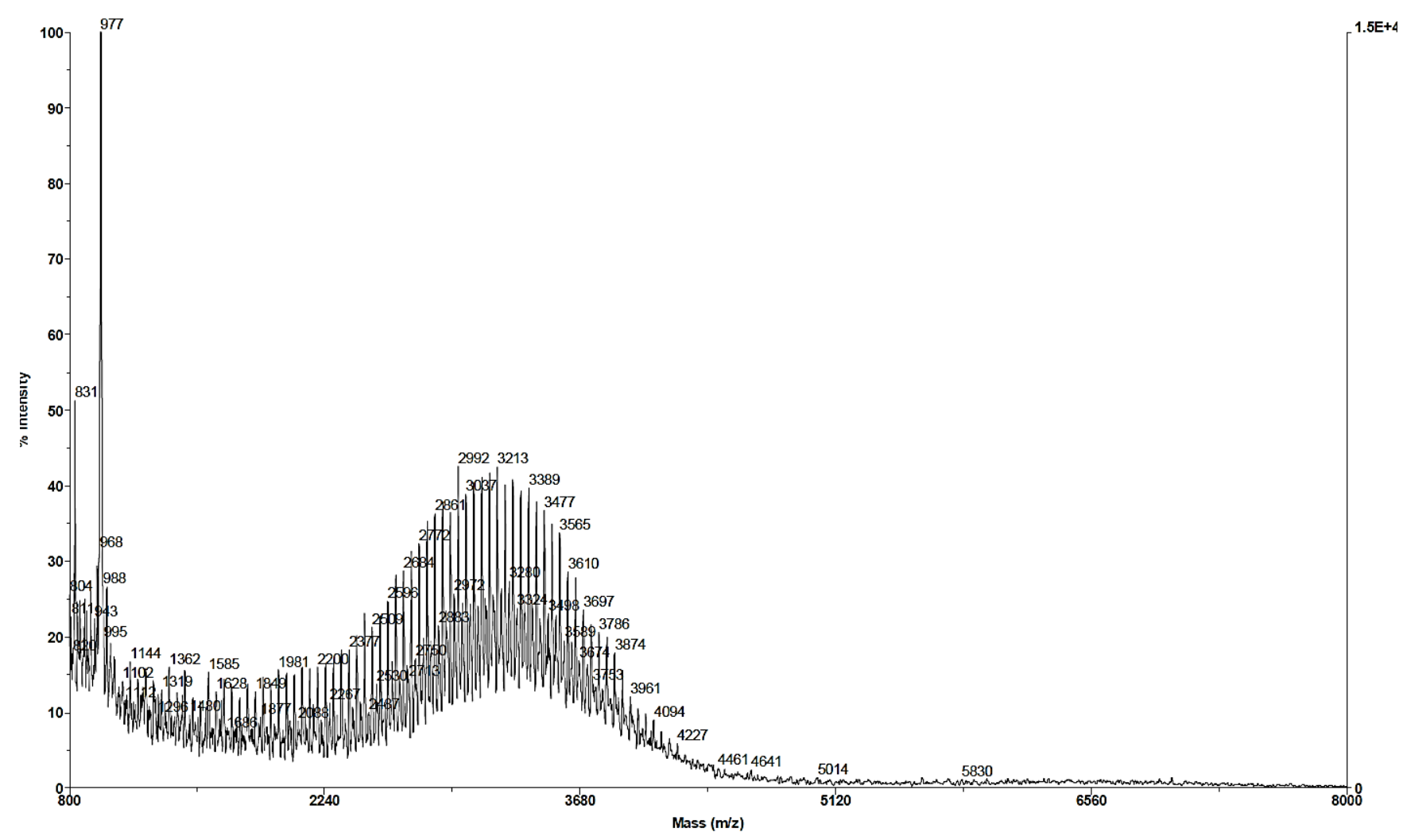



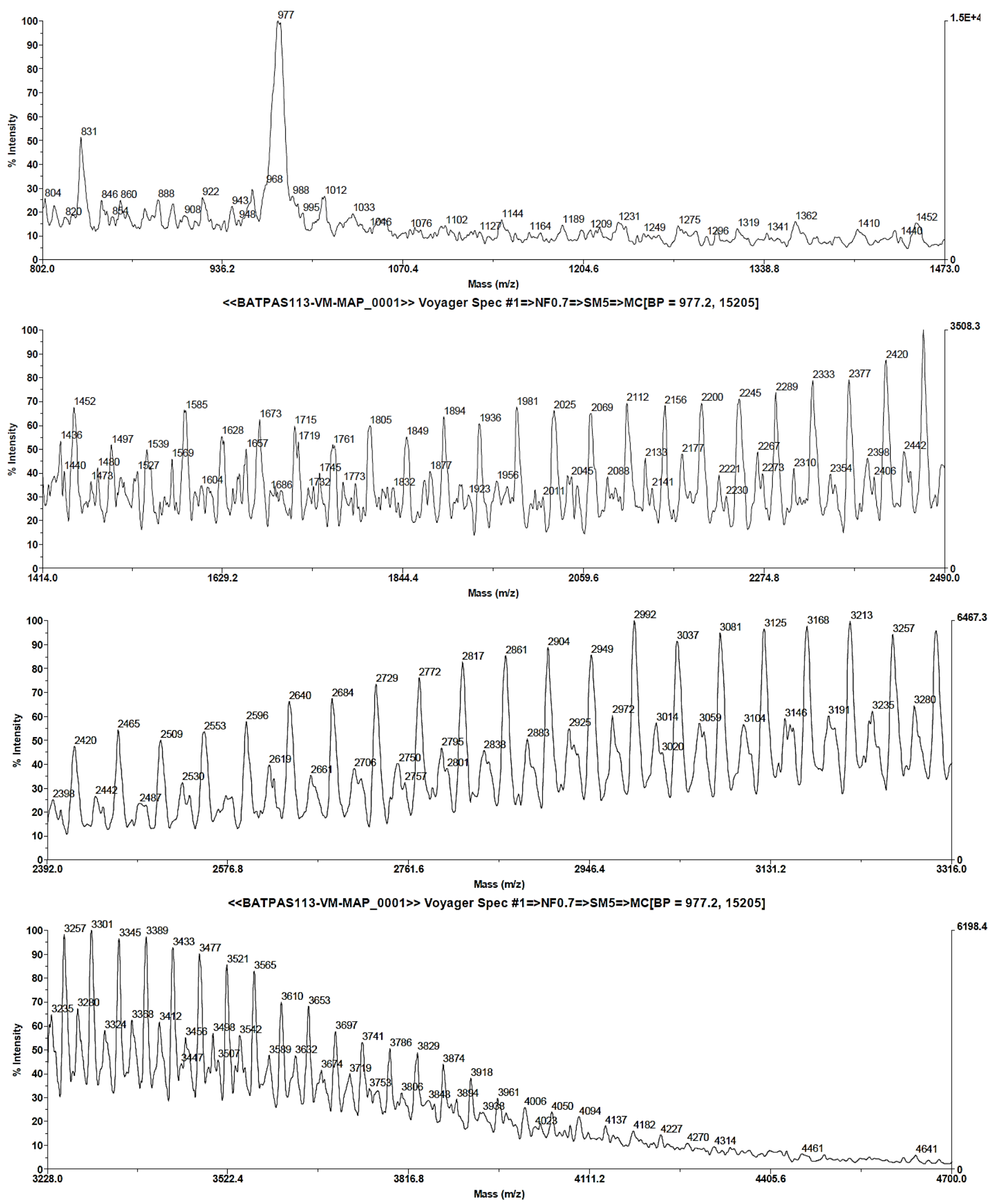

Figure S55. Mass spectra of GPC of Compound II (3 kDa). (THF PosLin [1:5] (Dith;THF) +NaOAc) 

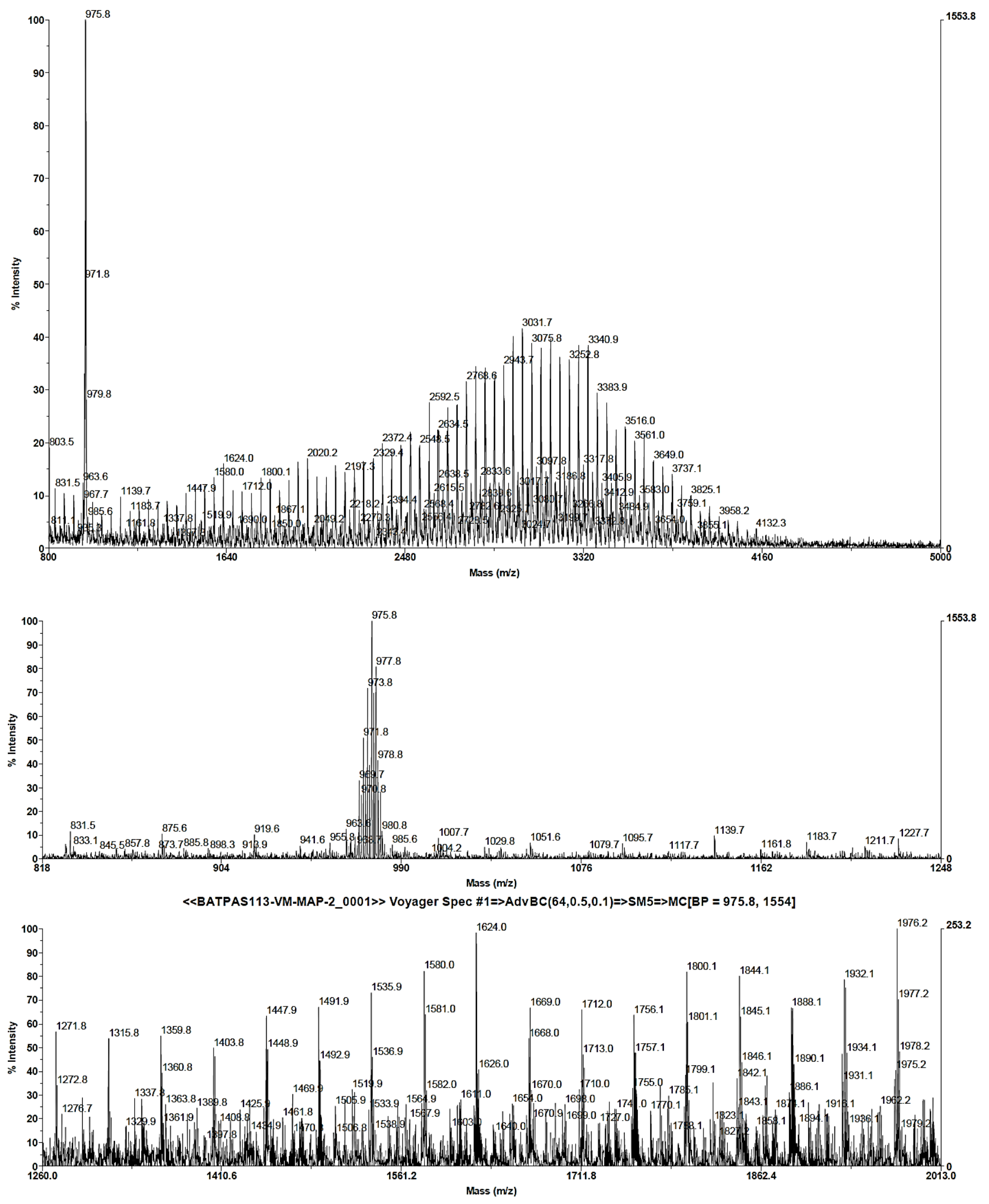

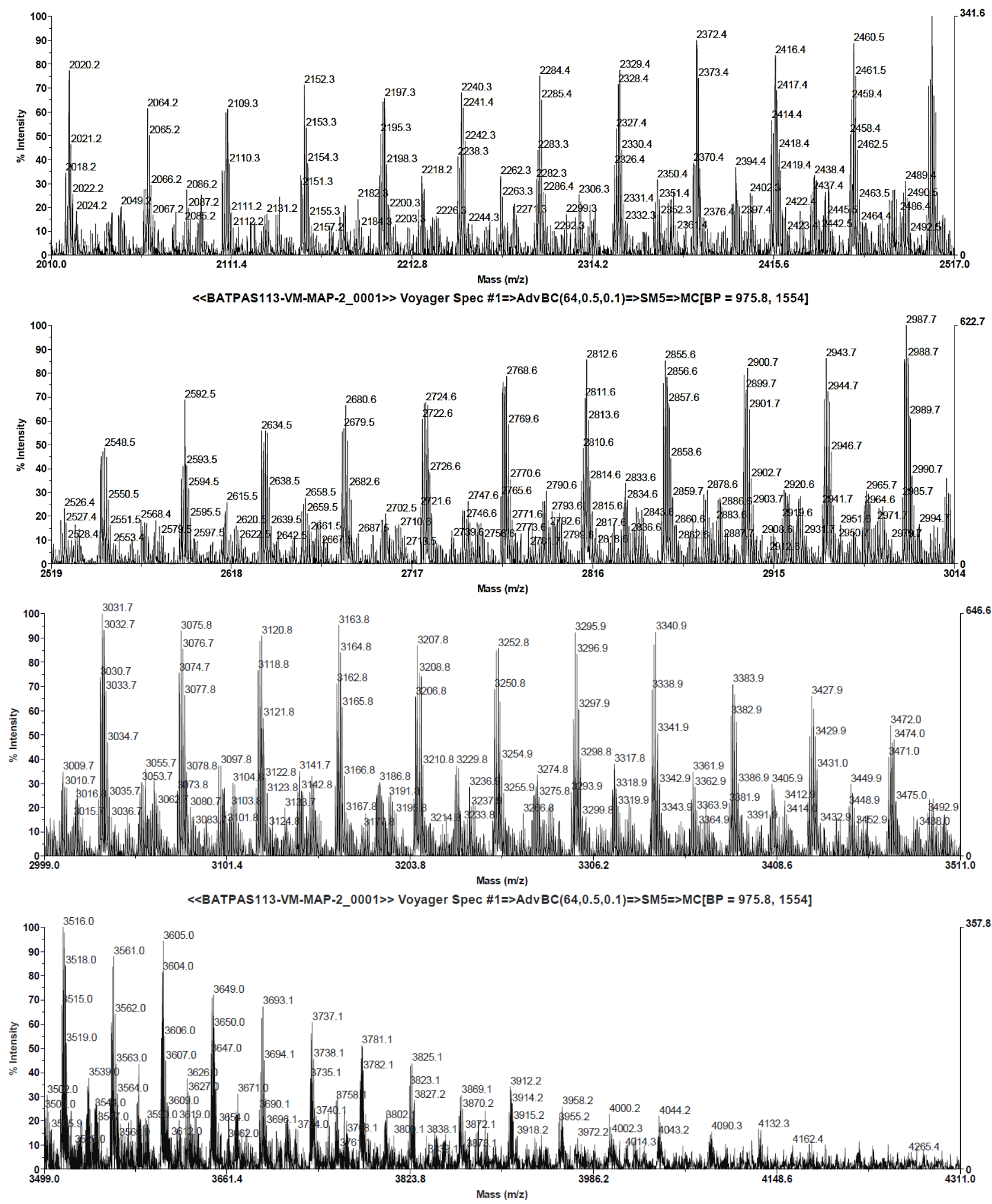

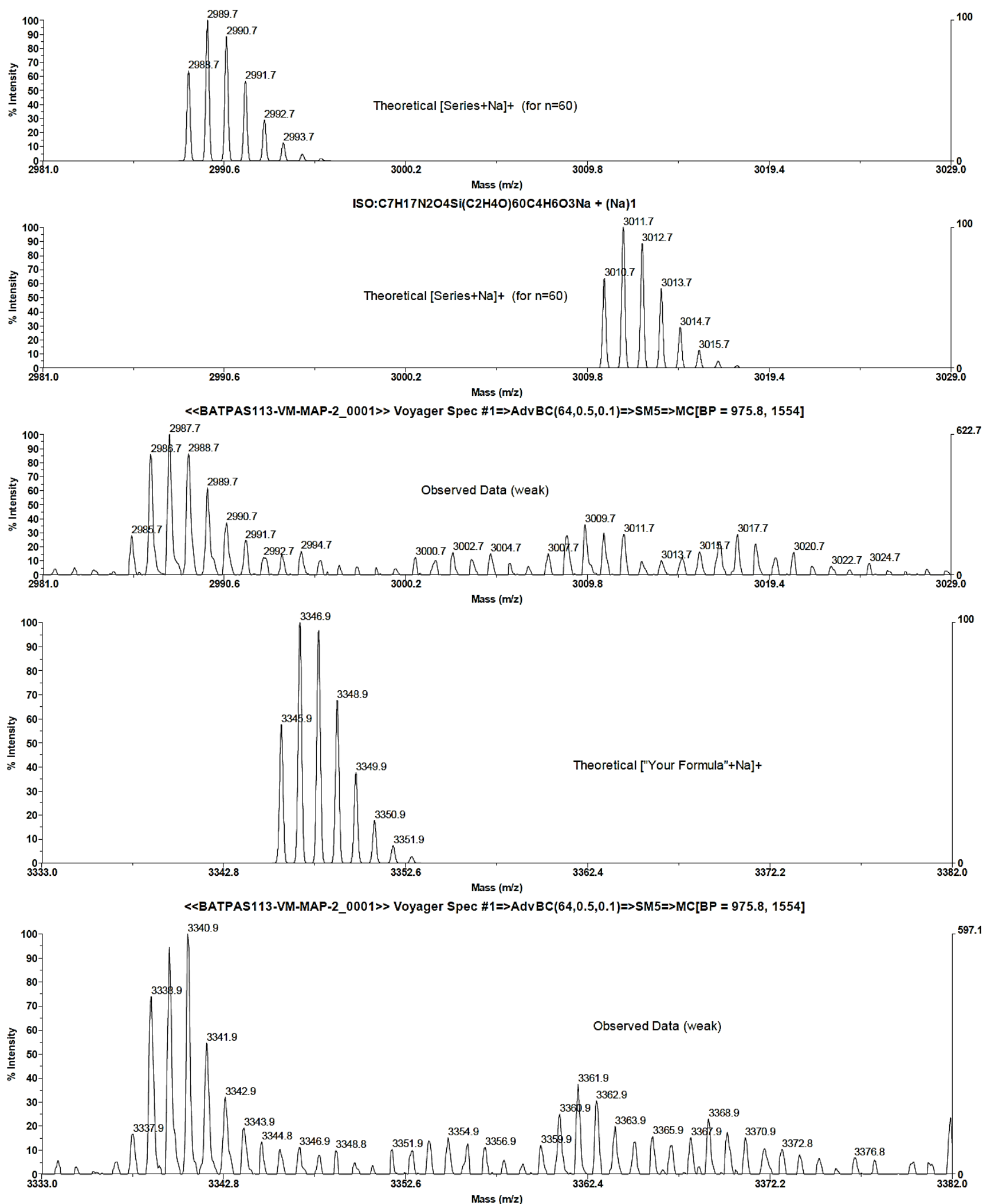

Figure S56. Mass spectra of GPC of Compound Type II (3 kDa). (THF PosRef [1:5] (Dith;THF) +NaOAc) 

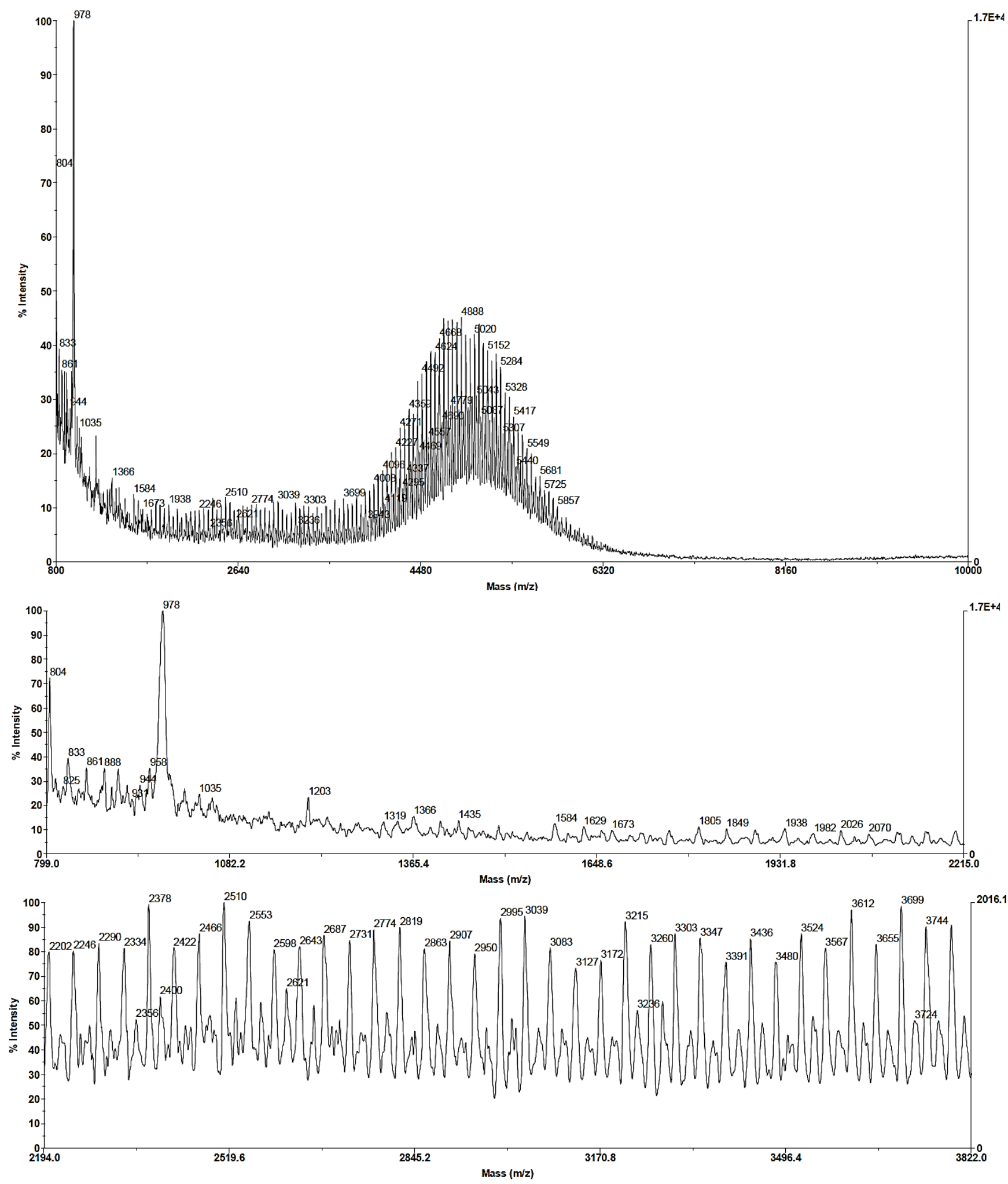


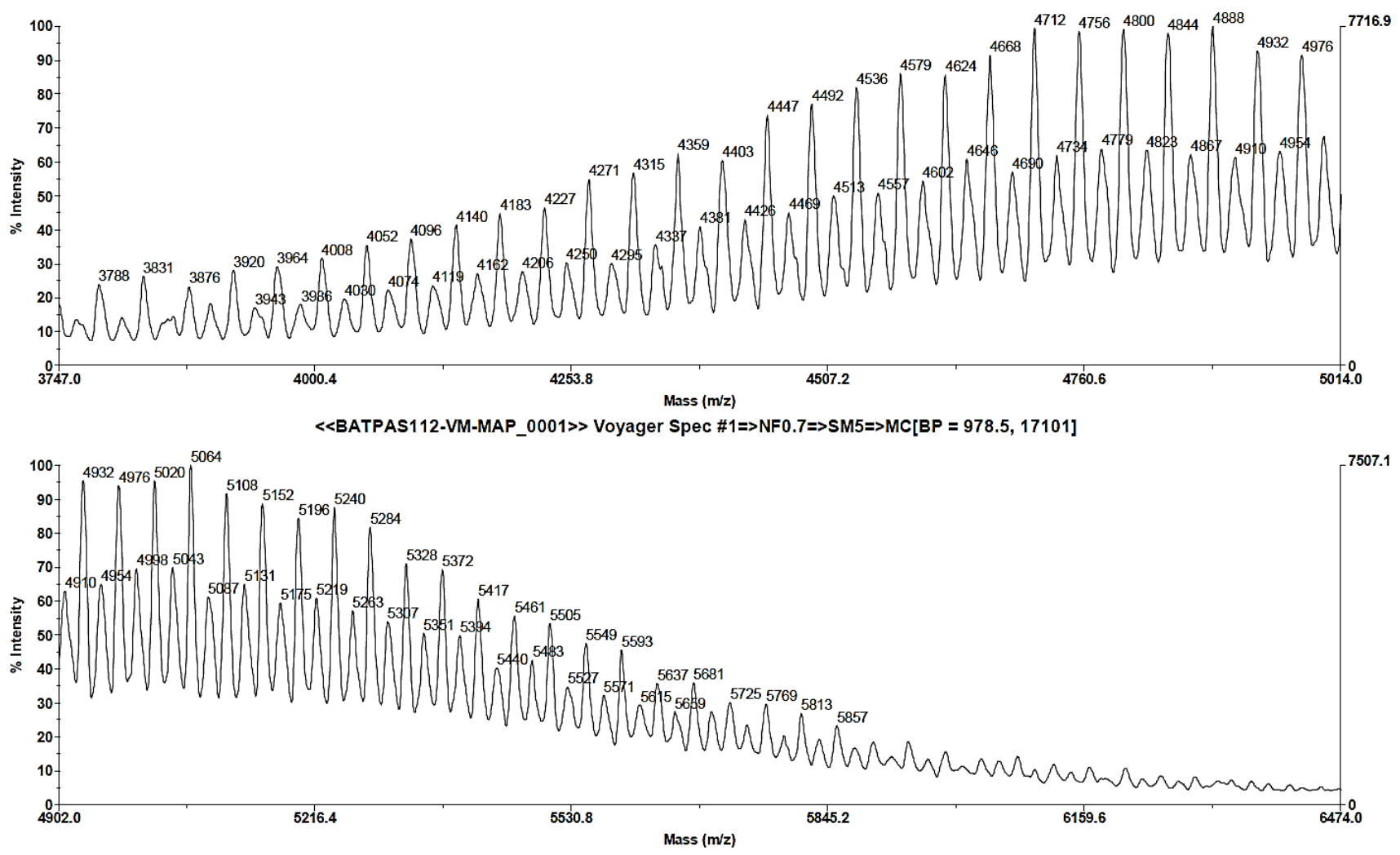

Figure S57. Mass spectra of GPC of Compound Type II (5 kDa). (THF PosLin [1:5] (Dith;THF) +NaOAc)

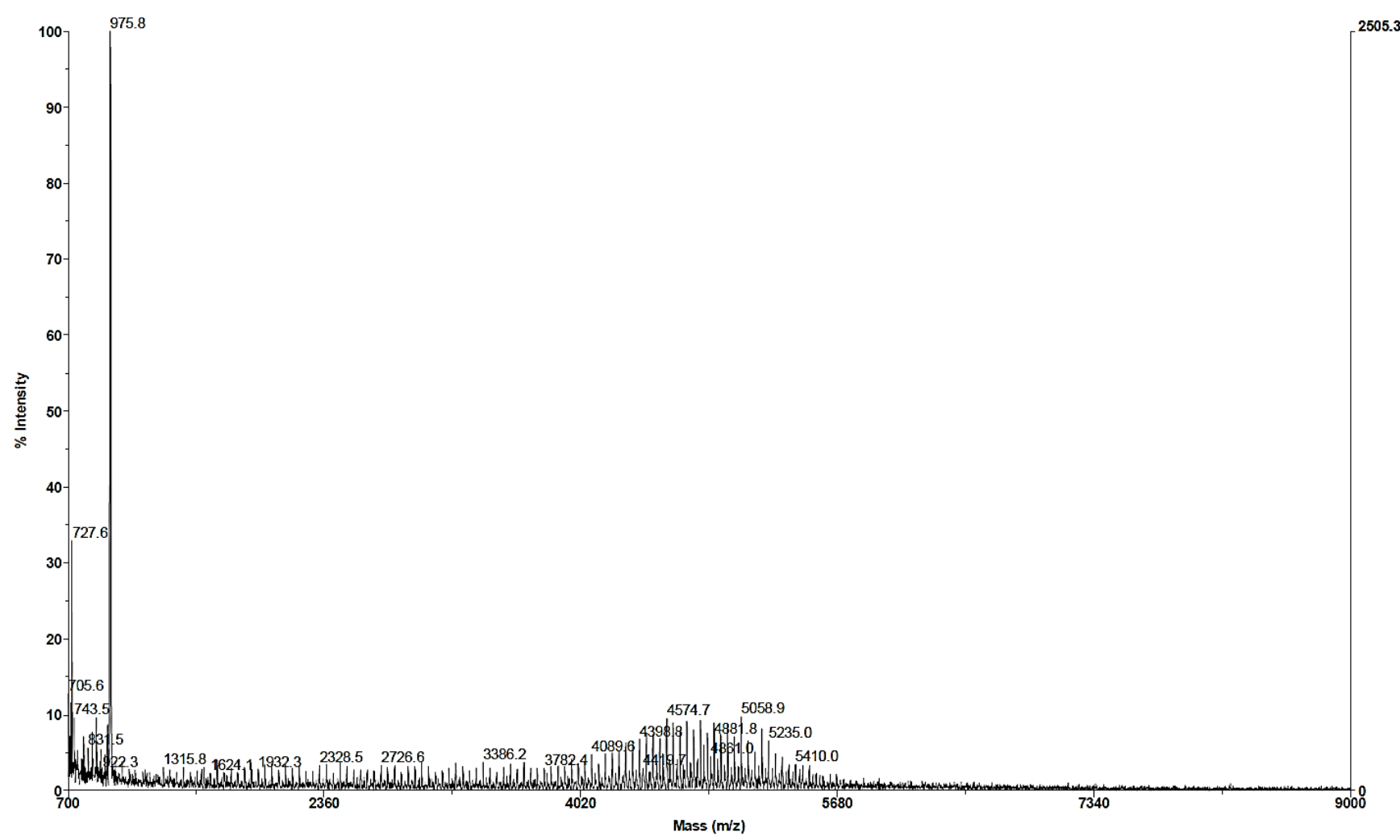



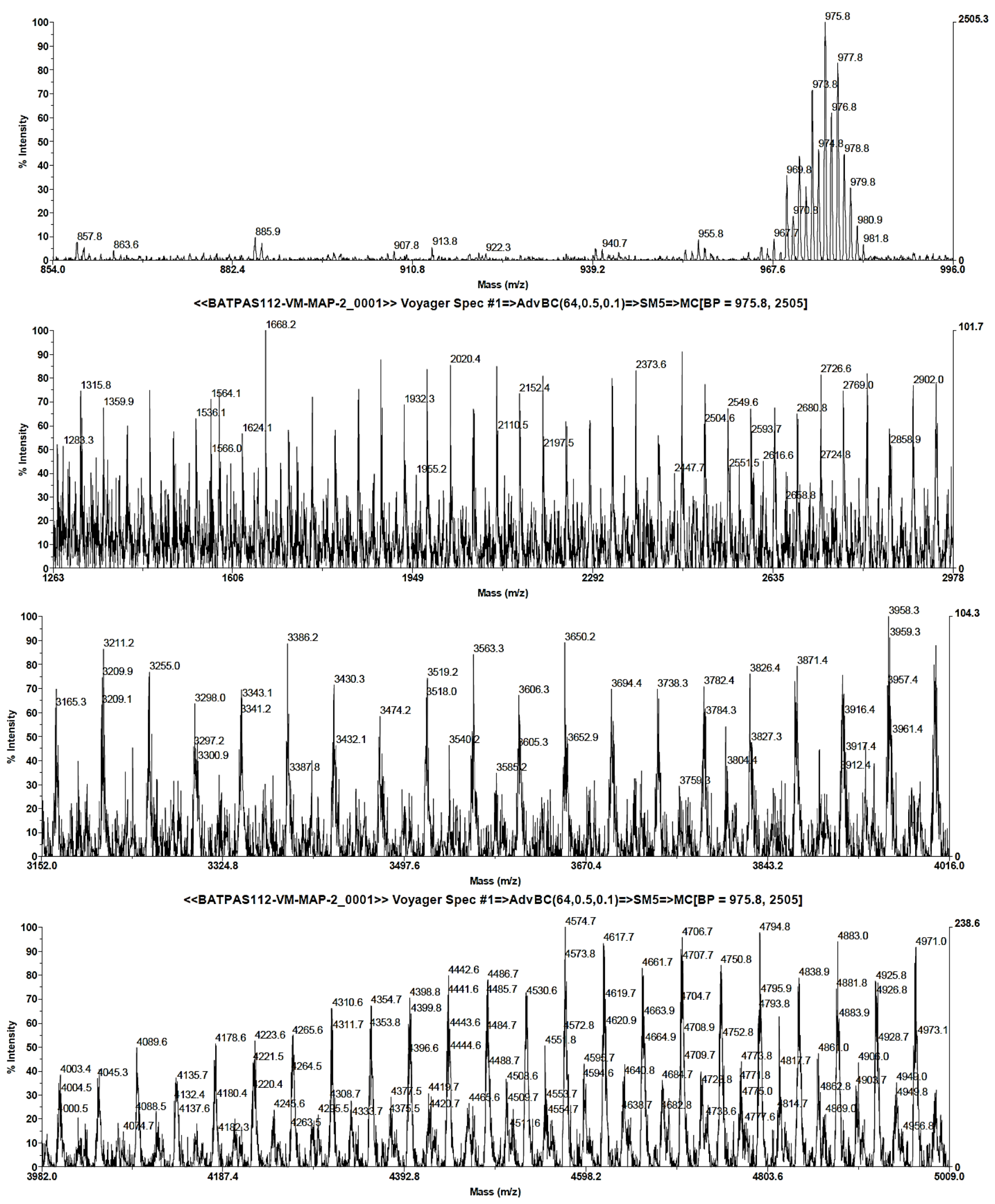

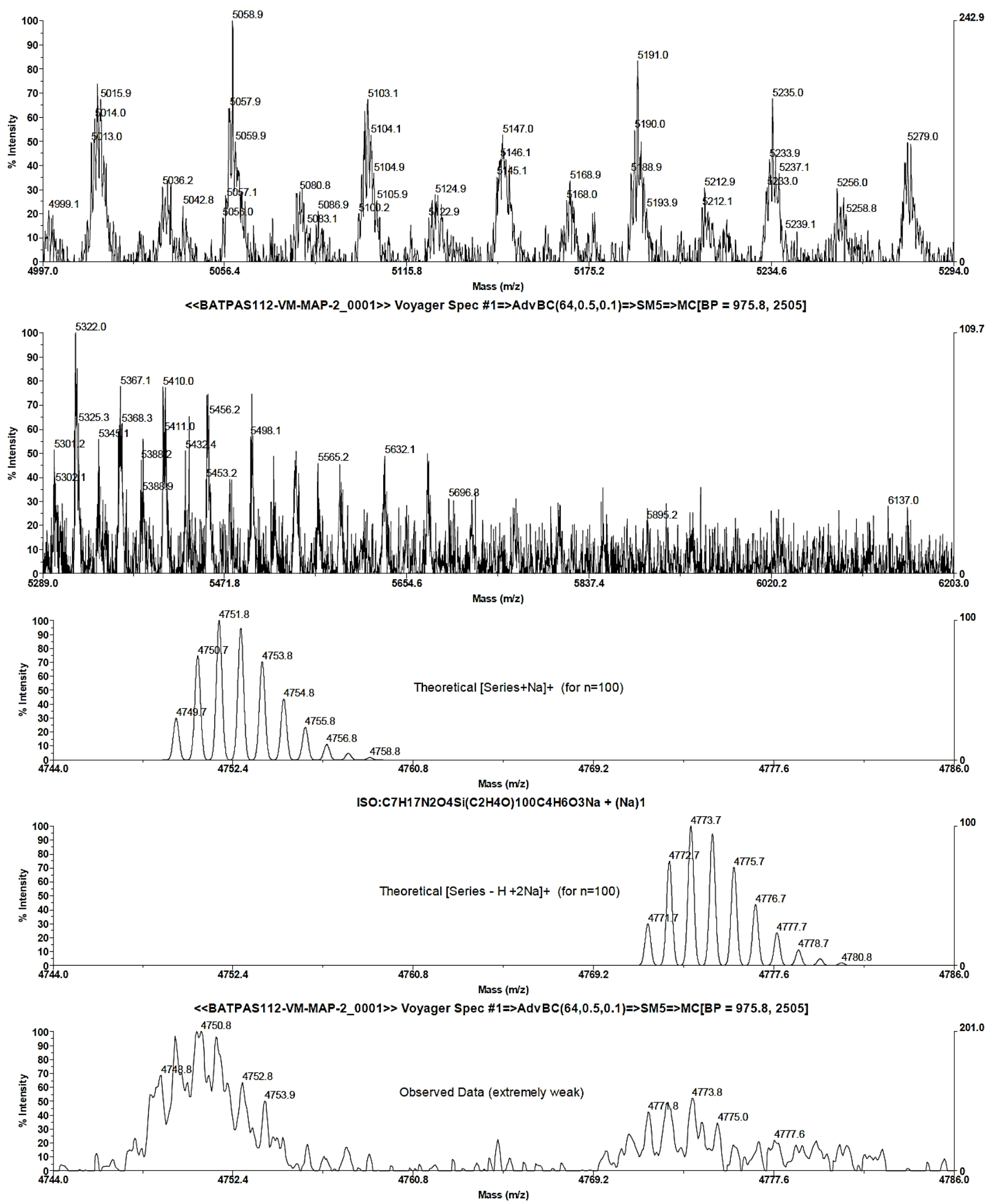

Figure S58. Mass spectra of GPC of Compound Type II (5 kDa). (THF PosRef [1:5] (Dith;THF) +NaOAc) 


\section{Confocal fluorescence imaging microscopy of $\mathrm{Y}_{0.9} \mathrm{Er}_{0.1} \mathrm{VO}_{4}$ and corresponding functional composites}

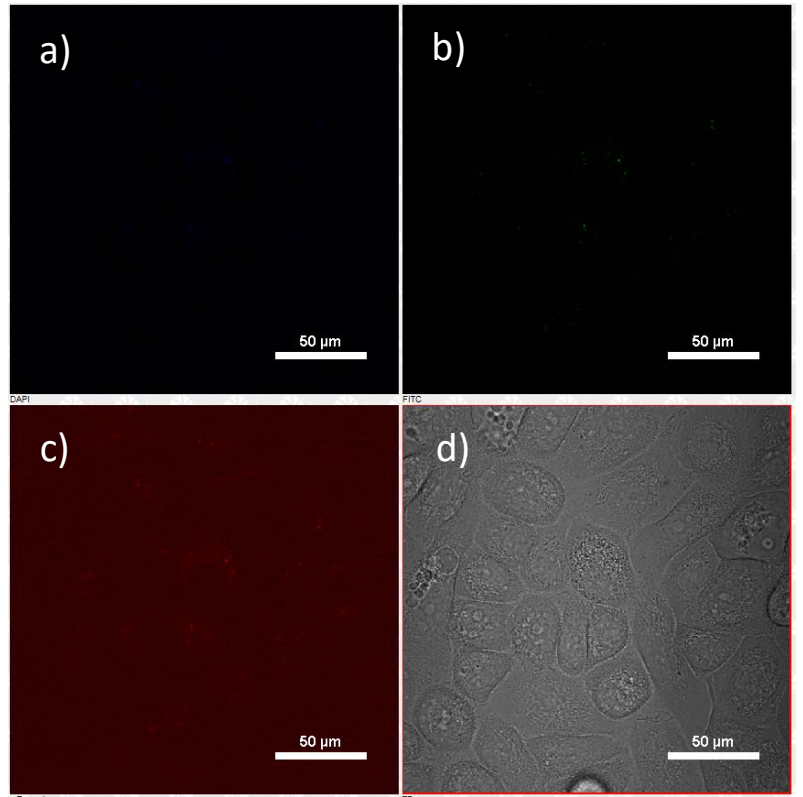

Figure S59. Confocal image of live PC-3 control cells. $\lambda_{\mathrm{ex}}=405 \mathrm{~nm}$; Scale bar: $50 \mu \mathrm{m}$; a) blue channel $\lambda_{\mathrm{em}}=420-480 \mathrm{~nm}$; b) green channel; $\lambda_{\mathrm{em}}=516-530 \mathrm{~nm}$; c) red channel $\lambda_{\mathrm{em}}=615-650 \mathrm{~nm}$; d) DIC channel.

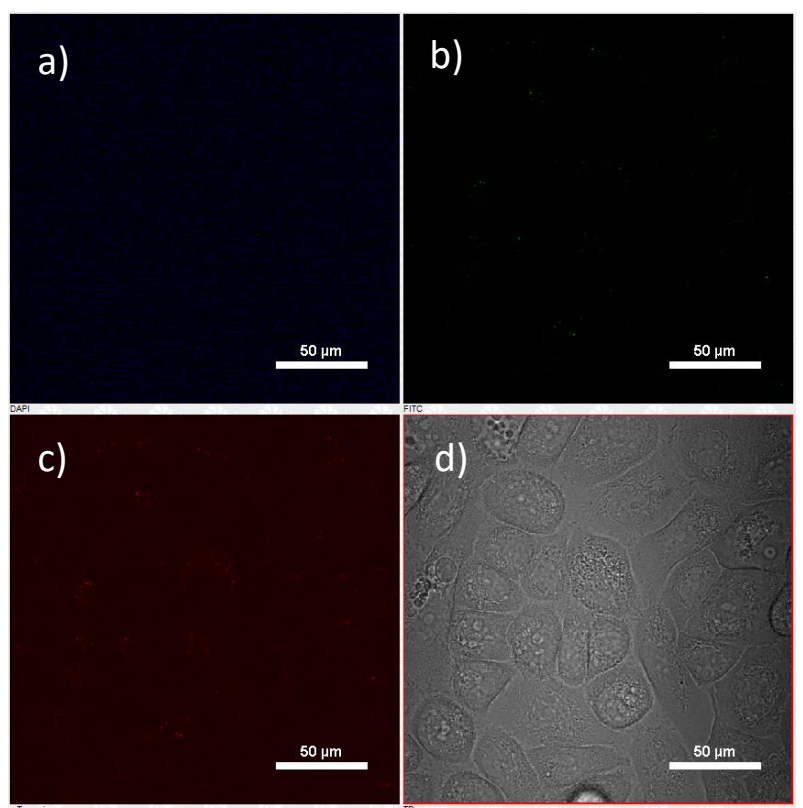

Figure S60. Confocal image of live PC-3 control cells. $\lambda_{\mathrm{ex}}=488 \mathrm{~nm}$. a) blue channel $\lambda_{\mathrm{em}}=420-480 \mathrm{~nm}$; b) green channel; $\lambda_{\mathrm{em}}$ $=516-530 \mathrm{~nm} ; \mathrm{c}$ ) red channel $\lambda_{\mathrm{em}}=615-650 \mathrm{~nm}$; d) DIC channel. 


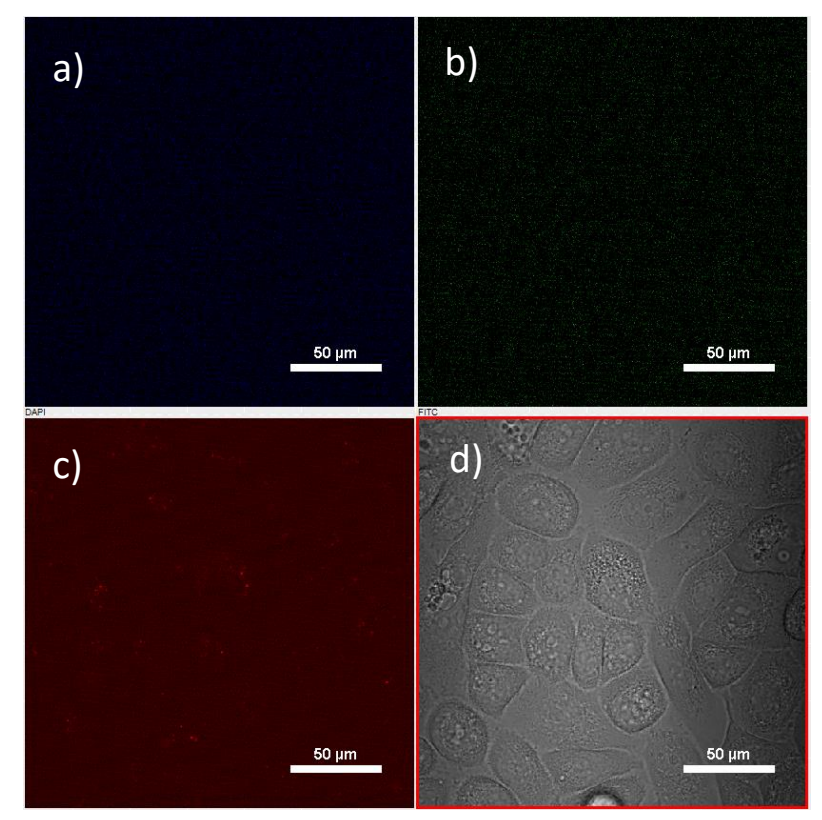

Figure S61. Confocal image of live PC-3 control cells. $\lambda_{\mathrm{ex}}=561 \mathrm{~nm}$. a) blue channel $\lambda_{\mathrm{em}}=420-480 \mathrm{~nm}$; b) green channel; $\lambda_{\mathrm{em}}$ $=516-530 \mathrm{~nm} ; \mathrm{c})$ red channel $\lambda_{\mathrm{em}}=615-650 \mathrm{~nm}$; d) DIC channel.

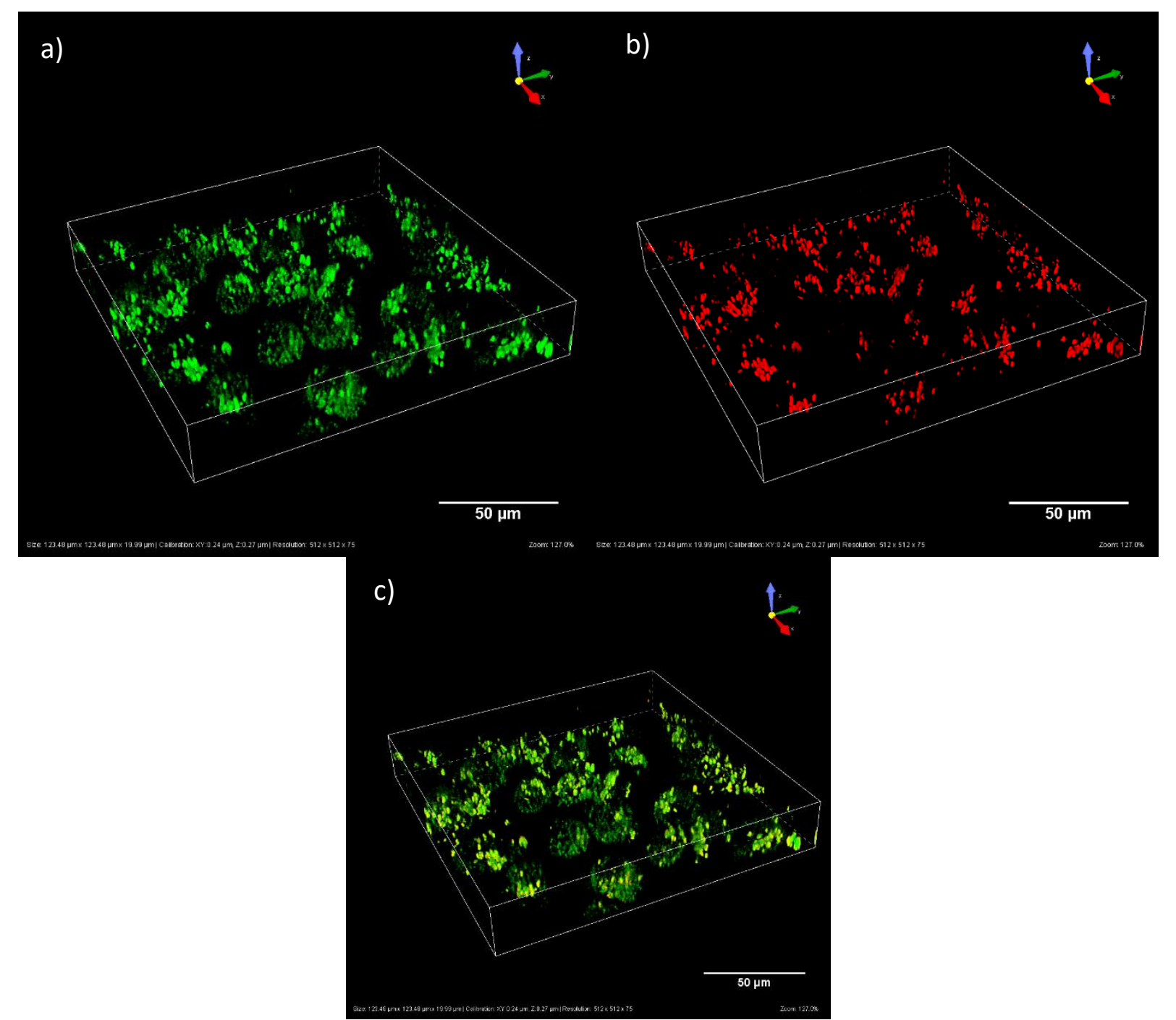

Figure S62. Confocal fluorescence image of live PC-3 cells incubated with the $\mathrm{Y}_{0.9} \mathrm{Er}_{0.1} \mathrm{VO}_{4} @$ @Chitosan composite at $1 \mathrm{mg} / \mathrm{ml}$ for $15 \mathrm{~min}$. 3D imaging representation. a) green channel $\lambda_{\mathrm{em}}=516-530 \mathrm{~nm}$; b) red channel $\lambda_{\mathrm{em}}=615-650$; c) overlay of green and red channels. $\lambda_{\mathrm{ex}}=488 \mathrm{~nm}$. 

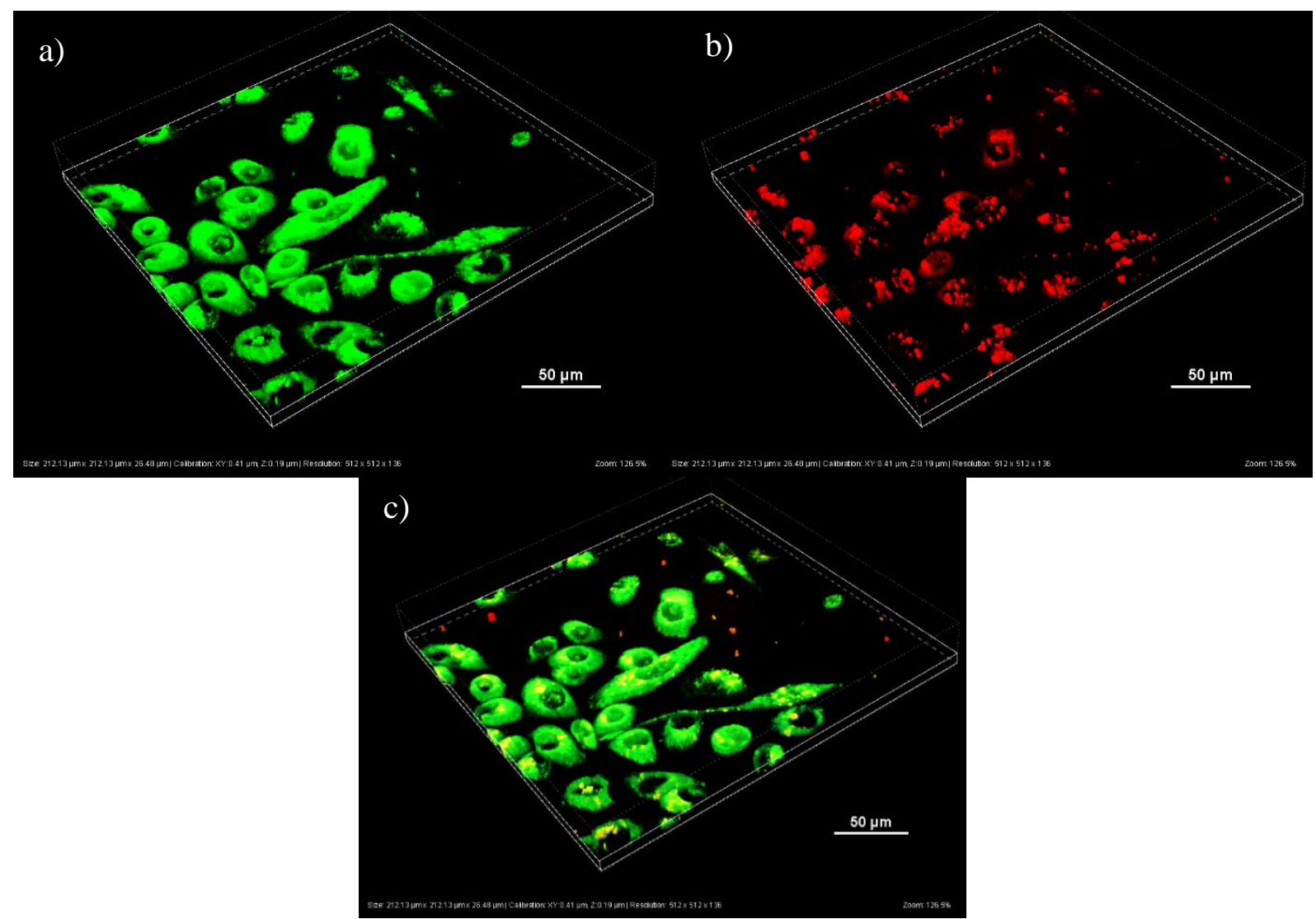

Figure S63. 3D confocal fluorescence imaging of live PC-3 cells incubated with $\mathrm{Y}_{0.9} \mathrm{Eu}_{0.1} \mathrm{VO}_{4} @ \mathrm{SiO}_{2}$ composite at $1 \mathrm{mg} / \mathrm{ml}$ for 15 min. a) green channel $\lambda_{e m}=516-530 \mathrm{~nm}$; b) red channel $\lambda_{e m}=615-650$; c) overlay of green and red channels. $\lambda_{e x}=488 \mathrm{~nm}$.

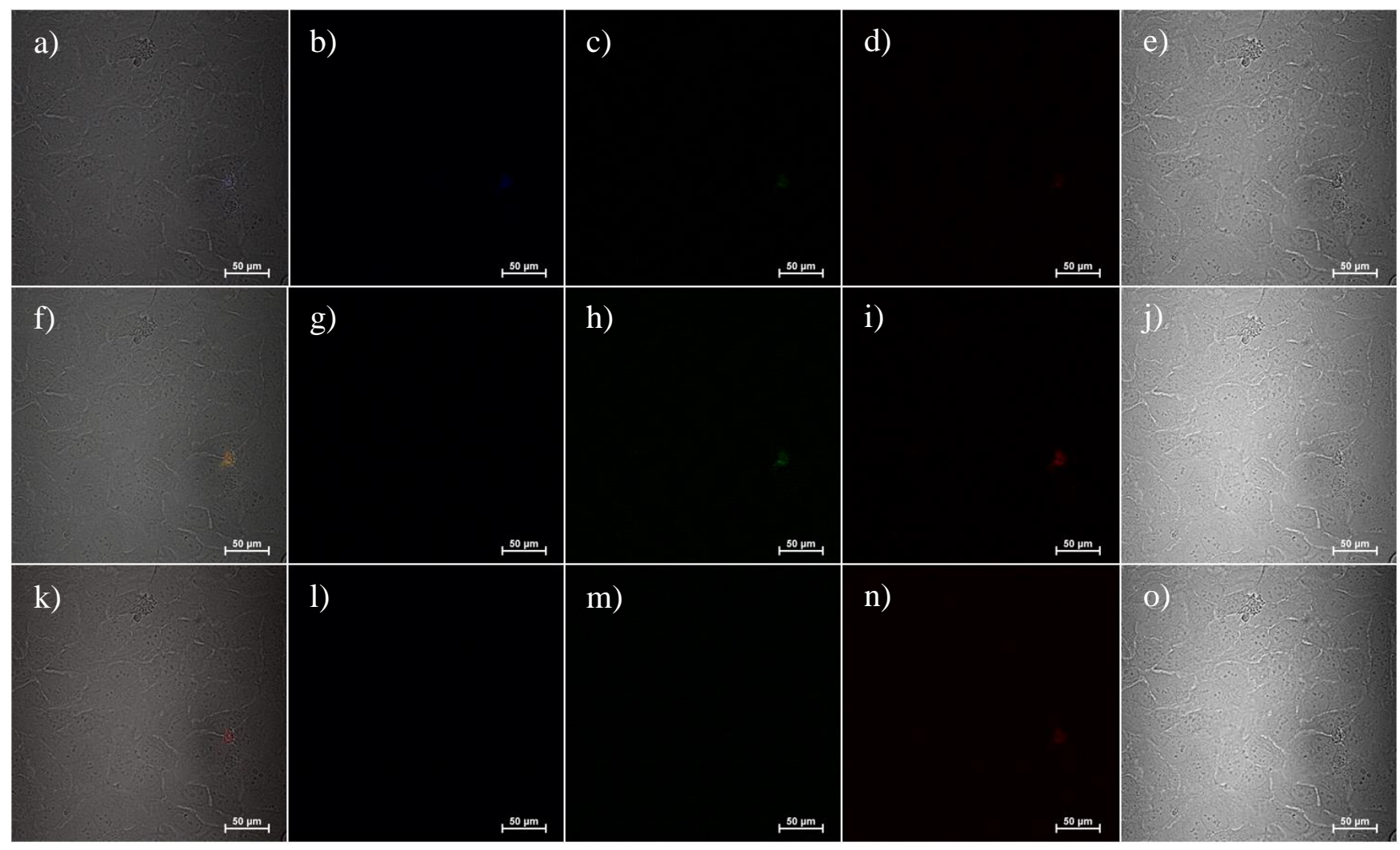

Figure S64. Confocal fluorescence imaging of live HeLa cells (control experiment, 15 min incubation, $1 \%$ DMSO, $37 \stackrel{\circ}{\circ} \mathrm{C}$ ). a),f),k) merged channel, b),g),I) blue channel; c),h),m) green channel; d),i),n) red channel; e),j),o) DIC channel of three different areas, $\lambda_{e x}=405 \mathrm{~nm}$; a) to e), $\lambda_{e x}=488 \mathrm{~nm}$; f) to j), $\lambda_{e x}=561 \mathrm{~nm}$; k) to o). Scale bar: $50 \mu \mathrm{m}$. 


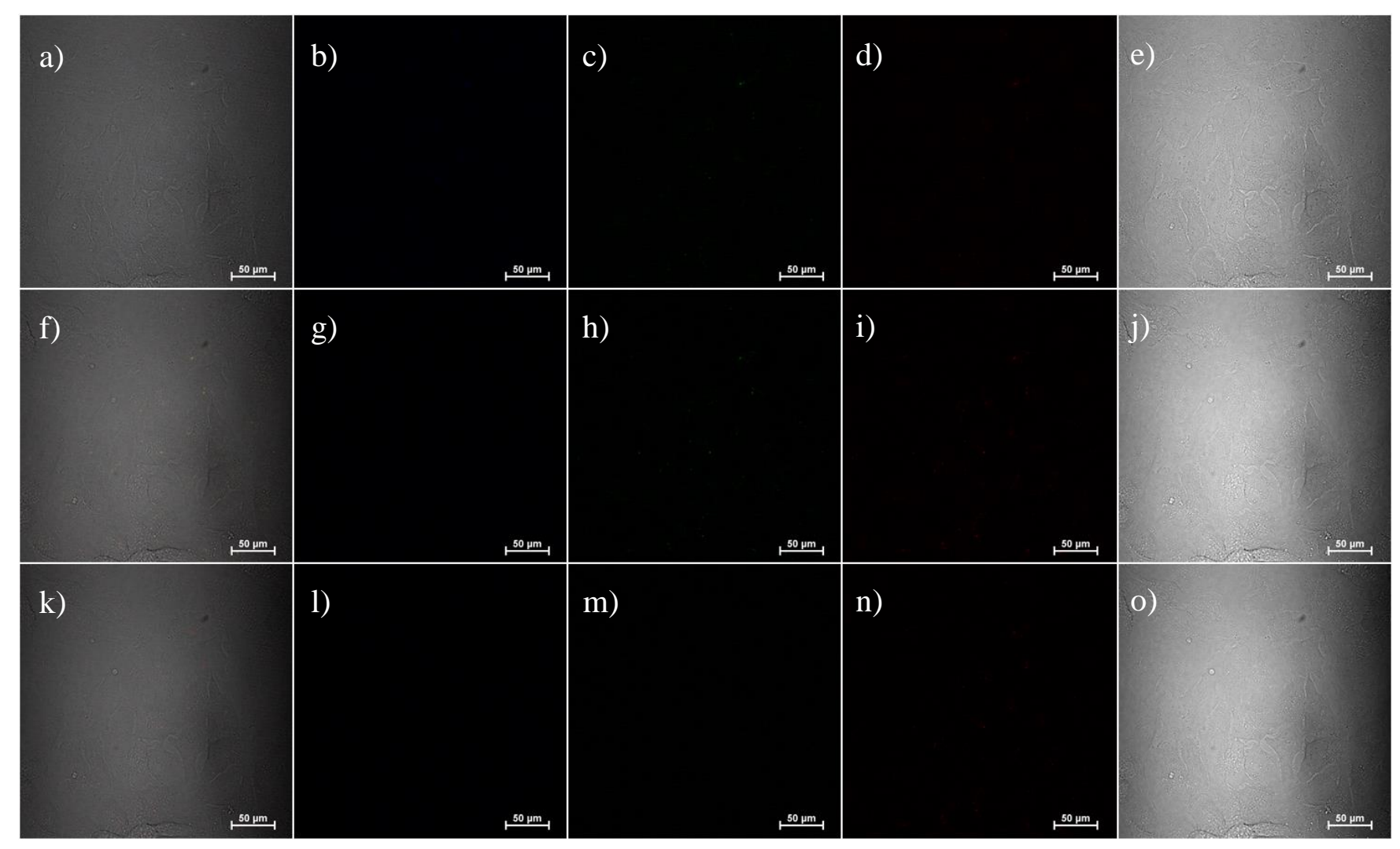

Figure S65. Confocal image of live HeLa control cells (15 min, 1\% DMSO, $37^{\circ} \mathrm{C}$ ). a),f),k) merged channel, b),g),l) blue channel; c),h),m) green channel; d),i),n) red channel; e),j),o) DIC channel of three different areas, $\lambda_{\mathrm{ex}}=405 \mathrm{~nm}$; a) to e), $\lambda_{\mathrm{ex}}=488 \mathrm{~nm}$; f) to j), $\lambda_{e x}=561 \mathrm{~nm} ; \mathrm{k}$ ) to o). Scale bar: $50 \mu \mathrm{m}$.

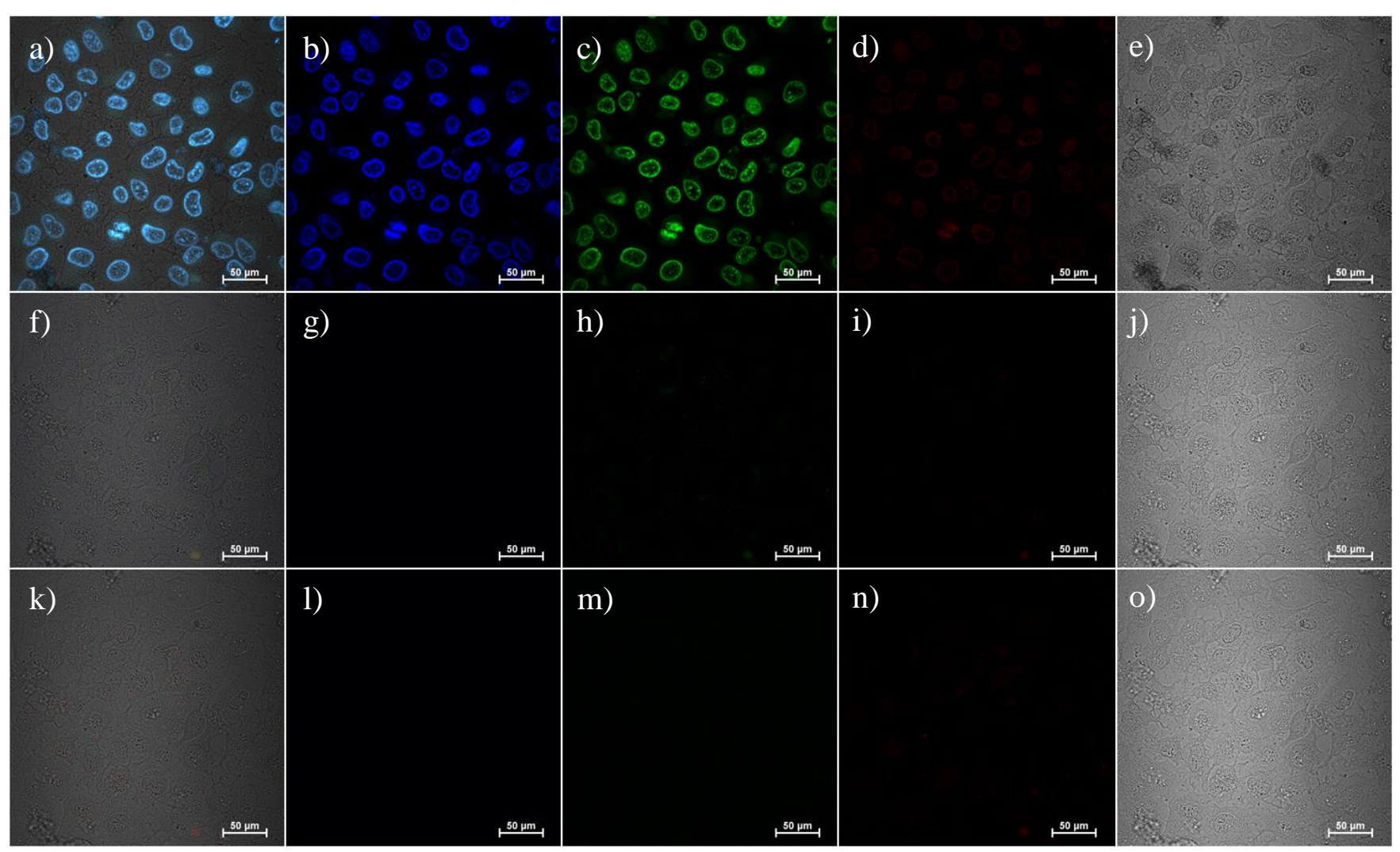

Figure S66. Confocal fluorescence imaging of live HeLa cells: 15 min incubation (as per control conditions) followed by addition of $1 \mu \mathrm{g} / \mathrm{mL}$ Hoechst dye and 30 min incubation (1\% DMSO, $\left.37^{\circ} \mathrm{C}\right)$. a),f),k) merged channel, b),g),l) blue channel; c), h), m) green channel; d),i),n) red channel; e),j),o) DIC channel of three different areas, $\lambda_{\text {ex }}=405 \mathrm{~nm}$; a) to e), $\lambda_{\mathrm{ex}}=488 \mathrm{~nm}$; f) to j), $\lambda_{\mathrm{ex}}=561$ $\mathrm{nm} ; \mathrm{k}$ ) to o). Scale bar: $50 \mu \mathrm{m}$. 


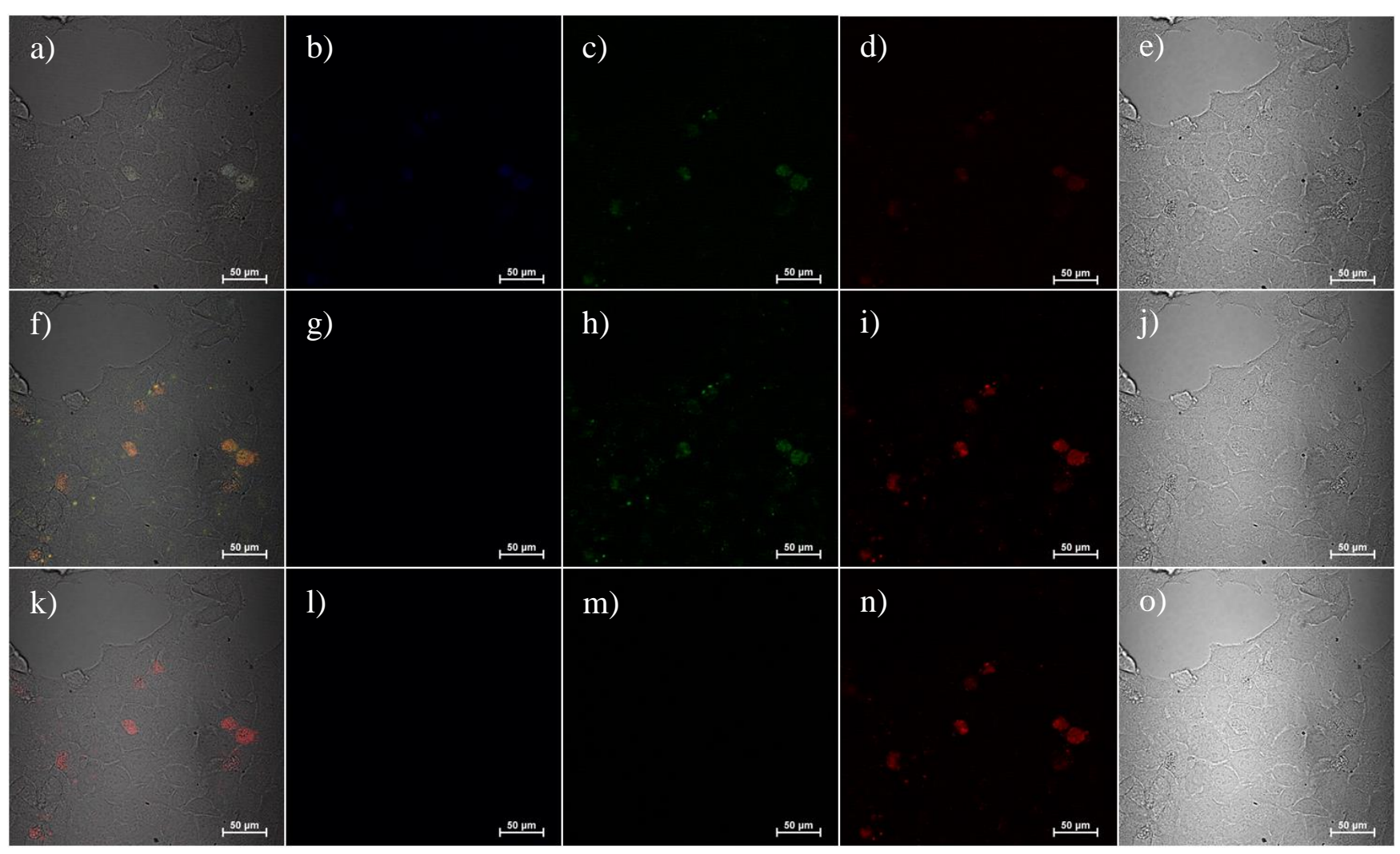

Figure S67. Confocal fluorescence imaging of live HeLa cells incubated with $\mathrm{Y}_{0.9} \mathrm{Eu}_{0.1} \mathrm{VO}_{4} @ \mathrm{SiO}_{2}$ composite at $10 \mu \mathrm{g} / \mathrm{ml}$ for 15 $\min \left(1 \%\right.$ DMSO, $\left.37^{\circ} \mathrm{C}\right)$ a),f),k) merged channel, b),g),l) blue channel; c),h),m) green channel; d),i), n) red channel; e),j),o) DIC channel of three different areas, $\lambda_{\mathrm{ex}}=405 \mathrm{~nm}$; a) to e), $\lambda_{\mathrm{ex}}=488 \mathrm{~nm}$; f) to j), $\lambda_{\mathrm{ex}}=561 \mathrm{~nm}$; k) to o). Scale bar: $50 \mu \mathrm{m}$.

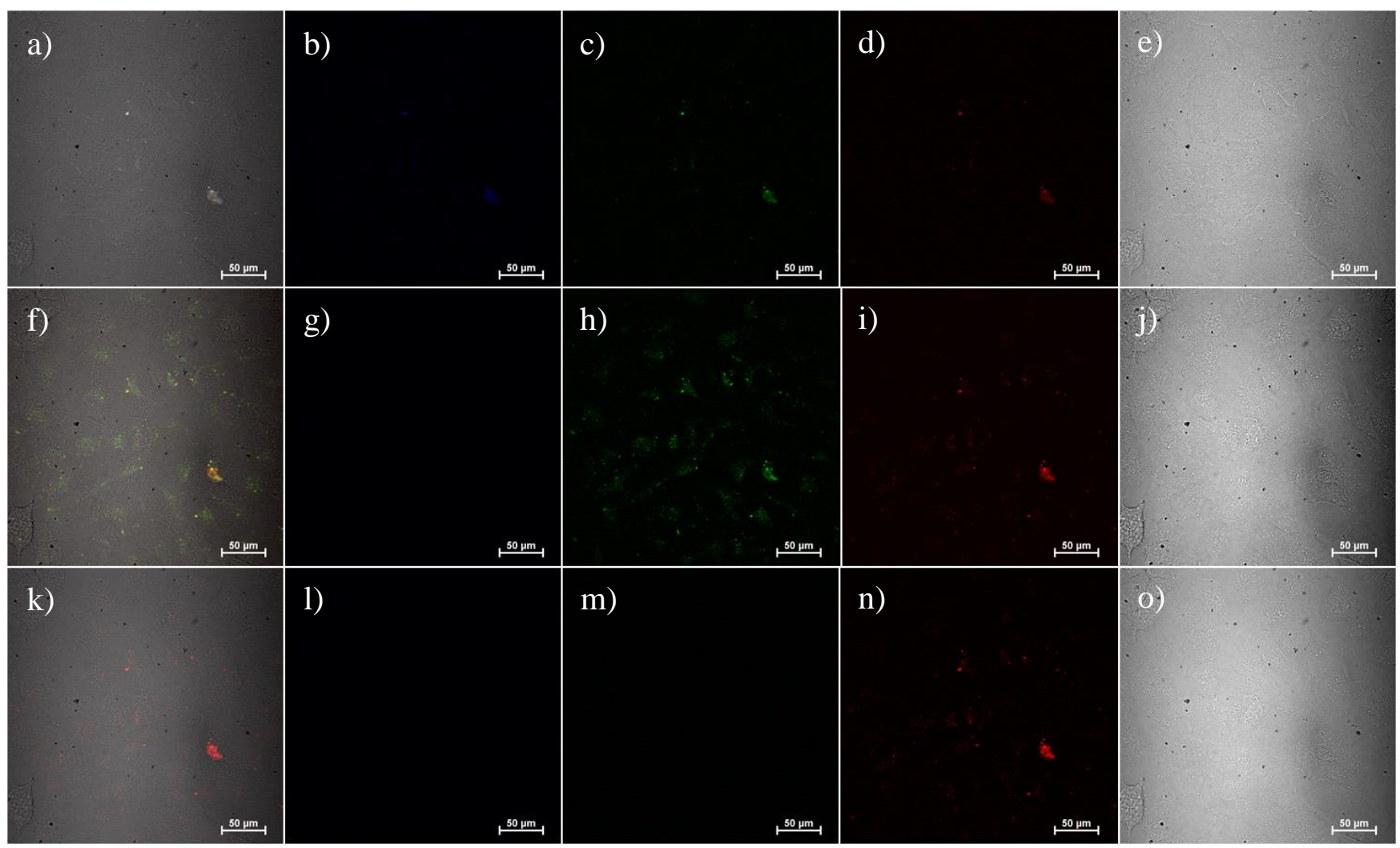

Figure S68. Confocal fluorescence imaging of live HeLa cells incubated with $\mathrm{Y}_{0.9} \mathrm{Eu}_{0.1} \mathrm{VO}_{4} @ \mathrm{SiO}_{2}$ composite at $10 \mu \mathrm{g} / \mathrm{ml}$ for 15 min (1\% DMSO, $37^{\circ}$ C). a),f),k) merged channel, b),g),I) blue channel; c),h),m) green channel; d),i),n) red channel; e),j),o) DIC channel of three different areas, $\lambda_{e x}=405 \mathrm{~nm}$; a) to e), $\lambda_{e x}=488 \mathrm{~nm}$; f) to j), $\lambda_{e x}=561 \mathrm{~nm}$; k) to o). Scale bar: $50 \mu \mathrm{m}$. 


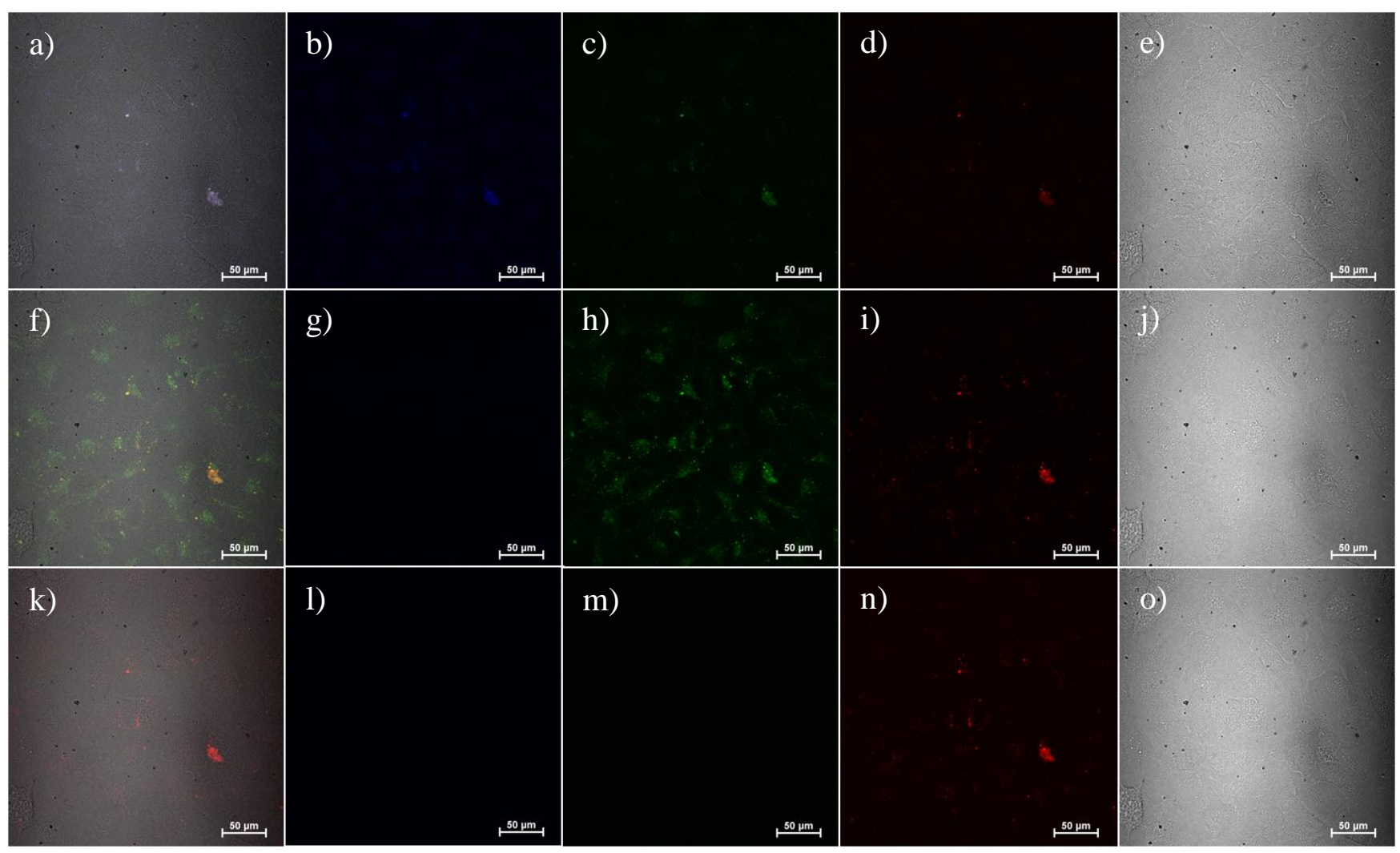

Figure S69. Confocal fluorescence imaging of live HeLa cells incubated with $\mathrm{Y}_{0.9} \mathrm{Eu}_{0.1} \mathrm{VO}_{4} @ \mathrm{SiO}_{2}$ composite at $10 \mu \mathrm{g} / \mathrm{ml}$ for 15 $\min \left(1 \%\right.$ DMSO, $\left.37^{\circ} \mathrm{C}\right)$. a),f),k) merged channel, b),g),l) blue channel; c),h),m) green channel; d),i),n) red channel; e),j),0) DIC channel of three different areas, $\lambda_{e x}=405 \mathrm{~nm}$; a) to e), $\lambda_{e x}=488 \mathrm{~nm}$; f) to j), $\lambda_{e x}=561 \mathrm{~nm}$; k) to o). Scale bar: $50 \mu \mathrm{m}$.

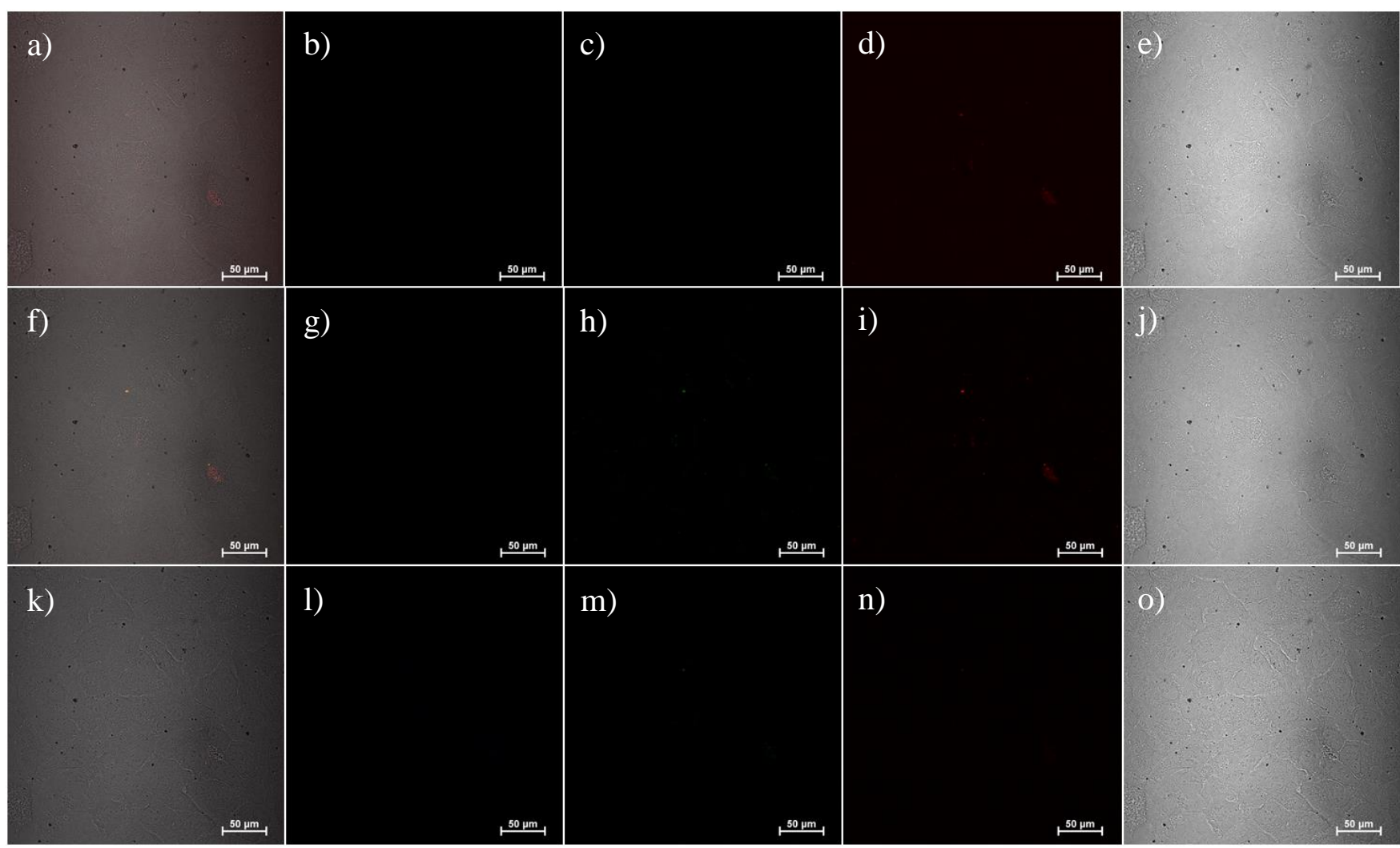

Figure S70. Confocal fluorescence imaging of live HeLa cells incubated with $\mathrm{Y}_{0.9} \mathrm{Eu}_{0.1} \mathrm{VO}_{4} @ \mathrm{SiO}_{2}$ composite at $10 \mu \mathrm{g} / \mathrm{ml}$ for 15 min (1\% DMSO, $37^{\circ}$ C) $)$ a),f),k) merged channel, b),g),l) blue channel; c),h),m) green channel; d),i),n) red channel; e),j),o) DIC channel of three different areas, $\lambda_{e x}=405 \mathrm{~nm}$; a) to e), $\lambda_{e x}=488 \mathrm{~nm}$; f) to j), $\lambda_{e x}=561 \mathrm{~nm}$; k) to o). Scale bar: $50 \mu \mathrm{m}$. 


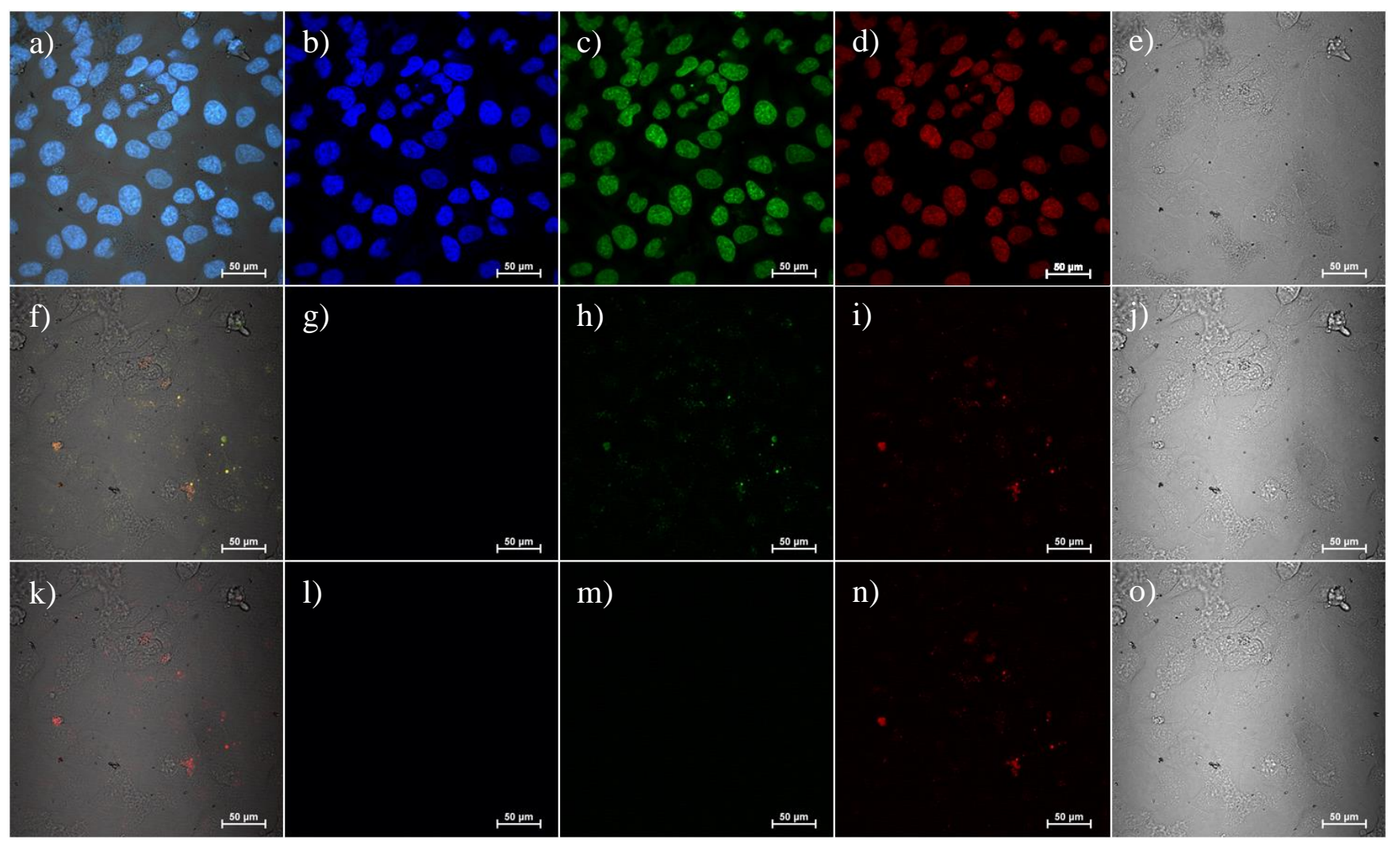

Figure S71. Confocal fluorescence imaging of live HeLa cells incubated with Y0.9Eu0.1 VO ${ }_{4} @ S_{2} \mathrm{O}_{2}$ composite at $10 \mu \mathrm{g} / \mathrm{ml}$ for 15 $\mathrm{min}+1 \mu \mathrm{g} / \mathrm{mL}$ Hoechst dye for $10 \mathrm{~min}\left(1 \% \mathrm{DMSO}, 37^{\circ} \mathrm{C}\right)$. a),f),k) merged channel, b),g),l) blue channel; c),h), $\mathrm{m}$ ) green channel; d),i),n) red channel; e),j), o) DIC channel of three different areas, $\lambda_{e x}=405 \mathrm{~nm}$; a) to e), $\lambda_{e x}=488 \mathrm{~nm}$; f) to j), $\lambda_{e x}=561 \mathrm{~nm}$; $k$ ) to o). Scale bar: $50 \mu \mathrm{m}$.

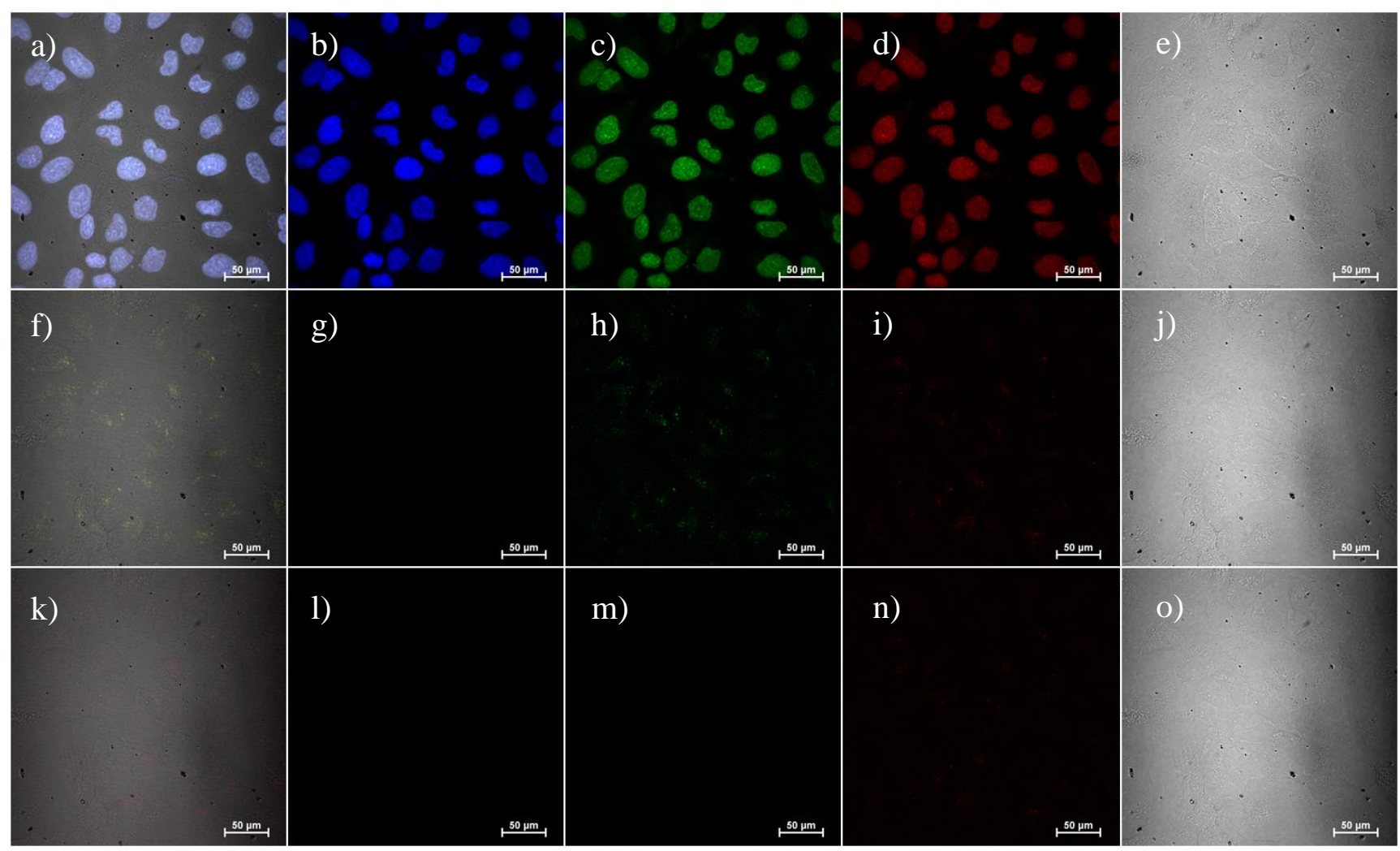

Figure S72. Confocal fluorescence imaging of live HeLa cells incubated with $\mathrm{Y}_{0.9} \mathrm{Eu}_{0.1} \mathrm{VO}_{4} @ \mathrm{SiO}_{2}$ composite at $10 \mu \mathrm{g} / \mathrm{ml}$ for 15 $\mathrm{min}+1 \mu \mathrm{g} / \mathrm{mL}$ Hoechst dye for $10 \mathrm{~min}\left(1 \%\right.$ DMSO, $\left.37^{\circ} \mathrm{C}\right)$. a),f),k) merged channel, b),g),l) blue channel; c),h),m) green channel; d),i),n) red channel; e),j), o) DIC channel of three different areas, $\lambda_{e x}=405 \mathrm{~nm}$; a) to e), $\lambda_{e x}=488 \mathrm{~nm}$; f) to j), $\lambda_{e x}=561 \mathrm{~nm}$; $k$ ) to o). Scale bar: $50 \mu \mathrm{m}$. 


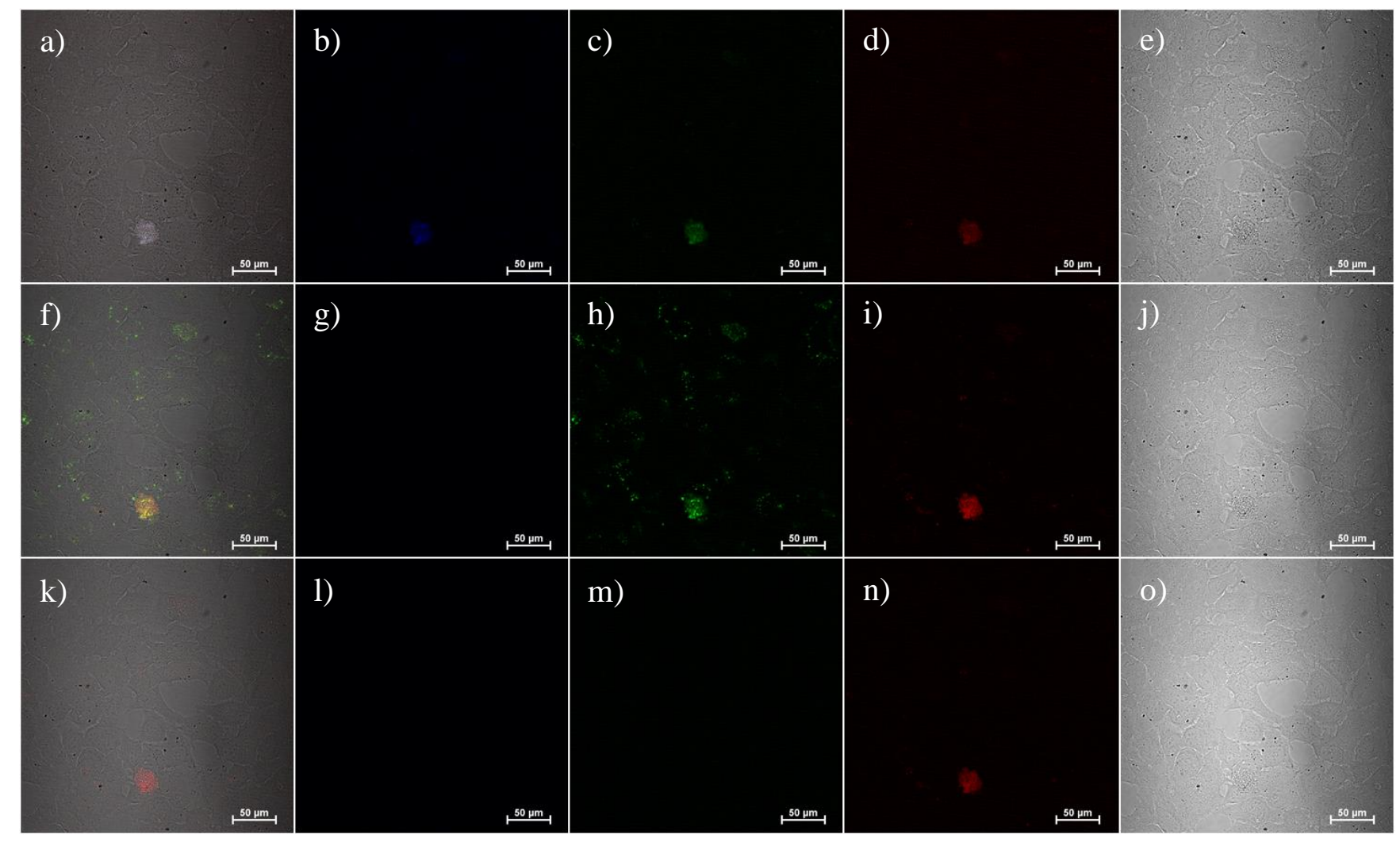

Figure S73. Confocal fluorescence imaging of live HeLa cells incubated with Y0.9Eu0.1 VO $\mathrm{BSiO}_{2}$ composite at $10 \mu \mathrm{g} / \mathrm{ml}$ for 24 hours (1\% DMSO, $37^{\circ}$ C). a),f),k) merged channel, b),g),I) blue channel; c),h),m) green channel; d),i),n) red channel; e),j),o) DIC channel of three different areas, $\lambda_{\mathrm{ex}}=405 \mathrm{~nm}$; a) to e), $\lambda_{\mathrm{ex}}=488 \mathrm{~nm}$; f) to j), $\lambda_{\mathrm{ex}}=561 \mathrm{~nm}$; $\mathrm{k}$ ) to o). Scale bar: $50 \mu \mathrm{m}$.

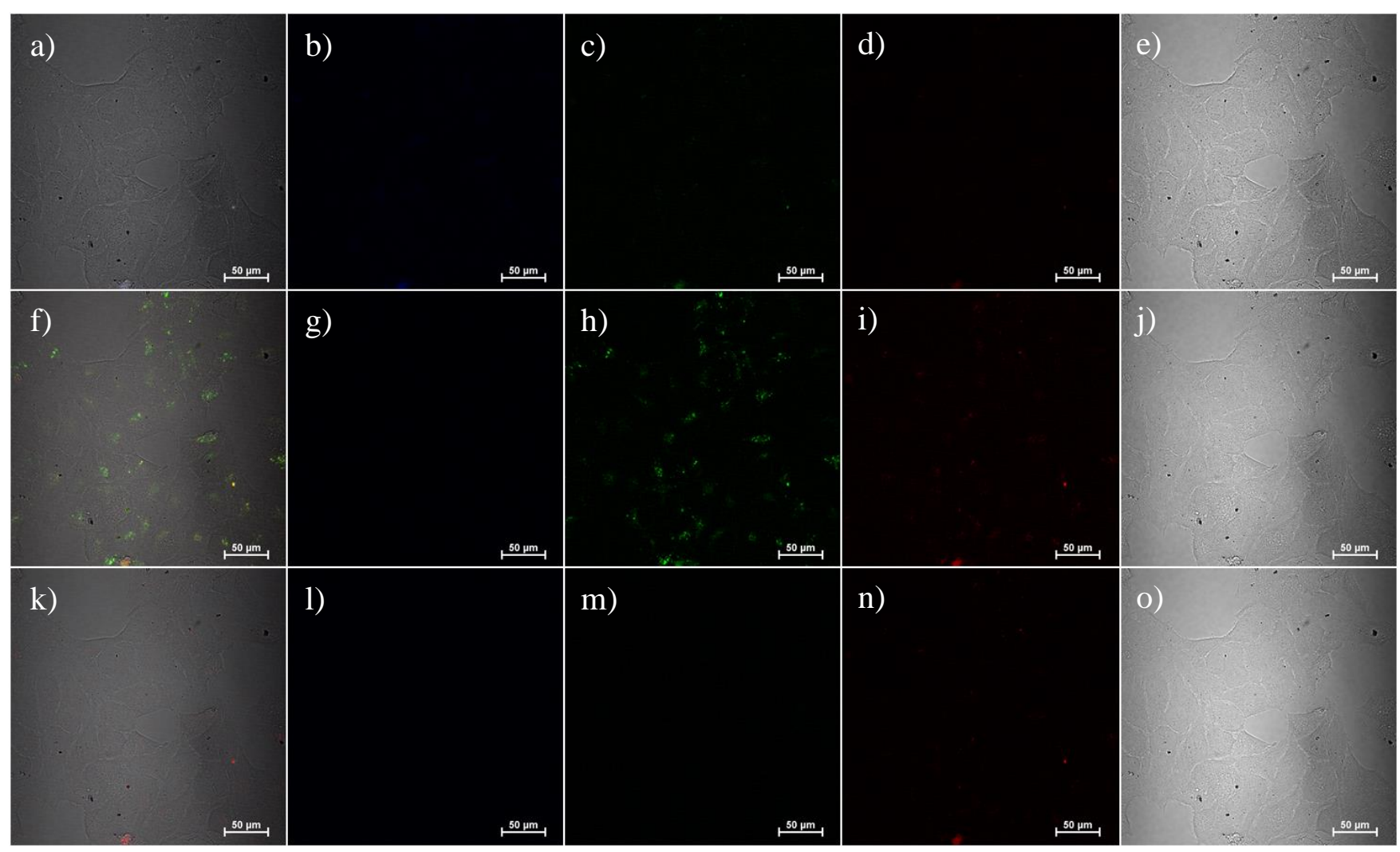

Figure S74. Confocal fluorescence imaging of live HeLa cells incubated with Y0.9Eu0.1 VO $\mathrm{QSSO}_{2}$ composite at $10 \mu \mathrm{g} / \mathrm{ml}$ for 24 hours (1\% DMSO, $37^{\circ}$ C). a),f),k) merged channel, b),g),I) blue channel; c),h),m) green channel; d),i),n) red channel; e),j),o) DIC channel of three different areas, $\lambda_{\mathrm{ex}}=405 \mathrm{~nm}$; a) to e), $\lambda_{\mathrm{ex}}=488 \mathrm{~nm}$; f) to j), $\lambda_{\mathrm{ex}}=561 \mathrm{~nm}$; ) to o). Scale bar: $50 \mu \mathrm{m}$. 


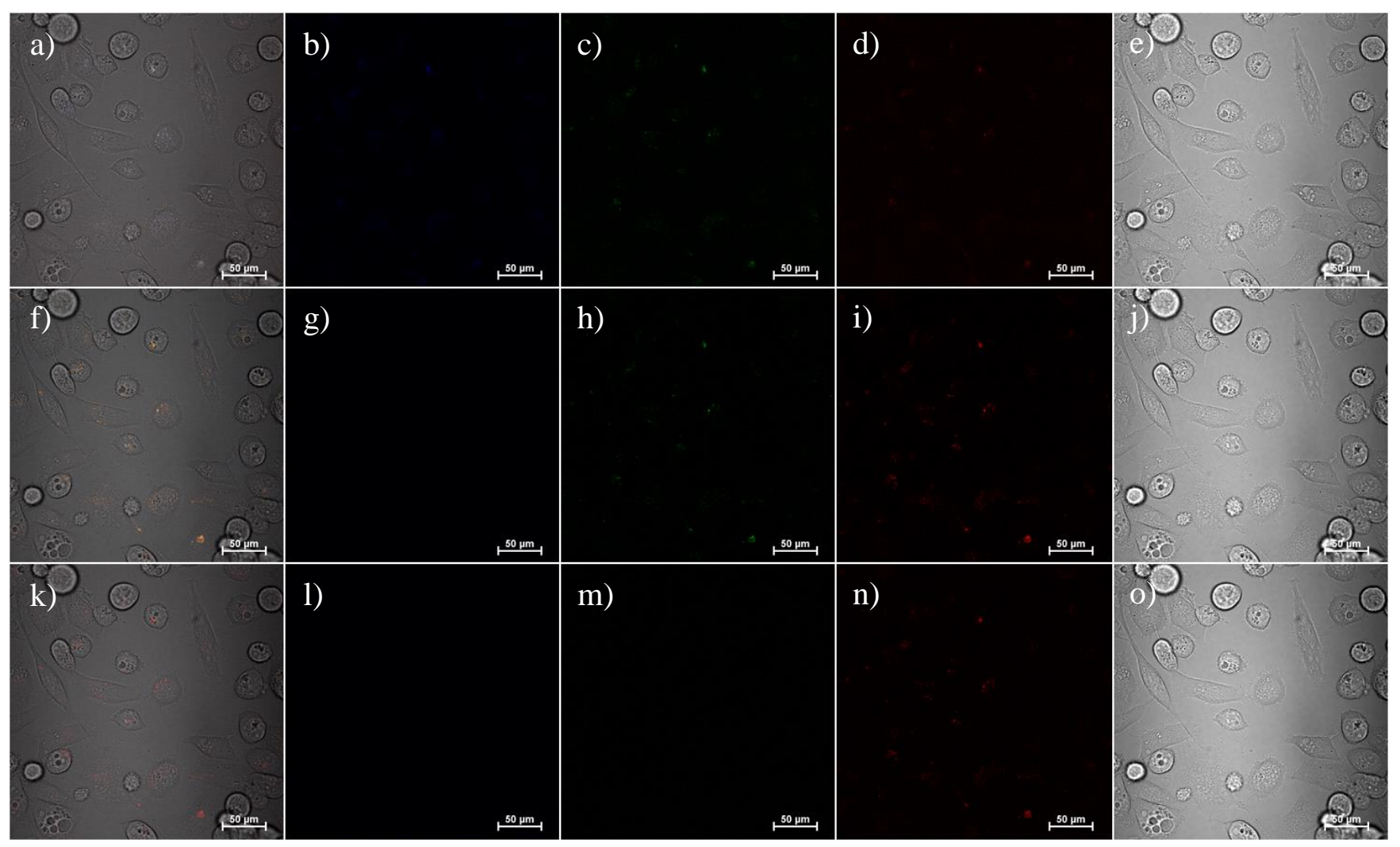

Figure S75. Confocal fluorescence imaging of live PC3 cells (controls, 15 min incubation, $1 \%$ DMSO, $37 \stackrel{\circ}{\circ} \mathrm{C}$ ). a), f),k) merged channel, b),g),I) blue channel; c),h),m) green channel; d),i),n) red channel; e),j),o) DIC channel of three different areas, $\lambda_{\text {ex }}=$ $405 \mathrm{~nm}$; a) to e), $\lambda_{e x}=488 \mathrm{~nm}$; f) to j), $\lambda_{e x}=561 \mathrm{~nm}$; k) to o). Scale bar: $50 \mu \mathrm{m}$.

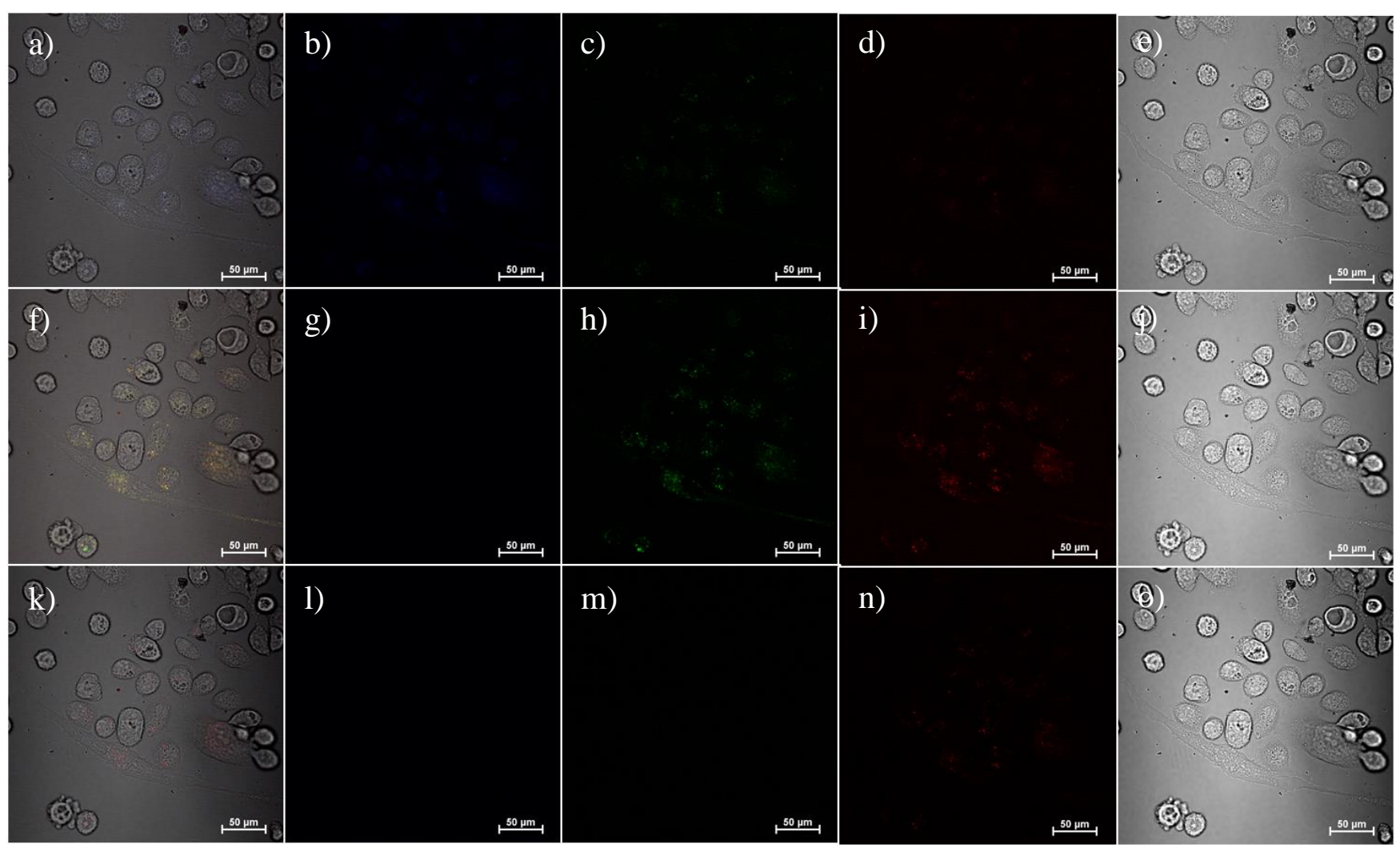

Figure S76. Confocal fluorescence imaging of live PC3 cells incubated with $\mathrm{Y}_{0.9} \mathrm{Eu}_{0.1} \mathrm{VO}_{4} @ \mathrm{SiO}_{2}$ composite at $10 \mu \mathrm{g} / \mathrm{ml}$ for 15 min (1\% DMSO, $37^{\circ}$ C). a),f),k) merged channel, b),g),I) blue channel; c),h),m) green channel; d),i),n) red channel; e),j),o) DIC channel of three different areas, $\lambda_{e x}=405 \mathrm{~nm}$; a) to e), $\lambda_{\mathrm{ex}}=488 \mathrm{~nm}$; f) to j), $\lambda_{\mathrm{ex}}=561 \mathrm{~nm}$; k) to o). Scale bar: $50 \mu \mathrm{m}$. 


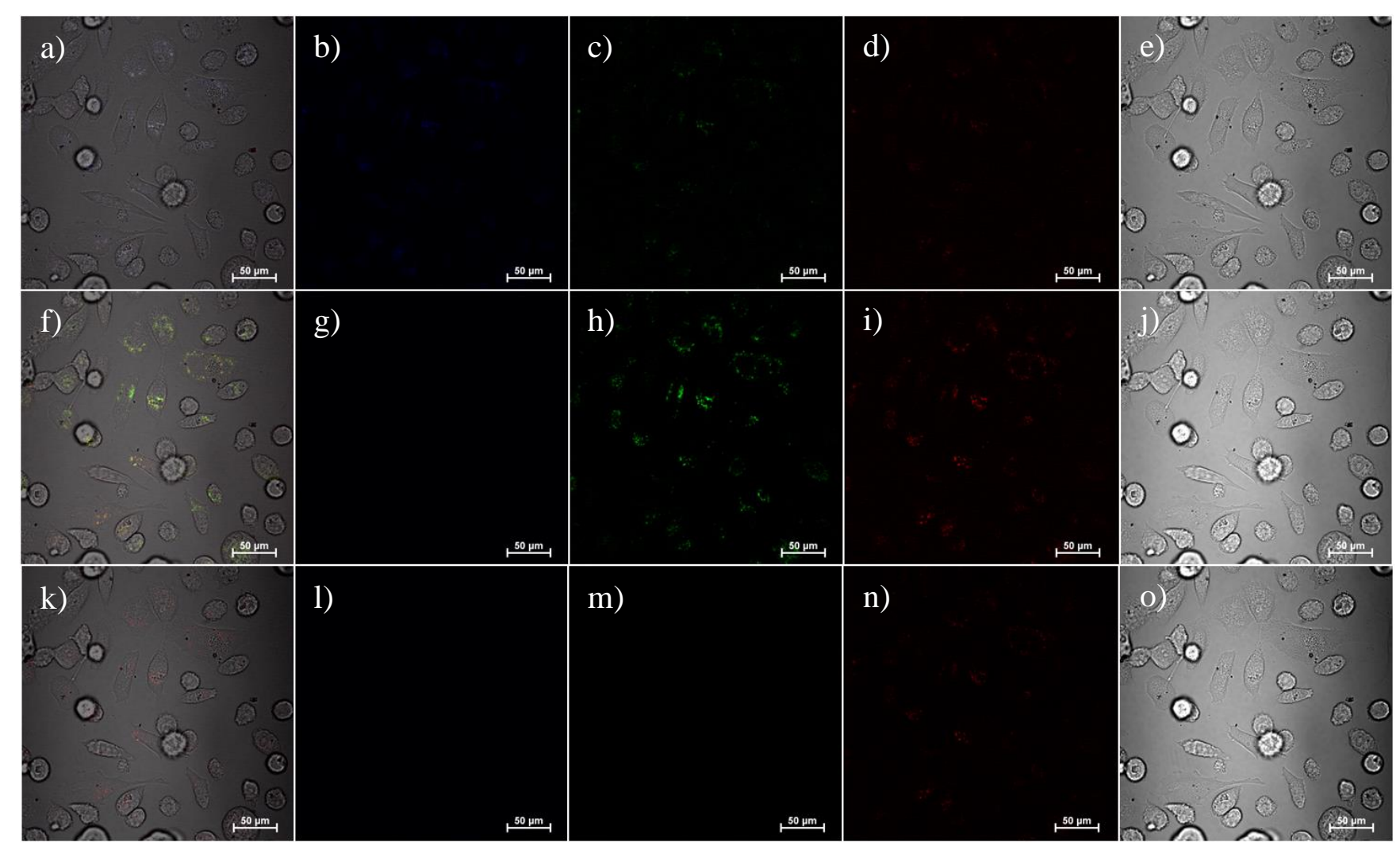

Figure S77. Confocal fluorescence imaging of live PC3 cells incubated with $\mathrm{Y}_{0.9} \mathrm{Eu}_{0.1} \mathrm{VO}_{4} @ \mathrm{SiO}_{2}$ composite at $10 \mu \mathrm{g} / \mathrm{ml}$ for 6 hours (1\% DMSO, $\left.37^{\circ} \mathrm{O}\right)$. a),f),k) merged channels, b),g),l) blue channel; c),h),m) green channel; d),i),n) red channel; e),j),o) DIC channel of three different areas, $\lambda_{\mathrm{ex}}=405 \mathrm{~nm}$; a) to e), $\lambda_{\mathrm{ex}}=488 \mathrm{~nm}$; f) to j), $\lambda_{\mathrm{ex}}=561 \mathrm{~nm}$; $\mathrm{k}$ ) to o). Scale bar: $50 \mu \mathrm{m}$.

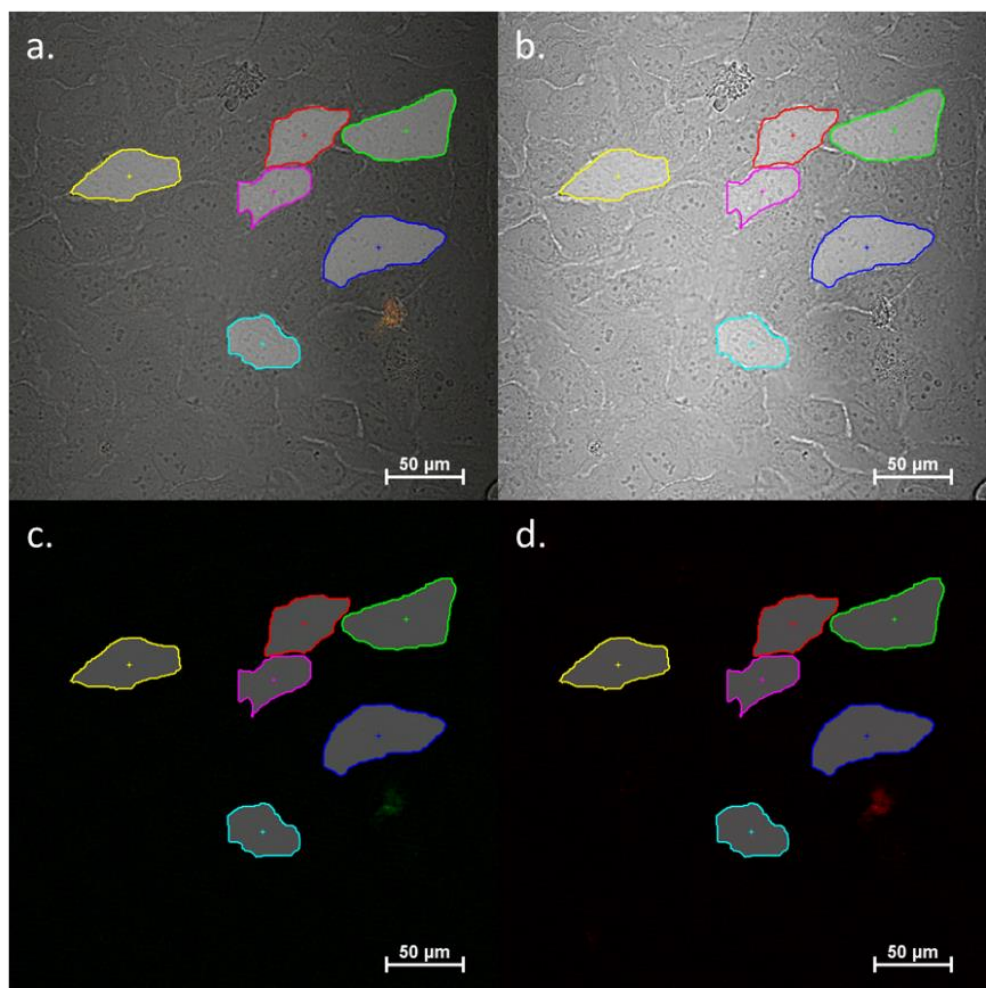

Figure S78. Confocal fluorescence imaging of live HeLa control cells ( $15 \mathrm{~min}, 1 \% \mathrm{DMSO}, 37^{\circ} \mathrm{C}$ ). a) merged image of green, red and DIC channel, b) DIC channel; c) green channel $\lambda_{\mathrm{ex}}=488 \mathrm{~nm}, \lambda_{\mathrm{em}}=515 \mathrm{~nm}$; d) red channel $\lambda_{\mathrm{ex}}=561 \mathrm{~nm}, \lambda_{\mathrm{em}}=630$ $\mathrm{nm}$. Scale bar: $50 \mu \mathrm{m}$. The average fluorescence intensity was calculated from six selected region of interest as shown in the micrograph. 


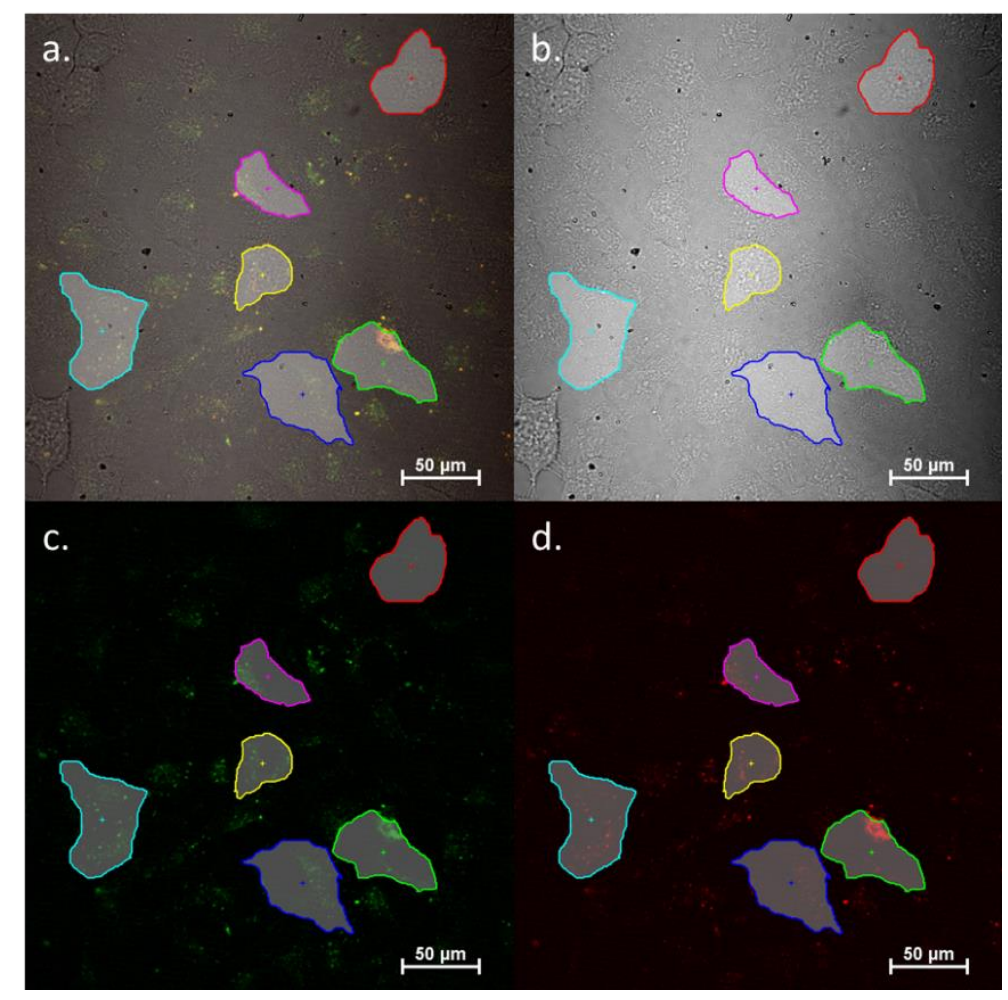

Figure S79. Confocal fluorescence imaging of live HeLa incubated with $\mathrm{Y}_{0.9} \mathrm{Eu}_{0.1} \mathrm{VO}_{4} @ \mathrm{SiO}_{2}$ composite at $10 \mu \mathrm{g} / \mathrm{ml}$ for $15 \mathrm{~min}$ (1\% DMSO, $37^{\circ} \mathrm{C}$ ). a) merged image of green, red and DIC channel, b) DIC channel; c) green channel $\lambda_{\mathrm{ex}}=488 \mathrm{~nm}, \lambda_{\mathrm{em}}=515$ $\mathrm{nm}$; d) red channel $\lambda_{\mathrm{ex}}=561 \mathrm{~nm}, \lambda_{\mathrm{em}}=630 \mathrm{~nm}$. Scale bar: $50 \mu \mathrm{m}$. The average fluorescence intensity was calculated from six selected region of interest as shown in the micrograph.

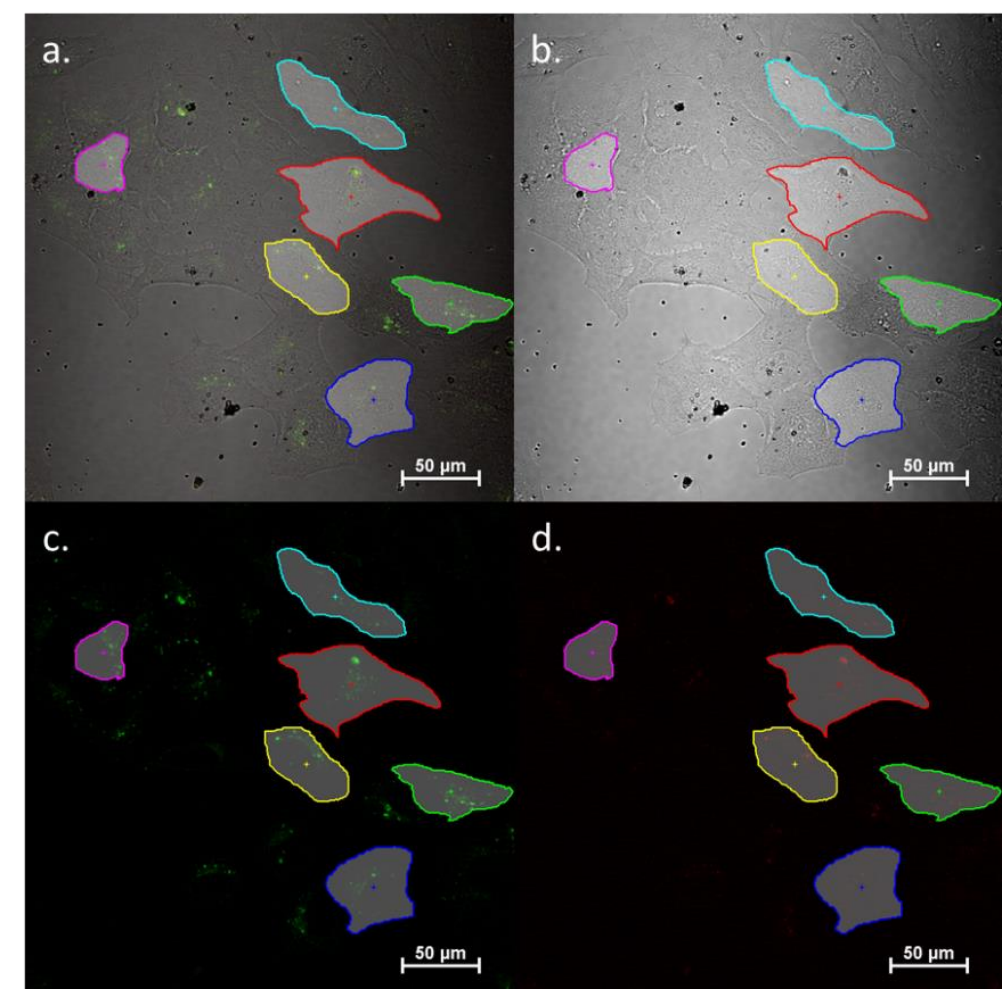

Figure S80. Confocal fluorescence imaging of live HeLa incubated with $\mathrm{Y}_{0.9} \mathrm{Eu}_{0.1} \mathrm{VO}_{4} @ \mathrm{SiO}_{2}$ composite at $10 \mu \mathrm{g} / \mathrm{ml}$ for 6 hours ( $1 \%$ DMSO, $37^{\circ} \mathrm{C}$ ). a) merged image of green, red and DIC channel, b) DIC channel; c) green channel $\lambda_{\mathrm{ex}}=488 \mathrm{~nm}, \lambda_{\mathrm{em}}=515$ $\mathrm{nm}$; d) red channel $\lambda_{\mathrm{ex}}=561 \mathrm{~nm}, \lambda_{\mathrm{em}}=630 \mathrm{~nm}$. Scale bar: $50 \mu \mathrm{m}$. The average fluorescence intensity was calculated from six selected region of interest as shown in the micrograph. 


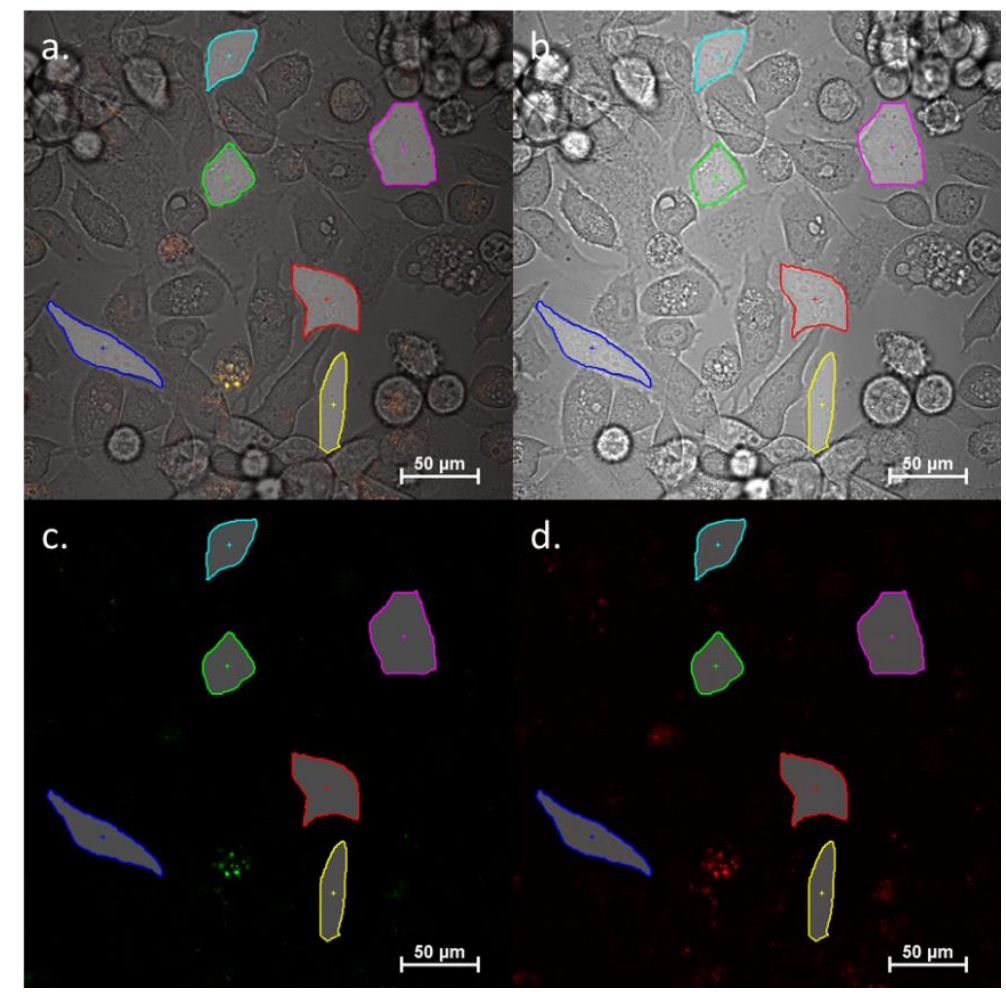

Figure S81. Confocal fluorescence imaging of live PC3 control cells (15 min, $1 \%$ DMSO, $37^{\circ} \mathrm{C}$ ). a) merged image of green, red and DIC channel, b) DIC channel; c) green channel $\lambda_{\mathrm{ex}}=488 \mathrm{~nm}, \lambda_{\mathrm{em}}=515 \mathrm{~nm}$; d) red channel $\lambda_{\mathrm{ex}}=561 \mathrm{~nm}, \lambda_{\mathrm{em}}=630$ $\mathrm{nm}$. Scale bar: $50 \mu \mathrm{m}$. The average fluorescence intensity was calculated from six selected region of interest as shown in the micrograph.

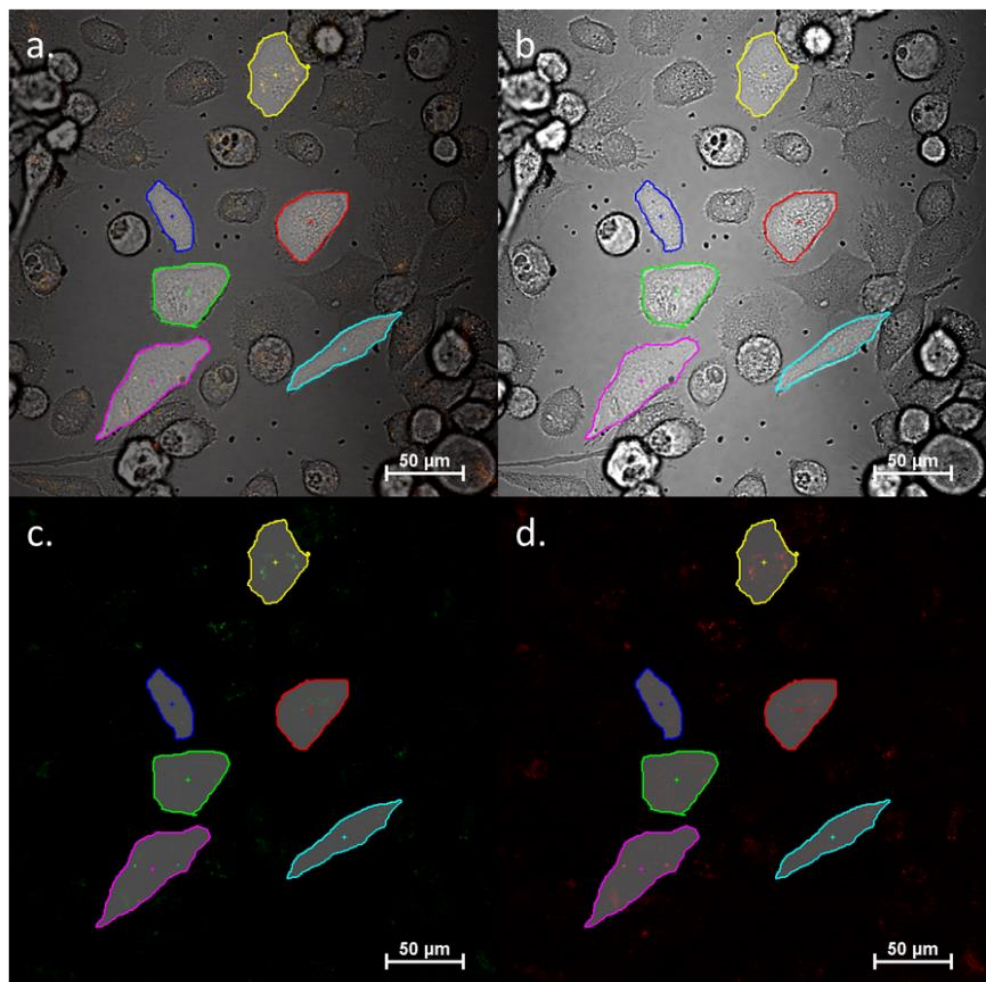

Figure S82. Confocal fluorescence imaging of live PC3 incubated with $\mathrm{Y}_{0.9} \mathrm{Eu}_{0.1} \mathrm{VO}_{4} @ \mathrm{SiO}_{2}$ composite at $10 \mu \mathrm{g} / \mathrm{ml}$ for $15 \mathrm{~min}$ $\left(1 \%\right.$ DMSO, $\left.37^{\circ} \mathrm{C}\right)$. a) merged image of green, red and DIC channel, b) DIC channel; c) green channel $\lambda_{\mathrm{ex}}=488 \mathrm{~nm}, \lambda_{\mathrm{em}}=515$ $\mathrm{nm}$; d) red channel $\lambda_{\mathrm{ex}}=561 \mathrm{~nm}, \lambda_{\mathrm{em}}=630 \mathrm{~nm}$. Scale bar: $50 \mu \mathrm{m}$. The average fluorescence intensity was calculated from six selected region of interest as shown in the micrograph. 


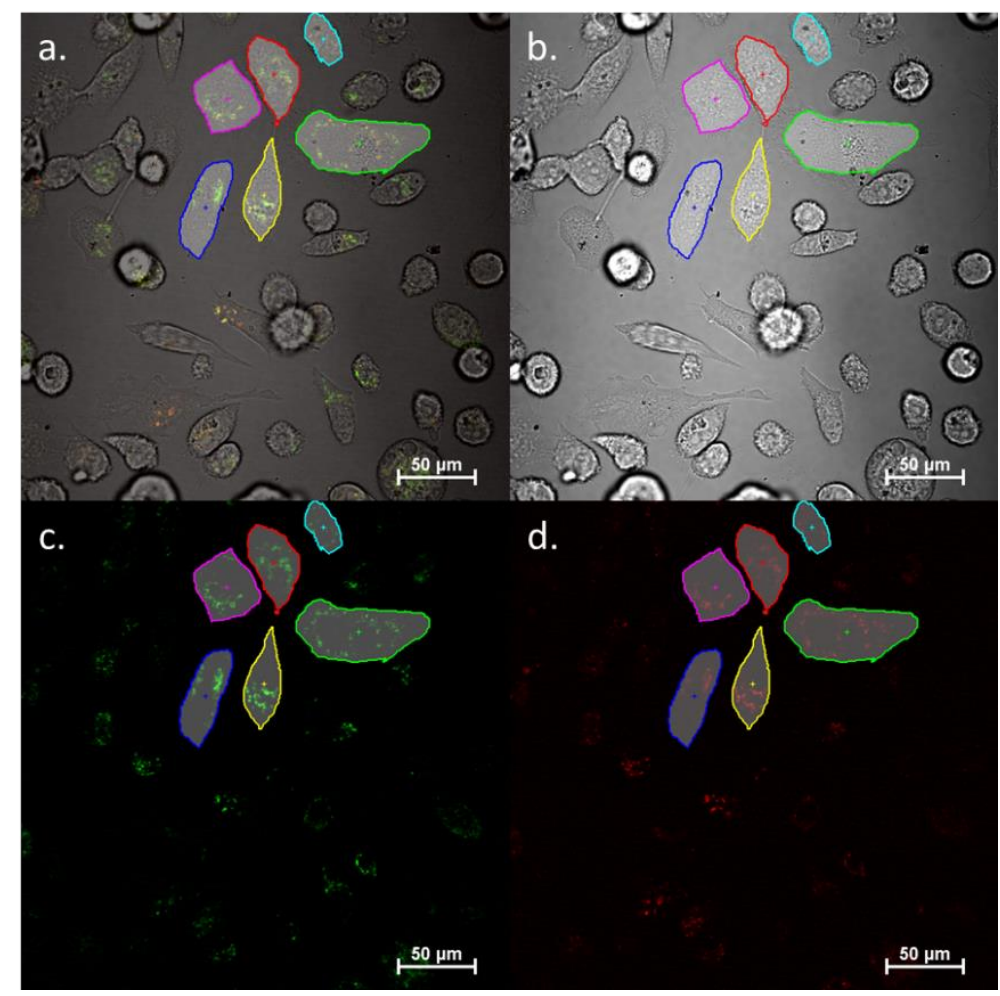

Figure S83. Confocal fluorescence imaging of live PC3 incubated with $\mathrm{Y}_{0.9} \mathrm{Eu}_{0.1} \mathrm{VO}_{4} @ \mathrm{SiO}_{2}$ composite at $10 \mu \mathrm{g} / \mathrm{ml}$ for 6 hours $\left(1 \%\right.$ DMSO, $\left.37^{\circ} \mathrm{C}\right)$. a) merged image of green, red and DIC channel, b) DIC channel; c) green channel $\lambda_{\mathrm{ex}}=488 \mathrm{~nm}, \lambda_{\mathrm{em}}=515$ $\mathrm{nm}$; d) red channel $\lambda_{\mathrm{ex}}=561 \mathrm{~nm}, \lambda_{\mathrm{em}}=630 \mathrm{~nm}$. Scale bar: $50 \mu \mathrm{m}$. The average fluorescence intensity was calculated from six selected region of interest as shown in the micrograph.
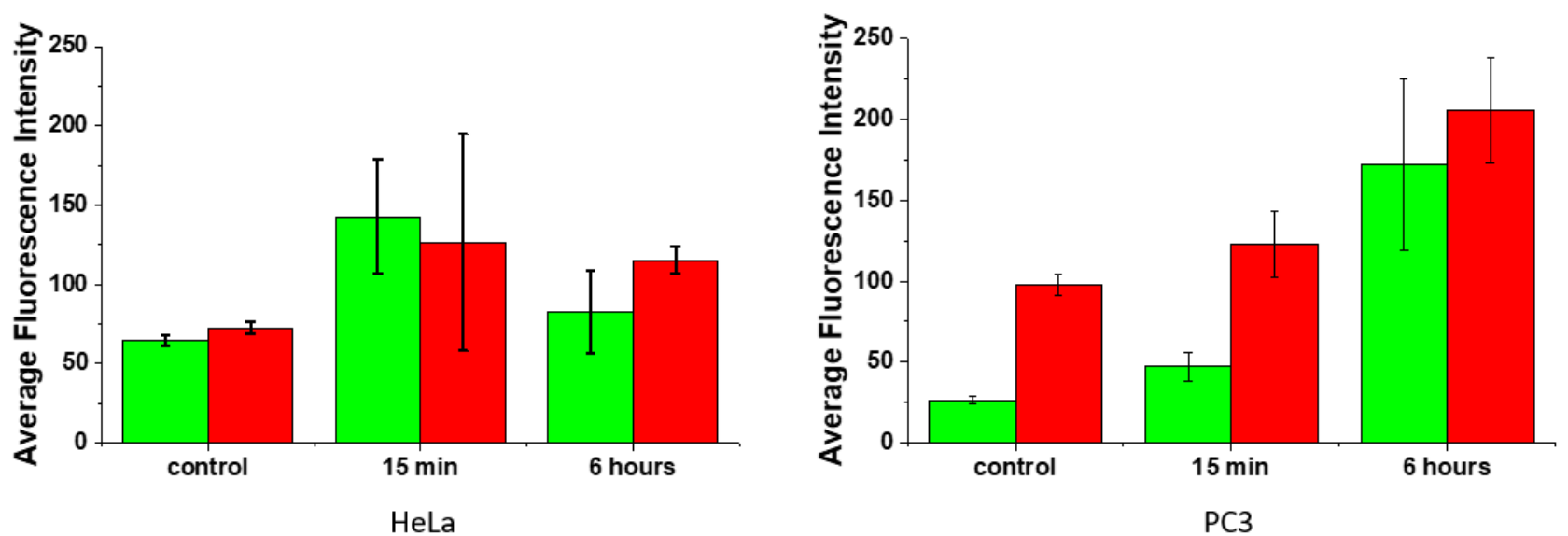

Figure S84. Average fluorescence intensities of HeLa and PC3 cells treated with 1\%DMSO (controls, 15 min incubation) vs. cells incubated with $10 \mu \mathrm{g} / \mathrm{mL}_{0.9} \mathrm{Eu}_{0.1} \mathrm{VO}_{4} @ \mathrm{SiO}_{2}$ for $15 \mathrm{~min}$ and similarly, for 6 hours incubation times $\left(37^{\circ} \mathrm{C}\right)$.

\section{General Cell culturing methods for fluorescence imaging}

HeLa and PC-3 cell lines were purchased from American type culture collection (ATCC). Cells were grown as monolayers in T75 tissue culture flasks and cultured in Eagle's Minimum Essential Medium (EMEM) for HeLa and Roswell Park Memorial Institute medium (RPMI) for PC-3, 1\% L-glutamine (200 mM), 0.5\% penicillin/streptomycin (10 $000 \mathrm{IU} \mathrm{mL}-1 / 10000 \mathrm{mg} \mathrm{mL}-1)$. Cells were cultured at $37^{\circ} \mathrm{C}$ in a humidified atmosphere of $5 \% \mathrm{CO}_{2}$ in air and split once $70 \%$ confluence had been reached, using the corresponding cell medium. All steps were performed in absence of phenol red. Once cells reached more than $70 \%$ confluence, the supernatant containing dead cell matter and excess protein was aspirated. The live adherent cells were then washed with $10 \mathrm{~mL}$ of phosphate buffer saline solution twice to remove any remaining media. Cells were incubated in $3 \mathrm{~mL}$ of trypsin solution $\left(0.25 \%\right.$ trypsin) for 5 to $7 \mathrm{~min}$ at $37^{\circ} \mathrm{C}$. 
After trypsinisation, $6 \mathrm{~mL}$ of medium containing $10 \%$ serum medium was added to inactivate the trypsin and the solution was centrifuged for $5 \mathrm{~min}\left(1000 \mathrm{rpm}, 25^{\circ} \mathrm{C}\right)$. The supernatant liquid was aspirated and 5 $\mathrm{mL}$ of serum medium was added to the cell matter left behind. Cells were counted using a haemocytometer and then seeded as appropriate.

For microscopy, cells were seeded into glass-bottomed Petri dishes and incubated for $12 \mathrm{~h}$ for HeLa and $24 \mathrm{~h}$ for PC-3 to ensure adhesion. Cells were plated in $35 \mathrm{~mm}$ uncoated $1.5 \mathrm{~mm}$ thick glass-bottomed dishes as $3 \times 10^{5}$ cells per dish and incubated for at least $24 \mathrm{~h}$ prior to imaging experiment. Once cells attached firmly, cells were washed with $990 \mu \mathrm{L}$ Hank's Balanced Salt Solution (HBSS) five times and refilled with $990 \mu \mathrm{L}$ of serum-free medium (SFM), then in each case, an aliquot of $10 \mu \mathrm{L}$ of the nanoparticulate material (generally as $1 \mathrm{mg} / \mathrm{mL}$ stock dispersion in DMSO) was added. Cells were incubated with compounds for 15 minutes, $1 \mathrm{~h}, 6 \mathrm{~h}$ or over-night at $37^{\circ} \mathrm{C}$, or longer, as required. Afterwards, cells were washed with $990 \mu \mathrm{L}$ Hank's Balanced Salt Solution (HBSS) three times to rinse any remaining probe traces from the medium and $990 \mu \mathrm{L}$ of SFM was added.

Once the cell dish was ready for the single photon confocal fluorescence imaging, cells were excited at $405 \mathrm{~nm}, 488 \mathrm{~nm}$ and $561 \mathrm{~nm}$ wavelength, then at each wavelength, there were five images captured namely a merged image, image between 420 and $480 \mathrm{~nm}$ wavelength, image between 516 and $530 \mathrm{~nm}$ wavelength, image between 615 and $650 \mathrm{~nm}$ wavelength and Differential Interference Contrast (DIC) image.

\section{Cellular Viability Tests}

Standard MTT assays of HeLa cells treated with $\mathrm{Y}_{0.9} \mathrm{Eu}_{0.1} \mathrm{VO}_{4} @ \mathrm{SiO}_{2}$ composite were performed in order to investigate the effect of silica encapsulation on the cellular viability. The results demonstrate that encapsulation of $\mathrm{Y}_{0.9} \mathrm{Eu}_{0.1} \mathrm{VO}_{4} \mathrm{NPs}$ within a silica shell improves the in vitro biocompatibility.

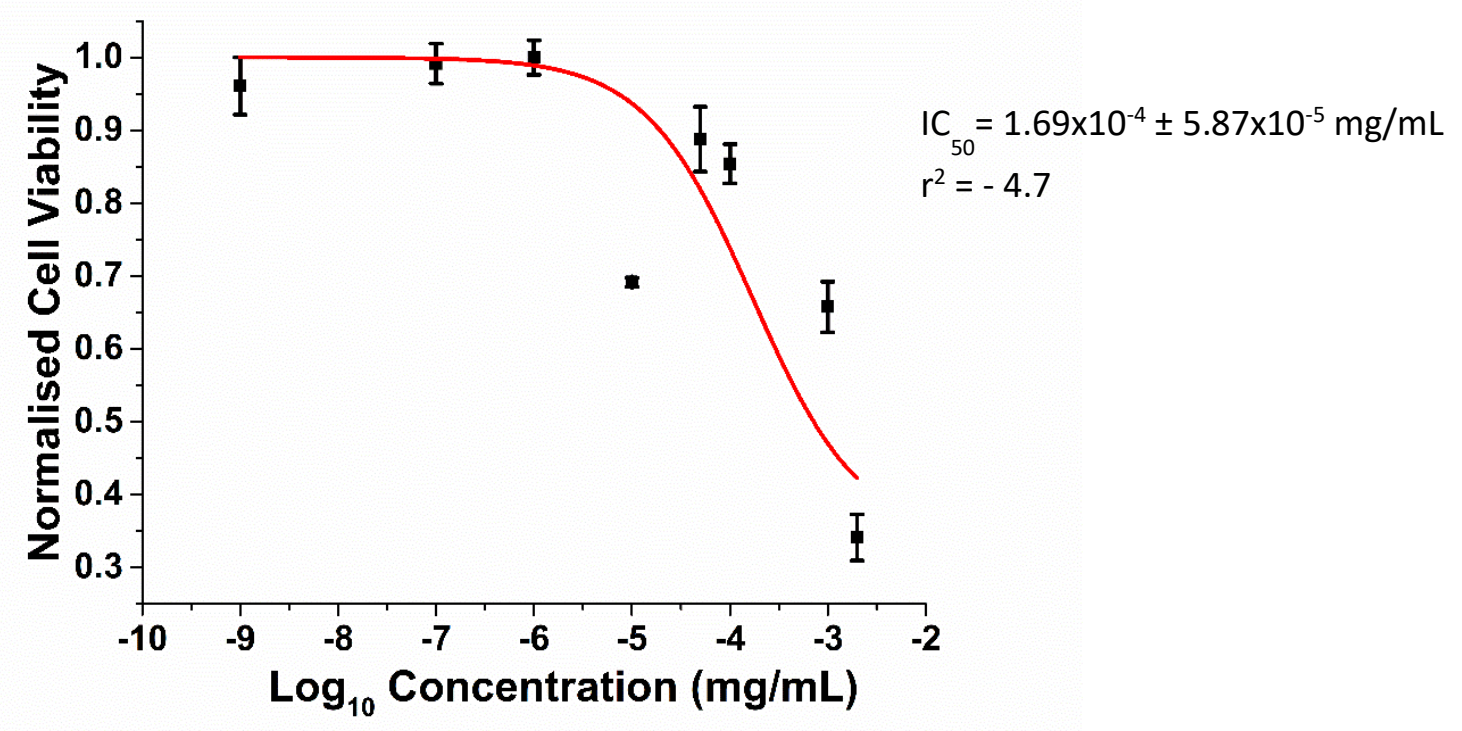

Figure S85. Dose response curve for $\mathrm{Y}_{0.9} \mathrm{Eu}_{0.1} \mathrm{VO}_{4} @ \mathrm{SiO}_{2}$ composite. Error bars stand for standard error calculated from the twelve repeats. 


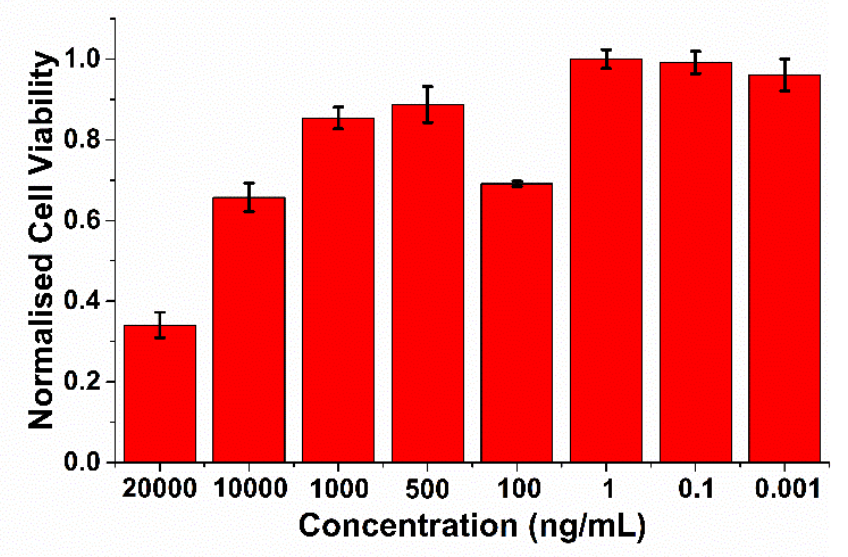

Figure S86. Normalised cell viability in in HeLa cells treated with $1 \mathrm{pg} / \mathrm{mL}-20 \mu \mathrm{g} / \mathrm{mL} \mathrm{Y}_{0.9} \mathrm{Eu}_{0.1} \mathrm{VO}_{4} @ \mathrm{SiO}_{2}$, cells seed and grow for 48 hours at $37{ }^{\circ} \mathrm{C}, \mathrm{Y}_{0.9} \mathrm{Eu}_{0.1} \mathrm{VO}_{4} @ \mathrm{SiO}_{2}$ was incubated for 48 hours at $37 \stackrel{\circ}{\circ} \mathrm{C}, 5 \mathrm{mg} / \mathrm{mL}$ MTT reagent was incubated for 3 hours. Error bars stand for standard error calculated from the twelve repeats.

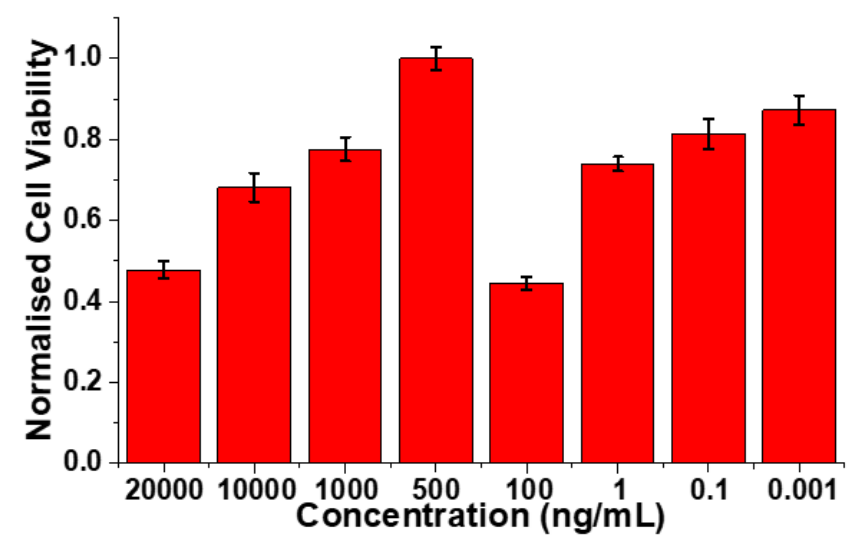

Figure S87. Normalised cell viability in in PC3 cells treated with $1 \mathrm{pg} / \mathrm{mL}-20 \mu \mathrm{g} / \mathrm{mL} \mathrm{Y}_{0.9} \mathrm{Eu}_{0.1} \mathrm{VO}_{4} @ \mathrm{SiO}_{2}$, cells seed and grow for 48 hours at $37^{\circ} \mathrm{C}, \mathrm{Y}_{0.9} \mathrm{Eu}_{0.1} \mathrm{VO}_{4} @ \mathrm{SiO}_{2}$ was incubated for 48 hours at $37 \stackrel{\circ}{\circ} \mathrm{C}, 5 \mathrm{mg} / \mathrm{mL}$ MTT reagent was incubated for 3 hours. Error bars stand for standard error calculated from the twelve repeats.

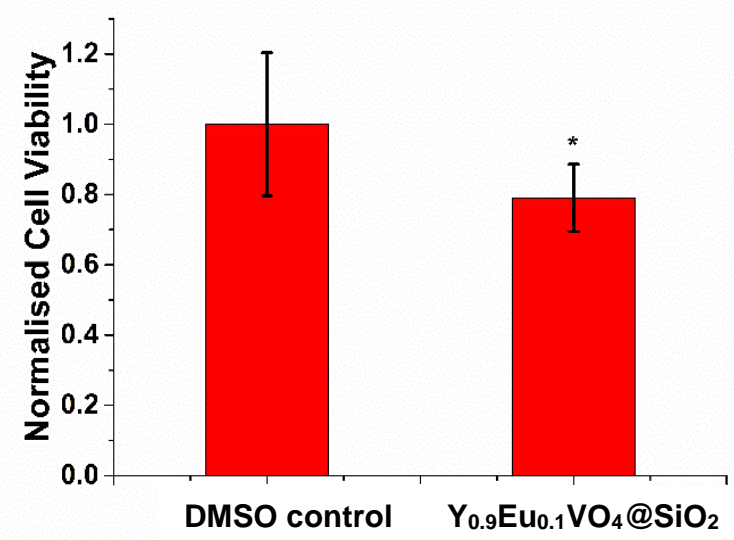

Figure S88. Normalised cell viability in HeLa cells treated with $\mathrm{Y}_{0.9} \mathrm{Eu}_{0.1} \mathrm{VO}_{4} @ \mathrm{SiO}_{2}$ composite for 48 hours. Significance in difference between two groups were tested by Student $t$ test. The asterisk marks a significant difference at the level of $p<0.05$. 


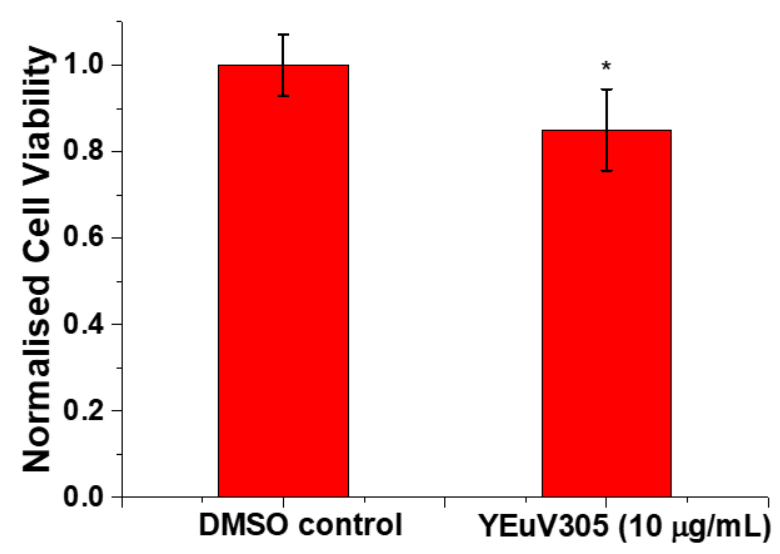

Figure S89. Normalised cell viability in PC3 cells treated with $\mathrm{Y}_{0.9} \mathrm{Eu}_{0.1} \mathrm{VO}_{4} @ \mathrm{SiO}_{2}$ composite for 48 hours. Significance in difference between two groups were tested by Student $t$ test. The asterisk marks a significant difference at the level of $p<0.05$.

\section{References}

(1) Townsend, J. B.; Shaheen, F.; Liu, R.; Lam, K. S. Jeffamine Derivatized TentaGel Beads and Poly(Dimethylsiloxane) Microbead Cassettes for Ultrahigh-Throughput in Situ Releasable Solution-Phase Cell-Based Screening of OneBead-One-Compound Combinatorial Small Molecule Libraries. J. Comb. Chem. 2010, 12 (5), 700-712. https://doi.org/10.1021/cc100083f. 